2003 Report of EnviroSync - A National Organization of

Environmental Science Users of Synchrotron Radiation Sources

\title{
Molecular Environmental Science:
}

An Assessment of Research

\section{Accomplishments, Available Synchrotron Radiation Facilities, and Needs}

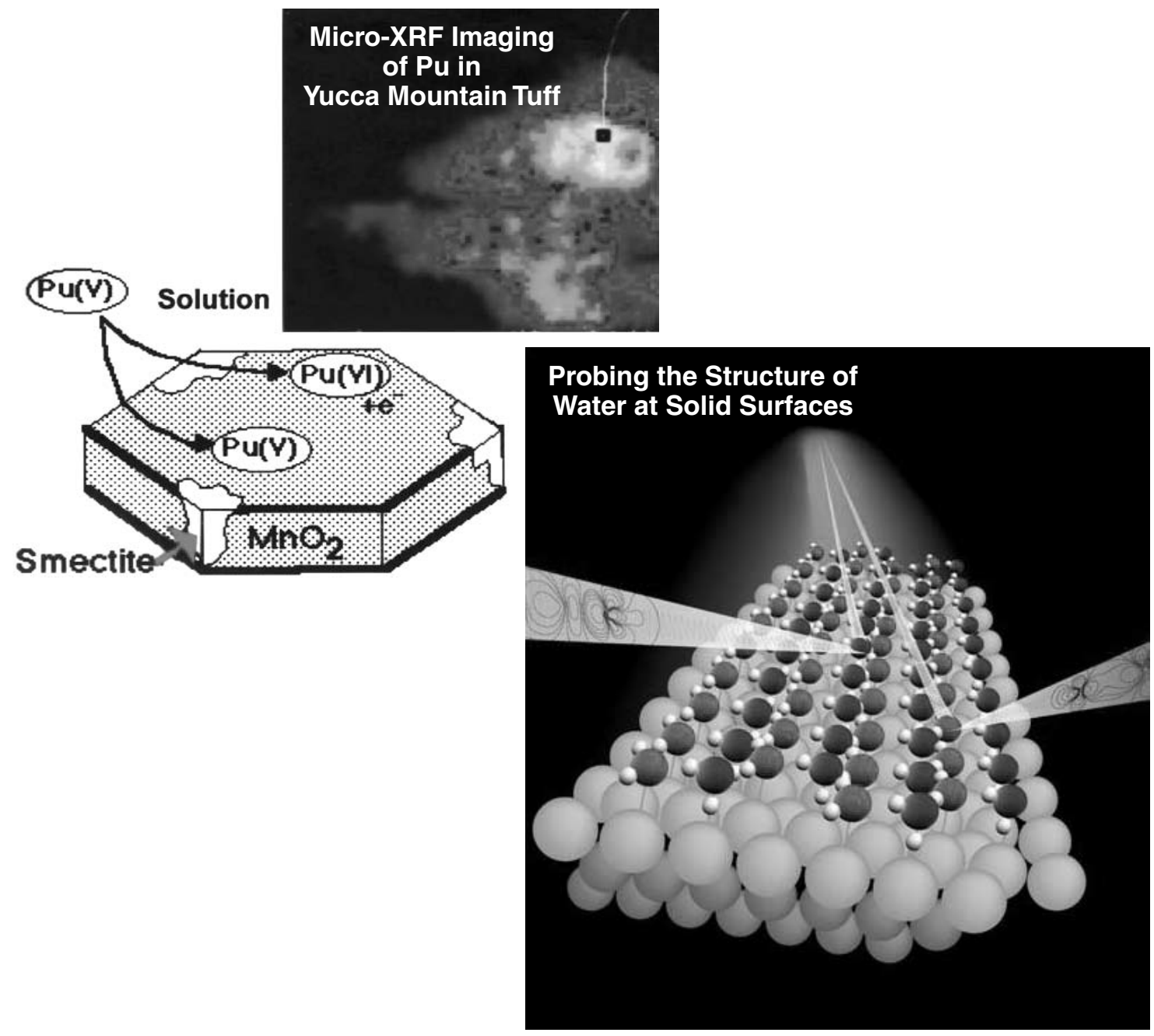


This document, and the material and data contained therein, was developed under sponsorship of the United States Government. Neither the United States nor the Department of Energy, nor the Leland Stanford Junior University, nor their employees, nor their respective contractors, subcontractors, or their employees, makes an warranty, express or implied, or assumes any liability of responsibility for accuracy, completeness or usefulness of any information, apparatus, product or process disclosed, or represents that its use will not infringe privately owned rights. Mention of any product, its manufacturer, or suppliers shall not, nor is it intended to, imply approval, disapproval, or fitness of any particular use. A royalty-free, nonexclusive right to use and disseminate same for any purpose whatsoever, is expressly reserved to the United States and the University. 
SLAC-R-704

UC-402, 403, 408

2003 Report of EnviroSync - A National Organization of Environmental

Science Users of Synchrotron Radiation Sources

\title{
Molecular Environmental Science: An Assessment of Research Accomplishments, Available Synchrotron Radiation Facilities, and Needs
}

\author{
Stanford Linear Accelerator Center \\ Stanford Synchrotron Radiation Laboratory \\ Stanford University, Stanford, CA 94309
}

SLAC-Report-704

February 2004

Prepared in part for the Department of Energy under contract number DE-AC03-76SF00515

Printed in the United States of America. Available from the National Technical Information Service, U.S. Department of Commerce, 5285 Port Royal Road, Springfield, VA 22161. 
A color version of this report is located electronically at:

http://www.slac.stanford.edu/cgi-wrap/pubpage?SLAC-R-704

Cover Figures: The upper figure shown on the cover is from a study by Duff et al. ( $J$. Synchrotron Rad. 1999, 6, 350-352), which examined the interaction of plutonium (V) with $\mathrm{MnO}_{2}$-coated grains of smectite clay from the Yucca Mountain Tuff using micro-X-ray fluorescence imaging methods at the Advanced Photon Source (BL ID-13). The lower figure was kindly provided by Anders Nilsson (SSRL) and shows the structure of water on the platinum (111) surface as probed by low energy synchrotron x-rays (for details, see Ogasawara et al., Phys. Rev. Lett. 2002, 89, 276102). 


\section{TABLE OF CONTENTS}

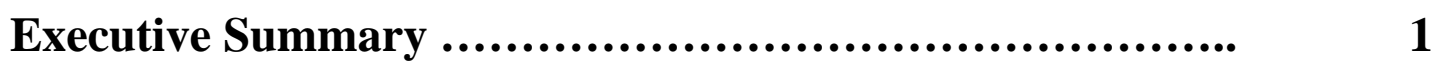

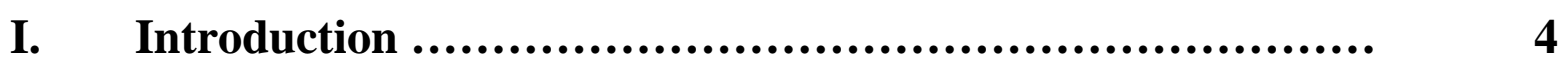

II. Synchrotron Radiation Sources and Capabilities ............. 7

III. The MES User Community and Community Building Activities 15

IV. Needs and Priorities of the MES Community ................ 17

V. MES Research Highlights at Seven U.S. SR Facilities ........ 23

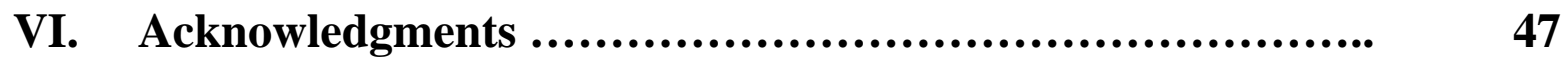

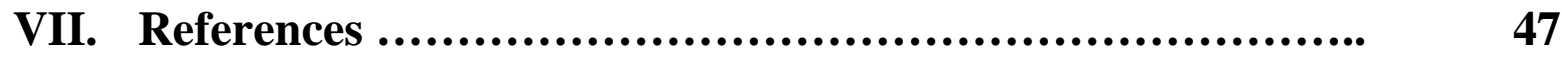

Appendix A. Description of MES-Related Beam Lines ....... $\quad 50$

Appendix B. EnviroSync ................................... $\quad 57$

Appendix C. Abbreviations Used .......................... $\quad 60$ 


\title{
Molecular ENVironmental SCiEnCE: An Assessment of Research Accomplishments, Available Synchrotron Radiation Facilities, and Needs
}

\author{
Prepared on behalf of EnviroSync by
}

Gordon E. Brown, Jr. ${ }^{1,2}$, Stephen R. Sutton ${ }^{3}$, John R. Bargar ${ }^{2}$, David K. Shuh ${ }^{4}$, William A. Bassett ${ }^{5}$, Paul M. Bertsch ${ }^{6}$, Joseph Bisognano ${ }^{7}$, William F. Bleam ${ }^{8}$, David L. Clark ${ }^{9}$, Pupa De Stasio ${ }^{7}$, Scott E. Fendorf ${ }^{1}$, Paul A. Fenter ${ }^{10}$, Ernest Fontes ${ }^{11}$, Josef Hormes ${ }^{12}$, Kenneth M. Kemner ${ }^{10}$, Satish C.B. Myneni ${ }^{13,14}$, Peggy A. O’Day ${ }^{15}$, Klaus H. Pecher ${ }^{16}$, Richard J. Reeder ${ }^{17}$, Amitava Roy ${ }^{12}$, Samuel J. Traina ${ }^{15}$, Clinton S. Willson ${ }^{18}$, and John M. Zachara ${ }^{19}$

\footnotetext{
${ }^{1}$ Department of Geological \& Environmental Sciences, Stanford University, Stanford, CA $;{ }^{2}$ Stanford Synchrotron Radiation Laboratory, SLAC, Stanford, CA $;^{3}$ GSECARS, University of Chicago and Advanced Photon Source, Argonne, IL; ${ }^{4}$ Chemical Sciences Division, Lawrence Berkeley National Laboratory, Berkeley, CA; ${ }^{5}$ Department of Geological Sciences, Cornell University, Ithaca, NY; ${ }^{6}$ Savannah River Ecology Laboratory, University of Georgia, Aiken, SC; ${ }^{7}$ The Synchrotron Radiation Center, University of Wisconsin-Madison, Stoughton, WI; ${ }^{8}$ Department of Soil Science, University of Wisconsin, Madison, WI; ${ }^{9}$ Seaborg Institute for Transactinium Chemistry, Los Alamos National Laboratory, Los Alamos, NM; ${ }^{10}$ Environmental Research Division, Argonne National Laboratory, Argonne, IL; ${ }^{11}$ Cornell High Energy Synchrotron Source, Cornell University, Ithaca, NY; ${ }^{12}$ J. Bennett Johnston Sr. Center for Advanced Microstructures and Devices, Lousiana State University, Baton Rouge, LA; ${ }^{13}$ Department of Geosciences, Princeton University, Princeton, NJ; ${ }^{14}$ Earth Sciences Division, Lawrence Berkeley National Laboratory, Berkeley, CA; ${ }^{15}$ School of Natural Sciences and Sierra Nevada Research Institute, University of California, Merced, CA; ${ }^{16}$ Environmental Molecular Sciences Laboratory, Pacific Northwest National Laboratory, Richland, WA; ${ }^{17}$ Department of Geosciences, State University of New York, Stony Brook, NY; ${ }^{18}$ Department of Civil \& Environmental Engineering, Louisiana State University, Baton Rouge, LA; ${ }^{19}$ Fundamental Science Directorate, Pacific Northwest National Laboratory, Richland, WA
}

\section{Executive Summary}

Synchrotron-based techniques are fundamental to research in Molecular Environmental Science (MES), an emerging field that involves molecular-level studies of chemical and biological processes affecting the speciation, properties, and behavior of contaminants, pollutants, and nutrients in the ecosphere. These techniques enable the study of aqueous solute complexes, poorly crystalline materials, solid-liquid interfaces, mineral-aqueous solution interactions, microbial biofilm-heavy metal interactions, heavy metal-plant interactions, complex material microstructures, and nanomaterials, all of which are important components or processes in the environment. Basic understanding of environmental materials and processes at the molecular scale is essential for risk assessment and management, and reduction of environmental pollutants at field, landscape, and global scales.

One of the main purposes of this report is to illustrate the role of synchrotron radiation (SR)based studies in environmental science and related fields and their impact on environmental problems of importance to society. A major driving force for MES research is the need to characterize, treat, and/or dispose of vast quantities of contaminated materials, including groundwater, sediments, and soils, and to process wastes, at an estimated cost exceeding 150 billion dollars through 2070. A major component of this problem derives from high-level nuclear waste. Other significant components come from mining and industrial wastes, 
atmospheric pollutants derived from fossil fuel consumption, agricultural pesticides and fertilizers, and the pollution problems associated with animal waste run-off, all of which have major impacts on human health and welfare. Addressing these problems requires the development of new characterization and processing technologies - efforts that require information on the chemical speciation of heavy metals, radionuclides, and xenobiotic organic compounds and their reactions with environmental materials. To achieve this goal, both fundamental and targeted studies of complex environmental systems at a molecular level are needed, and examples of both types of studies are presented herein. These examples illustrate the fact that MES SR studies have led to a revolution in our understanding of the fundamental physical and chemical aspects of natural systems.

The MES SR user community has continued to experience strong growth at U.S. SR laboratories, with MES researchers comprising up to $15 \%$ of the total user base. Further growth and development of the MES community is being hindered by insufficient resources, including support personnel, materials preparation facilities, and available beam time at U.S. SR laboratories. EnviroSync* recommends the following actions, in cooperation with U.S. SR laboratory directors, to meet the MES community's needs.

Increase Operations Funding for Existing Beam Line Stations: Increased operations funding (for support staff, capital equipment, equipment upgrades, and maintenance) is needed for beam lines dedicated to or used heavily by the MES community from the current level $(<\$ 350 \mathrm{~K}$ per beam line station per year) to a level approaching that of the Structural Molecular Biology community ( $\sim 750 \mathrm{~K}$ per beam line station per year). This recommendation is projected to cost on the order of $\$ 7.5 \mathrm{M}$ per year for the 10 full time equivalent beam line stations currently used by the MES community. Environmental research is broad and spreads across many disciplines, and as such, MES research and the required SR facilities should be supported by a broad range of federal agencies. EnviroSync should work with the directors of the U.S. SR sources to help build the funding base needed to support the MES SR user community.

Increase Beam Line Station Availability for MES Activities: Over-subscription of beam line stations used in MES research is great and growing. The challenge is to develop new beam lines and enhance the capabilities of existing beam lines to meet the current and future needs of the MES community in a coherent and responsible manner. Enhanced resources should be achieved in three ways:

- Redirect Existing Beam Line Stations: Identify existing beam line stations that could be redirected to MES activities. We envision a growing need for micro-spectroscopy and imaging facilities at SR sources because of the increasing need for information on hetrogeneities in environmental samples at increasingly small spatial scales. Redirection of appropriate beam line stations for micro-spectroscopy is, therefore, of high priority. The funding needed to upgrade these beam line stations and to provide the necessary scientific and engineering staff to support MES and other users of these re-directed beam line stations should be sought through proposals to appropriate federal agencies. 
- Plan for New Beam Line Stations: Advanced planning is essential for new beam line facilities that will serve the MES community because several years are required for design and construction of beam lines.

- Enhance Access to Existing Innovative Beam Line Stations: Enhanced access by MES researchers to innovative instrumentation will allow new classes of MES problems to be effectively addressed. For example, x-ray microscopy and spectromicroscopy methods (STXM, TXM, PEEM) can provide information on the speciation of environmental contaminants (and nutrients) at spatial scales $(25-100 \mathrm{~nm})$ that have heretofore been inaccessible under in situ conditions. Because of the complexity of these methods, increased scientific staff support is required to help the MES community effectively utilize these beam line stations. Funding should be sought to make this increased support possible.

Increase Funding for Essential Equipment and Sample Handling Facilities: The equipment and non-beam line facilities required to support MES experiments at many desirable beam line stations are lacking. Increased availability of specialized instruments, e.g., high throughput solid-state detectors and cryostats, is essential. Dedicated facilities are also needed for radioactive sample handling and preparation of biological samples. EnviroSync should work with U.S. SR laboratory directors to seek the funding required for this infrastructure from relevant federal agencies.

EnviroSync should conduct another survey of the MES community to determine the highest priorities and needs for (1) infrastructure support of existing beam line stations, (2) capital equipment needs, and (3) needs for new beam line stations dedicated to MES research. The last such survey was conducted in 1995, when the MES research area was in its infancy.

EnviroSync should continue to function as an advisory group to the federal agencies that fund SR sources, beam line stations, and infrastructure, providing advice on priorities for re-direction of existing beam line stations and construction of new beam lines optimized for MES research, and organizing workshops that focus on the accomplishments and needs of the MES community as well as new research opportunities.

* EnviroSync is a national organization representing environmental science users at U.S. synchrotron radiation sources. A brief history of this organization and a list of the current members of the EnviroSync Steering Committee are presented in Appendix B. 


\section{Introduction}

\section{A. Molecular Environmental Science}

Molecular-scale studies of environmental science problems have grown in importance over the past decade because of the need for fundamental information about the speciation or chemical form of environmental pollutants and the basic chemical and biological processes determining their behavior and their effects on human health. The main drivers for this growth are the need to understand how to remediate contaminated soils, natural waters, and the atmosphere and to safely isolate from the biosphere toxic and radioactive wastes from past U.S. weapons production and from agricultural, energy producing, manufacturing, and mining activities, as illustrated in Figure 1. The main scientific issues involving environmental contaminants concern their speciation, distribution, reactivity, transformations, mobility, biogeochemical cycling, and bioavailability. These issues ultimately depend on molecular-scale structure and properties.

A rapidly growing multidisciplinary field referred to as molecular environmental science (MES) has emerged during the last few years due to the unique role that SR sources have begun to play in addressing the above issues. This is because the very high intensity, brightness, and energy tunability of X-rays and VUV light from synchrotron storage rings permit element-specific spectroscopic studies of very dilute levels of pollutants in highly complex environmental samples and in model systems designed to serve as simplified analogs of environmental samples. These types of studies have led to unique information on many of the chemical processes that affect contaminant elements, particularly those occurring at solid-water interfaces [1], and they have

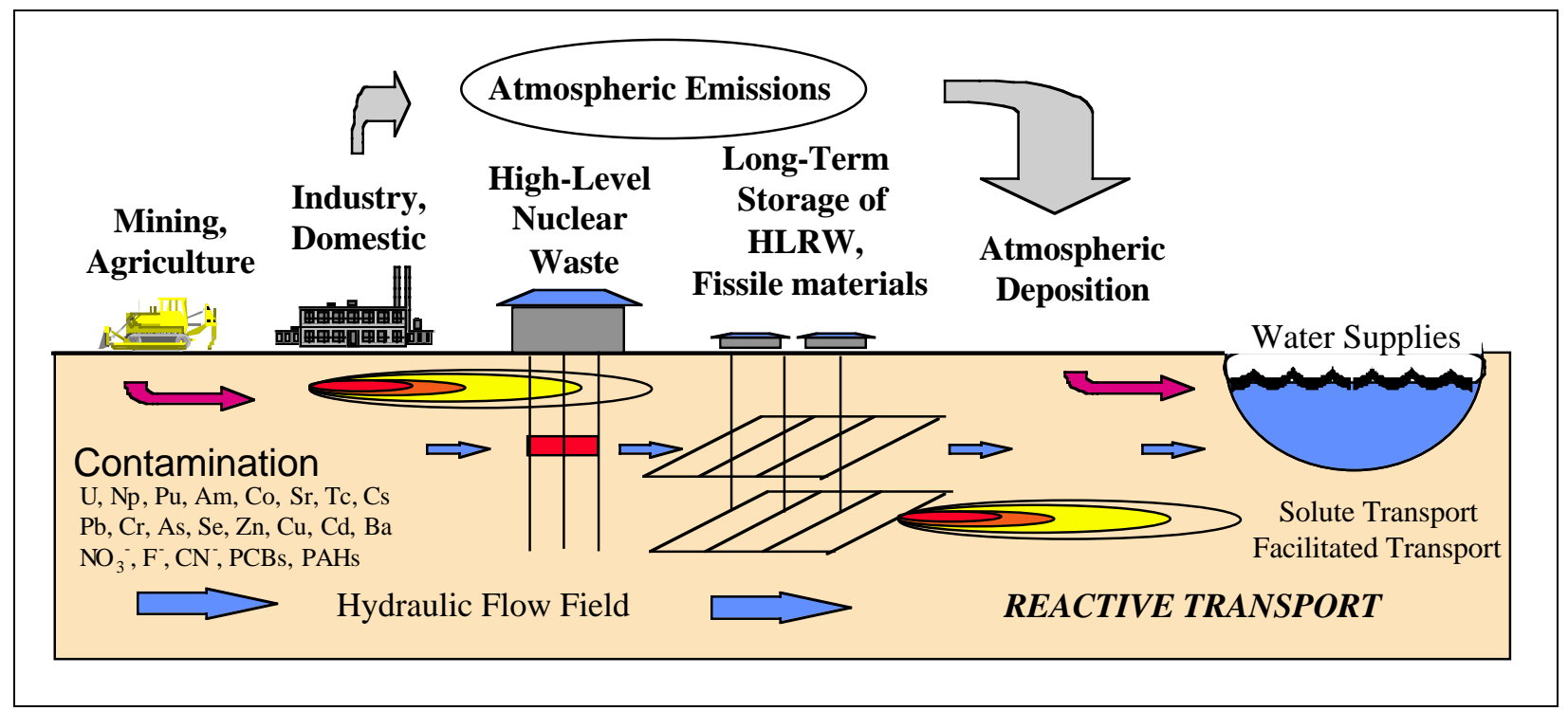

Figure 1. Field-scale schematic view of sources and transport of environmental contaminants and pollutants.

provided a great deal of basic data on the speciation and spatial distribution of radioactive and toxic species in environmental samples (reference [2] provides a review of a number of these 
studies). Such information is beginning to play a critical role in designing remediation strategies and in setting environmental standards.

Figure 2 is a schematic illustration of some of the molecular-scale processes that affect the fate of environmental contaminants. Such processes range from dissolution of mineral particles in soils, which can release natural contaminants into pore waters, to the binding or sorption of metals (M) and organic compounds (L) to mineral surfaces, which can effectively immobilize contaminants and reduce their bioavailability. Some contaminant elements such as chromium, arsenic, or selenium can undergo oxidation or reduction when they interact with mineral surfaces and organic compounds. In addition, microorganisms and plants can have a profound influence on chemical reactions occurring at the earth's surface. For example, microorganisms often play a major role in the degradation of organic contaminants and in the oxidation and reduction of heavy metals. The root-soil interface (rhizosphere - see circled area in soil profile) is an area of particularly intense chemical and biological activity where organic acids, sugars, and other organic compounds are exuded by live plant roots. The $\mathrm{pH}$ can be as much as 2 units lower, and microbial counts can be 10 to 50 fold higher at the root surface than in the bulk soil a few millimeters away. Thus, mineral weathering and the solubility of natural and anthropogenic contaminants are generally greater in surface soils, where plant and microbial activity are higher,

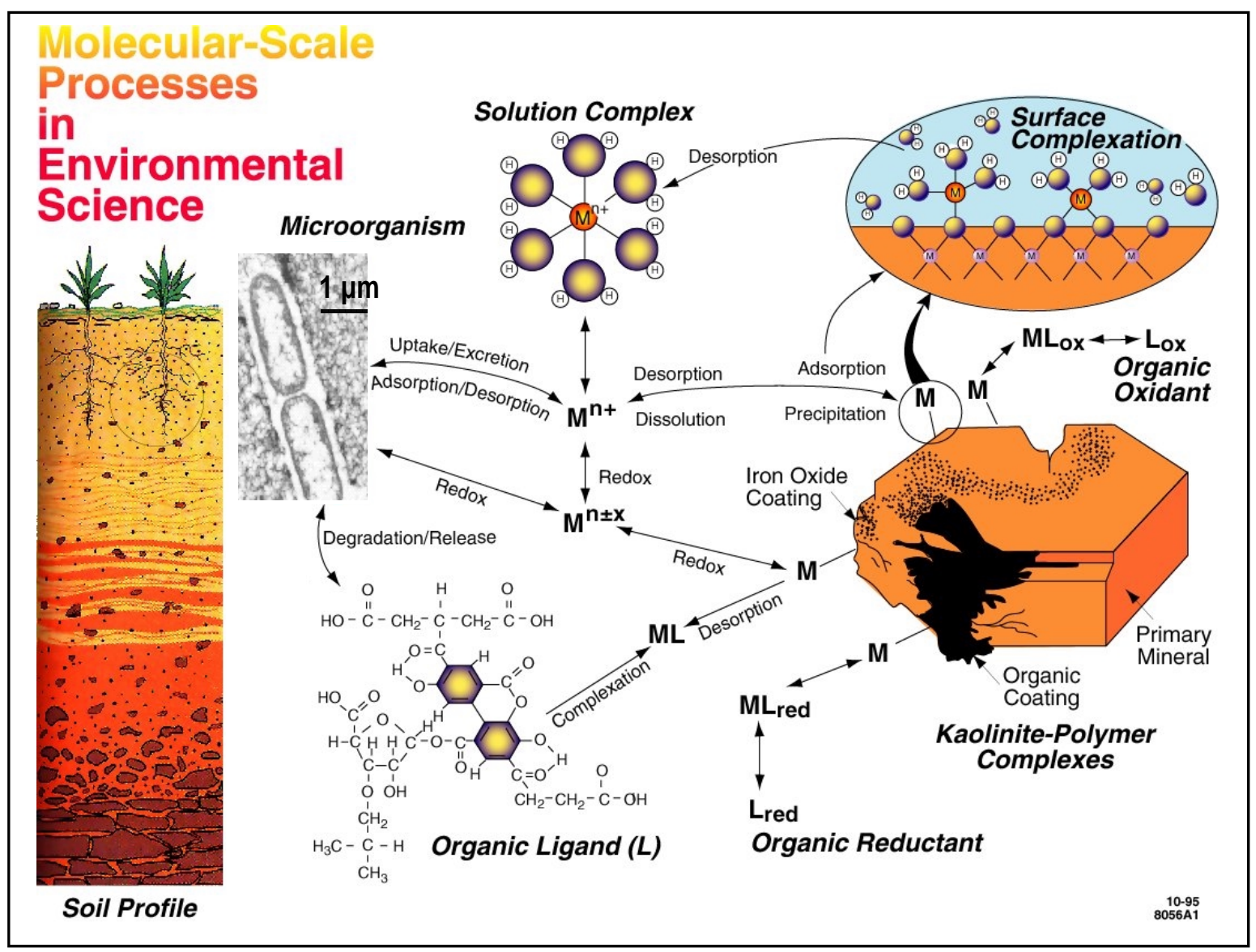

Figure 2. Examples of molecular-scale environmental processes in soils and aquatic systems. (from [3]) 
than in deeper parts of the soil and geologic column. An understanding of the molecular-scale mechanisms and rates of these processes requires knowledge of the types, spatial distribution, and reactivity of contaminant species, the nature of mineral surfaces (including coatings that affect their reactivity) and colloidal particles, the types and distribution of organic compounds and microorganisms in soils and pore waters, and the effect of a host of variables on the rates of dissolution, adsorption, desorption, precipitation, degradation, and redox reactions.

\section{B. Why is MES important?}

Who cares about the distances between atoms? Just about everyone should, including your nextdoor neighbor, because such distances define molecular structure which in turn defines properties or functions in all materials including those occurring in the environment and in living cells. The molecular form or speciation of environmental contaminants such as chromium, arsenic, lead, uranium, and plutonium determines their toxicity and availability to organisms. A good example of the importance of chemical speciation on properties is chromium, which occurs in two dominant forms in nature - hexavalent chromium [Cr(VI)], which is typically coordinated by four oxygens in aquatic systems, and trivalent chromium [Cr(III)], which is coordinated by six
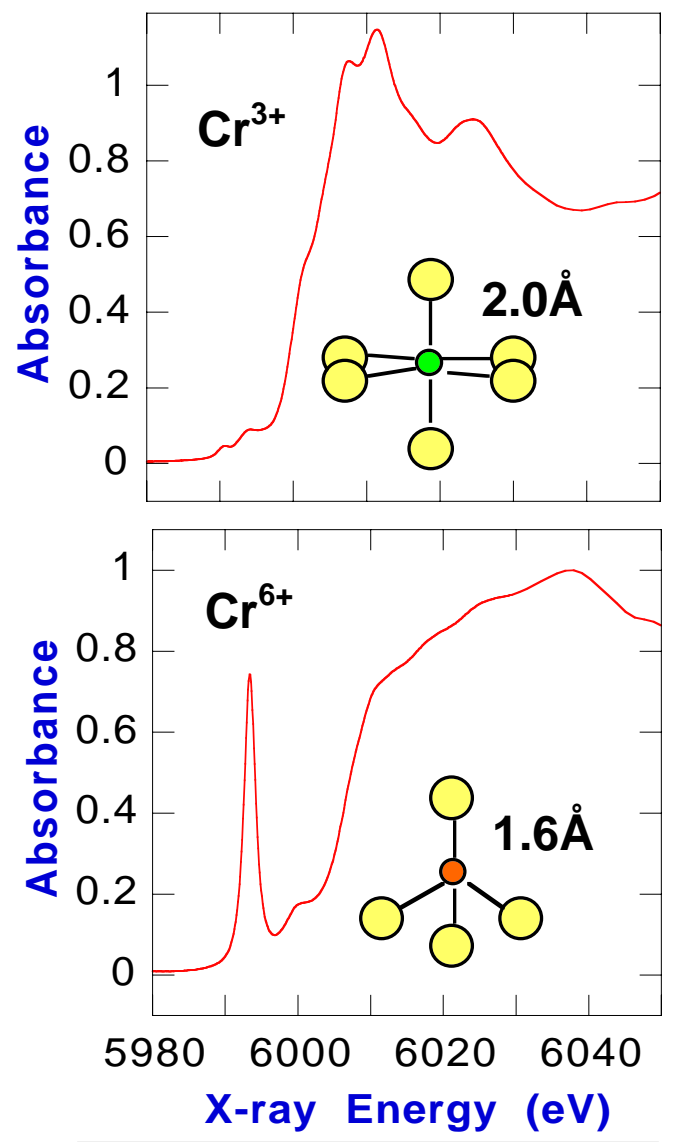

Figure 3. XANES spectra of $\mathrm{Cr}$ in the trivalent (top; green atom) and hexavalent (bottom; red atom) chemical forms. (from [4]) oxygens. $\mathrm{Cr}(\mathrm{VI})$ is highly toxic, mutagenic, teratogenic, and carcinogenic to organisms and is highly soluble in aqueous solutions, thus is quite mobile in groundwater. In contrast, $\mathrm{Cr}$ (III) is nontoxic and occurs in solids that are highly insoluble in groundwater. Figure 3 shows X-ray absorption near edge structure (XANES) spectra of $\mathrm{Cr}$ in these two chemical forms, with molecular models illustrating the differences in structure of the two forms, including the difference in interatomic distance $\left(2.0 \AA\right.$ for $\mathrm{Cr}(\mathrm{III}) \mathrm{O}_{6}$ versus $1.6 \AA$ for $\left.\mathrm{Cr}(\mathrm{VI}) \mathrm{O}_{4}\right)$. The XANES spectra show striking differences in the pre-edge (5990-5995 eV) and main-edge (5995-6040 eV) regions of the spectra, which are definitive indicators of each form.

The importance of correlating the chemical speciation of a contaminant with spatial location in a complex environmental sample is illustrated in Figure 4 which shows a $\mathrm{Pu} \mathrm{L} \alpha \mathrm{X}$-ray fluorescence map $(150 \mu \mathrm{m} \times 150 \mu \mathrm{m})$ of a sample of Yucca Mountain tuff after exposure to a $\mathrm{Pu}(\mathrm{V})$-containing aqueous solution. This study found that plutonium sorbs preferentially on manganese oxide coatings on smectite particles in the tuff and not on iron oxides or on other phases such as zeolites that also occur in the altered tuff. Such information is critical for understanding how plutonium may be sequestered in complex natural samples in the 


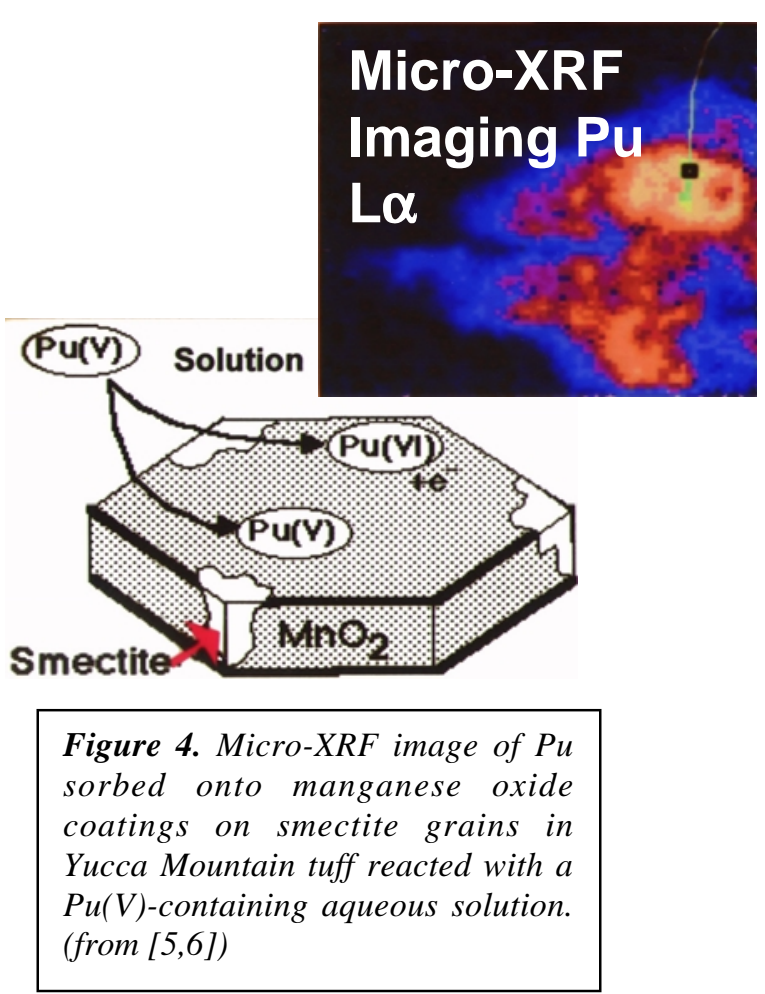

vicinity of the designated high-level waste repository. This study also suggested that $\mathrm{Pu}(\mathrm{V})$ is partially oxidized to $\mathrm{Pu}(\mathrm{VI})$ during its reaction with $\mathrm{MnO}_{2}$. This study represents the first detailed investigation of the interaction of actinides with manganese oxides, which are very common coatings on minerals.

MES research directly impacts the core missions of federal agencies through investigations related to (1) discovery of fundamental knowledge about environmental materials, and chemical interactions between these materials and environmental pollutants, microbial communities, and natural waters, (2) remediation of heavy metals contamination at U.S. sites, (3) quantification of radionuclide transport and risk assessment at highlevel waste disposal and radioisotope production sites, (4) science-based stockpile stewardship, (5) design of plant species to remediate contaminated soils, and (6) photooxidation of crude oils. For example, XAFS studies of core samples from beneath the Hanford Tank Farm are providing some of the first information about the chemical forms of chromium and uranium in the vadose zone beneath the Hanford High Level Waste Storage site. Such studies are also revealing the extent of Pu contamination at the Rocky Flats Environmental Technology Site (RFETS), and have shown that the main $\mathrm{Pu}$ species present in these soils is $\mathrm{PuO}_{2}$, which is highly insoluble. This information has already resulted in modifications of the remediation strategy at RFETS and significant cost savings. In model system studies designed to simulate more complex environmental systems, XAFS spectroscopy is providing unique information on reactions of heavy metal and radionuclide contaminants with particle surfaces and on the forms of $\mathrm{Np}$ and $\mathrm{Pu}$ in highly alkaline Hanford Tank waste. Other examples of MES research conducted at the seven U.S. SR sources are presented in $\S \mathrm{V}$.

\section{Synchrotron Radiation Sources and Capabilities}

The growing importance of SR to scientists in the U.S. and many other countries is clearly shown by the increase in number of SR laboratories over the past 25 years. There are currently about 70 such laboratories worldwide, with new national facilities under construction or in design stages in the U.K., France, Canada, and Australia. In the U.S. there are seven major SR sources: the Advanced Light Source (ALS) at Lawrence Berkeley National Laboratory, the Advanced Photon Source (APS) at Argonne National Laboratory, the National Synchrotron Light Source (NSLS) at Brookhaven National Laboratory, the Stanford Synchrotron Radiation Laboratory (SSRL) at the Stanford Linear Accelerator Center, the Cornell High Energy Synchrotron Source (CHESS) at Cornell University, the Synchrotron Radiation Center (SRC) at Stoughton, Wisconsin, and the Center for Advanced Microstructures and Devices (CAMD) at Louisiana State University in Baton Rouge. All of these general user facilities in the U.S. have become saturated as increasing numbers of users seek beam time. The most rapidly growing 
synchrotron user communities over the past decade have been structural molecular biology (SMB) and molecular environmental science (MES). A typical growth plot for the MES area is shown in Figure 7.

Figure 5 illustrates the enormous gain in brilliance of SR sources over conventional sealed-tube or rotating-anode laboratory X-ray sources. This attribute, coupled with the tunability of SR over a broad energy range (typically $<50 \mathrm{eV}$ to $>1000 \mathrm{eV}$ for soft X-ray/VUV BLs and 5000 to $50,000 \mathrm{eV}$ for hard X-ray BLs), have made it possible to conduct $\mathrm{X}$-ray spectroscopy and X-ray scattering experiments on environmental samples that were simply not feasible prior to the general availability of SR sources. In addition, the brilliance of modern SR sources, particularly $3^{\text {rd }}$-generation sources with low emittances, and the availability of focusing optics, which can produce focused hard X-ray beams with sub- $\mu \mathrm{m}$ diameters and focused soft X-ray beams with $50 \mathrm{~nm}$ diameters, have made $\mu \mathrm{XANES}, \mu \mathrm{XRF}$, $\mu \mathrm{XRD}, \mu$-tomography, and X-ray microscopy studies possible (see Appendix $\mathrm{C}$ for definition of acronyms).

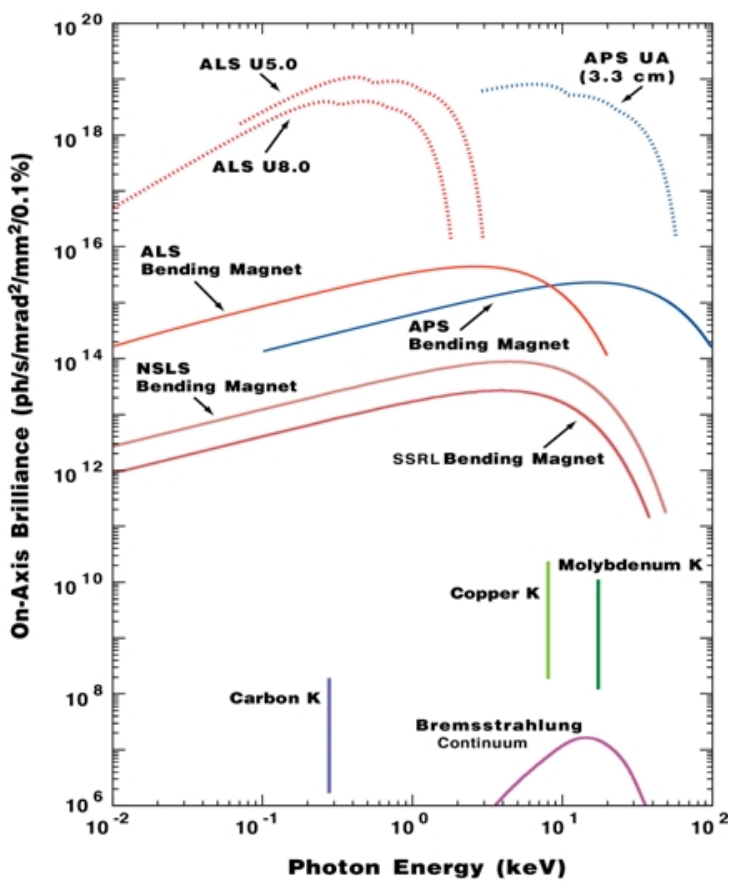

Figure 5. Synchrotron source brilliance curves vs. brilliances of conventional laboratory sources such as sealed or rotating anode tubes (lower part of figure).

These are particularly useful methods for environmental samples, which are often heterogeneous on spatial scales of a few $\mu \mathrm{m}$ or less. As illustrated by the examples in $\S \mathrm{V}$, these methods are being applied to a variety of environmental problems, ranging from studies of the interaction of heavy metal, radionuclide, and organic contaminants with plants and microbial organisms to imaging changes in the macromolecular structure of natural organic matter in water. For instance, scanning transmission X-ray microscopy (STXM) methods are now being used to image iron oxides in the presence of humic substances at sub- $\mu \mathrm{m}$ spatial resolution, and combined STXM and $\mu$ XANES measurements are revealing the identity of soil organic particles.

The very high brightness of SR sources also allows X-ray reflectivity and X-ray standing wave studies of mineral surfaces in contact with aqueous solutions and microbial biofilms that are not possible with conventional laboratory X-ray sources. Such studies are providing detailed information on the dissolution mechanisms of minerals and of the effects of bacteria on heavy metal-mineral interactions, which are of great importance in metal sequestration in the biosphere.

The most common environmental problem being addressed using SR sources in the U.S. and other countries is the molecular-level speciation of metal contaminants and pollutants in complex environmental samples. The toxicity, mobility, and fate of environmental contaminants and pollutants are largely determined by their speciation, as discussed earlier. Because of the very high flux of SR sources, dilute levels $(<50 \mathrm{ppm})$ of these metals can be detected and characterized using XAFS spectroscopy methods. This approach is particularly useful when the pollutant or contaminant species is adsorbed to particle surfaces or is present in a poorly crystalline phase, which X-ray diffraction methods cannot typically detect. 


\section{A. The Advanced Light Source - Lawrence Berkeley National Laboratory}

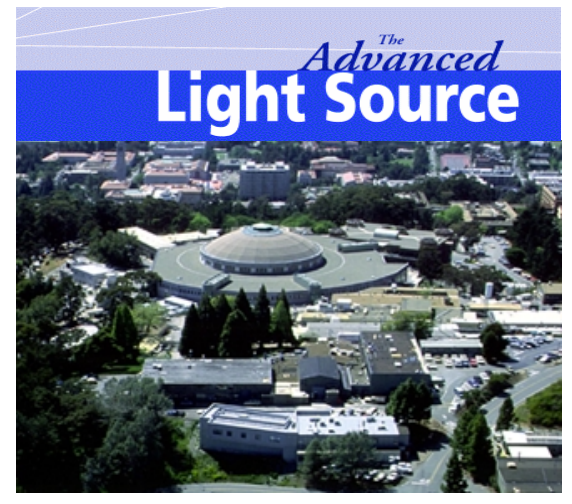

The Advanced Light Source (ALS) began operations in October 1993, and is one of the world's brightest sources of ultraviolet light, soft X-rays, and hard X-rays to $30 \mathrm{keV}$ from superbend sources. Soft X-rays from the ALS are ideal for a wide range of electronic structural studies and are particularly useful for X-ray microscopy, surface science, and solid-state physics of carbides, actinides, and oxides. Such regions of the spectrum also offer special opportunities for research in microbial-mineral interactions, chemical physics, electron spectroscopy, microscopy, X-ray emission spectroscopy, and holography.

Several recent developments at the ALS will have a major impact on the field of molecular environmental science. In 1999 DOE-Basic Energy Sciences initiated development and construction of a Molecular Environmental Science beam line at the ALS. Shown schematically in Figure 6, the beam line (11.0.2) consists of two separate branch lines, each with respective experimental stations, and each supplied by very intense and brilliant soft X-ray/VUV radiation from an undulator insertion device. The MES beam line will operate in the energy range from 75-2100 eV with a spot size of 7 x $15 \mu \mathrm{m}$, which coincides with the $\mathrm{K}$ edges of the most prevalent set of elements on the surface of the earth $(\mathrm{C}, \mathrm{N}, \mathrm{O}, \mathrm{Na}, \mathrm{Mg}, \mathrm{Al}$, and $\mathrm{Si}$ ), and with the L edges of all of the important transition metals (Ti, V, Cr, Mn, Fe, Co, Ni, Cu and Zn) as well as the $\mathrm{L}$ edges of $\mathrm{P}, \mathrm{S}, \mathrm{Cl}, \mathrm{K}$ and $\mathrm{Ca}$. The end stations on the first beam line are dedicated to an upgraded state-of-the-art STXM with resolution of $30 \mathrm{~nm}$, and a pair of "wet" spectroscopy end stations allowing X-ray absorption, emission, and photoelectron spectroscopy to be done on samples kept in equilibrium with ambient water vapor. Analogous studies using existing apparatus at the ALS have already led to important new findings about the macromolecular structure of fulvic acid in solution, on the structure of liquid water, and on the effect of microbial organisms on redox transformations of transition metal ions on mineral surfaces.

Another development at the ALS is the use of the $\mu$ FTIR BL station (1.4.3) to determine the reactions of cell components with toxic chemicals under various conditions, and the specifics of bacterial remediation processes, such as the conversion of carcinogenic $\mathrm{Cr}$ (VI) into $\mathrm{Cr}$ (III), which has low toxicity. Beam line station 1.4 .3 can produce $\mu$-beams down to $10 \mu \mathrm{m}$ in diameter subject to the diffraction limit with brightness up to 200 times that of a laboratory globar source.

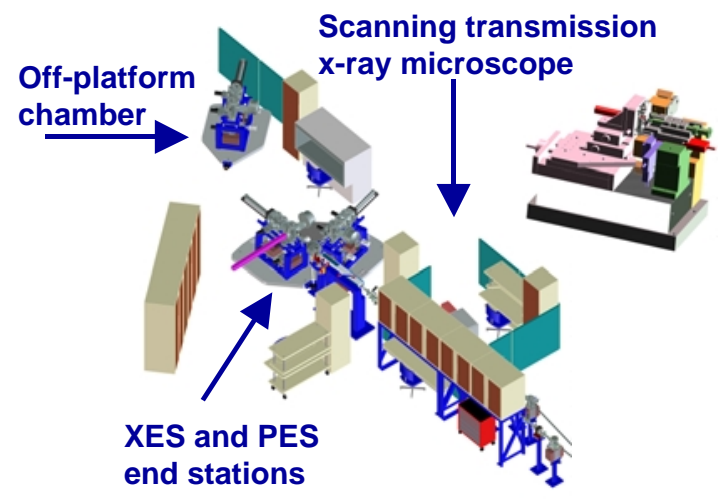

As cells are not killed by exposure to focused IR radiation, living species can be examined both in an IR imaging mode and in a point spectroscopy mode. Organic functional groups and metal ion coordination can be deduced from the far and mid FTIR spectrum, so that complex metal interactions with organic structures in particular cell units can be identified.

Figure 6. Schematic of the MES beam line (11.0.2) at the Advanced Light Source. 
Other BL stations at the ALS of interest to environmental scientists are those devoted to X-ray fluorescence microprobe analysis (10.3.1), $\mu$ XAFS (10.3.2), $\mu$ XRD (7.3.3), and a new beam line being designed for X-ray $\mu$-tomography (8.3.2). The first two BL stations have been used to study a variety of environmental problems, as well as topics important to semiconductor physics and manufacturing, while the last will be used in part for the study of microchannels in oilbearing rocks (with reference to trapped oil recovery) and in vadose zones (where fluid flow is incompletely understood yet important for toxic metal transport and reaction rates).

\section{B. The Advanced Photon Source - Argonne National Laboratory}

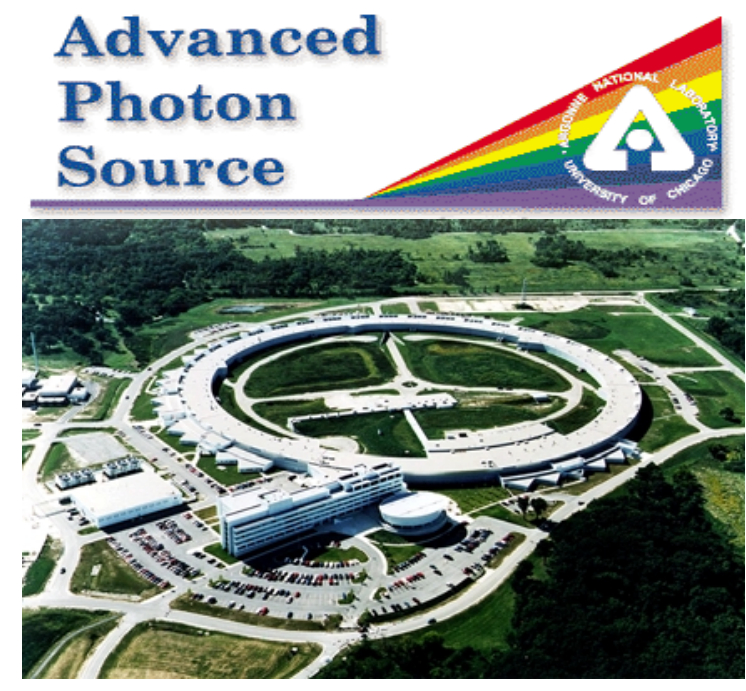

The APS is a third-generation synchrotron radiation source specifically designed to accommodate insertion devices that cause electrons or positrons to wiggle or undulate through a series of alternating magnetic poles, resulting in orders of magnitude increases in brightness relative to previous approaches. The APS produced its first undulator beam in 1995 , the $100^{\text {th }}$ anniversary of Röntgen's discovery of X-rays. Qualified users have access to the APS either as members of Collaborative Access Teams (CATs) or as General Users. Each CAT is responsible for building and operating the beam lines in one or more of APS's 34 sectors (twentyseven sectors are currently operational, or assigned, leaving only 7 sectors for new CATs).

One CAT, known as GeoSoilEnviroCARS-CAT (GSECARS-CAT; Sector 13), is operated by the Consortium for Advanced Radiation Sources (CARS) as a national user facility (supported by DOE, NSF, and the W. M. Keck Foundation) for state-of-the-art research on earth materials. All beam time at GSECARS is allocated to members of the scientific community through a proposal-based system. The undulator beamline (13-ID) contains a Kirkpatrick-Baez mirrorbased X-ray microprobe (3-50 KeV, $3 \mu \mathrm{m}$ beam spot, $\mu \mathrm{XRF}, \mu \mathrm{XAFS}$, fluorescence computed $\mu$ tomography, X-ray standing wave-fluorescence yield spectroscopy), a general-purpose kappa diffractometer (surface diffraction and spectroscopy with fully focused undulator radiation, $\mu$ crystallography) and high-pressure apparatus. The bending magnet beam line (13-BM) includes instrumentation for computed $\mu$-tomography, $\mu$ XRD, XAFS, and high-pressure experiments.

The Basic Energy Sciences Synchrotron Radiation Center (BESSRC-CAT; Sectors 11 and 12) has capabilities for mineral surface studies (reflectivity, CTR, XSW) and electrochemical experiments on actinides. The Materials Research CAT (MR-CAT; Sector 10) emphasizes XAFS, scattering, and reflectivity studies. Pacific Northwest Consortium (PNC-CAT), which is locted at sector 20 and offers $\mu$ XAFS and microprobe capabilities, is affiliated with the Pacific Northwest National Laboratory and its Environmental Molecular Sciences Laboratory (EMSL). Sector 2 (X-ray Operations and Research group, formerly SRI-CAT) operates a zone plate-based $\mathrm{X}$-ray microprobe $(0.1 \mu \mathrm{m}$ spot) and $\mu$-tomography apparatus. Both DND-CAT (Sector 6) and 
BIO-CAT (Sector 18) have XAFS instrumentation for environmental studies. An actinide handling facility in the ANL-Chemistry Division is available to APS Users.

\section{The Center for Advanced Microstructures \& Devices - Louisiana State University}

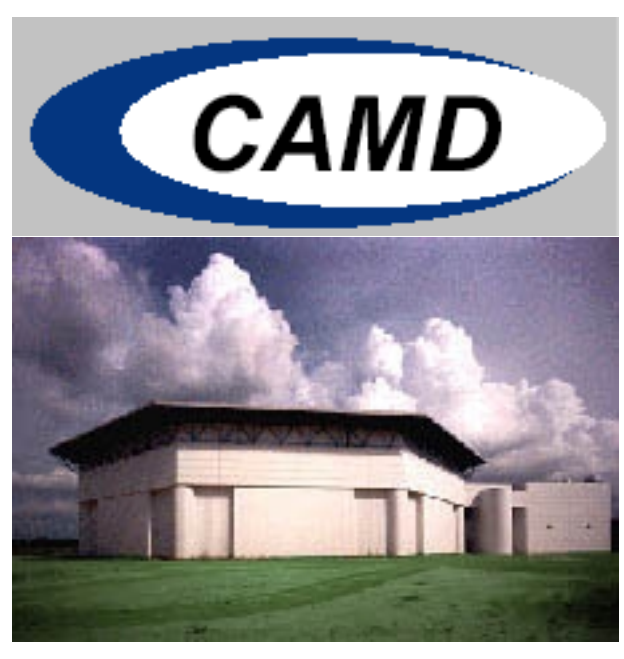

The J. Bennett Johnston Sr. Center for Advanced Microstructures and Devices (CAMD) in Baton Rouge, Louisiana, operates a $1.3 \mathrm{GeV}$ storage ring as a synchrotron radiation facility. Thus, CAMD is a "soft $\mathrm{X}$ ray facility" with a characteristic energy $\mathrm{E}_{\mathrm{c}}$ of about 1.7 $\mathrm{keV}$. To reach the harder $\mathrm{X}$-ray region up to about 30 $\mathrm{keV}$, a $7 \mathrm{~T}$ superconducting wiggler is used.

There are 12 operational beam lines: 4 for microfabrication, 4 UV/VUV beam lines, and 5 X-ray beam lines. Two more beam lines: a first IR beam line and a beam line with two X-ray monochromators in series (one using multilayers for "low resolution" applications and the second using a "normal" Si-double crystal monochromator) are under construction. The double monochromator beam line is on a wiggler beam line and will be used for element-specific X-ray tomography and for X-ray absorption spectroscopy. The IR beam line will be equipped with an IR microscope and a Fourier transform spectrometer.

Four X-ray beam lines are used for environmental science research: double crystal monochromator (DCM), X-ray microprobe (XMP), small angle X-ray scattering and grazing incidence X-ray absorption spectroscopy (SAXS/GIXAS), and pink-light X-ray tomography/Xray fluorescence. The DCM beam line covers the energy range from about $1.2 \mathrm{keV}$ up to about $12 \mathrm{keV}$ with a variety of crystals (including InSb (111) for the Si-K-edge, and $\mathrm{YB}_{66}$ for the Al-Kedge). This beam line is operated without any windows in front of the monochromator so that very high intensity is available at several of the low-Z-elements of environmental importance ( $\mathrm{Si}$, $\mathrm{P}, \mathrm{S}$ ). This beam line is mainly used for X-ray absorption spectroscopy but in some cases also for X-ray fluorescence with monochromatic excitation. The XMP beam line is a "mirror image" of the DCM beam line and covers about the same energy range. This beam line has a KirkpatrickBaez optic that allows focusing the beam down to about $15 \mu \mathrm{m}$ x $15 \mu \mathrm{m}$ even at the P-K-edge. A smaller spot size is available using additional apertures. The SAXS/GIXAS beam line covers the energy range from about $2.5 \mathrm{keV}$ up to about $13 \mathrm{keV}$ and has two experimental stations. One is for small angle X-ray scattering (SAXS), and the other one is for X-ray absorption spectroscopy under grazing incidence conditions (GIXAS). The Tomography/Fluorescence beamline uses "pink" (filtered) radiation for high resolution X-ray tomography (about $3 \mu \mathrm{m}$ resolution) or for Xray fluorescence investigations of dilute samples. 


\section{The Cornell High Energy Synchrotron Source - Cornell University}

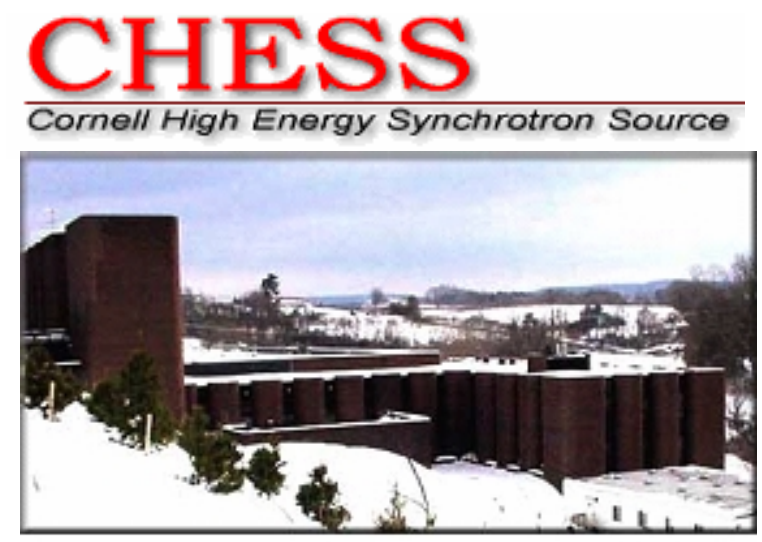

The Cornell High Energy Synchrotron Source (CHESS) is a user-oriented National Facility to provide state-of-the-art SR facilities to the scientific community. Supported by grants from the Division of Materials Research of the National Science Foundation, CHESS encompasses a multifaceted research and development program, which is partly in-house and partly collaborative, with a wide spectrum of experimental groups from Universities, National Laboratories, and Industry. Each year, 400-500 scientists and scientists in training visit CHESS to collect data that comprises all or part of their research programs. Also, a significant effort of the staff is aimed at developing synchrotron radiation experimental facilities and methods that utilize the high intensity photon flux provided by the Cornell Electron Storage Ring (CESR). CHESS was constructed in the period from 1978 to 1980 as a synchrotron x-ray facility parasitic to the CESR High Energy Physics program. The original laboratory, CHESS West, included three instrumented beam lines, A, B, and C, that provided six independent experimental stations. The total experimental West area is about 1000 square feet. The CHESS East laboratory was constructed during 1988-1989, adding two beam lines, D and F, and four instrumented experimental stations. CHESS East contains a biohazard level BL3 facility (built with funds from the NIH), which is part of the F1 station. Construction began in 1999 for an addition to the facility through funds provided by Cornell University. This new addition is to be the home to the new G-line and associated three additional experimental stations, which are being constructed with a grant from the NSF. The new facility will be operated in conjunction with CHESS by a Cornell University consortium to provide additional capabilities for experimenters. The new G3 station is being constructed with extensive toxic gas handling capabilities, thus advancing the prospects for in situ crystal growth experiments. Other facilities include a well-equipped modern darkroom, cold room for crystal mounting, experimental laboratories for user set-up, a central computer facility, and a machine shop with two resident machinists. There are general areas for setting up experiments, which include a chemical room with fume hood and user-accessible shop facilities. A user lounge is available to help make a long 24-hour day a bit more tractable.

\section{E. The National Synchrotron Light Source - Brookhaven National Laboratory}

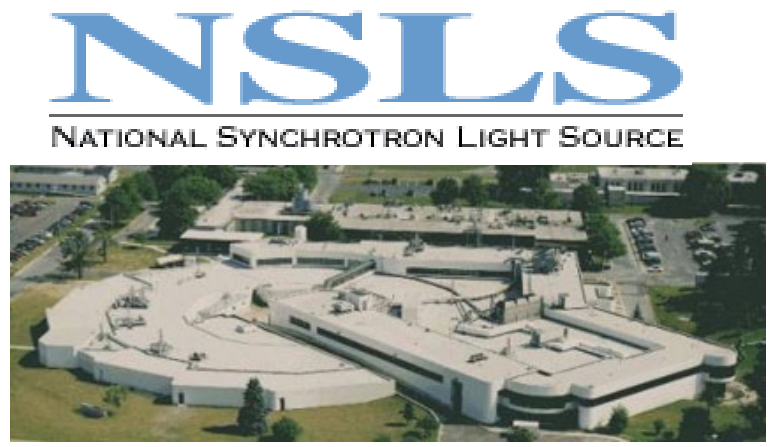

The National Synchrotron Light Source (NSLS) provides intense focused light from the infrared through the X-ray region of the spectrum by operating two electron storage rings: an X-ray ring $(2.8 \mathrm{GeV})$ and a vacuum ultraviolet (VUV) ring $(0.75 \mathrm{GeV})$. X-Ray, ultraviolet, visible, and IR light from the storage rings is guided into 30 X-ray and 17 VUV beam ports, most of which are split into two to four experimental stations. The 
NSLS was commissioned in 1982. Annually, 2,300 scientists representing more than 350 institutions, over 50 of them corporations, conduct research at the NSLS in the fields of biology, chemistry, geology, materials science, medicine, metallurgy, and physics. In the basic sciences, researchers investigate the absorption and scattering of light to determine the properties of matter such as crystal structure, bonding energies of molecules, details of chemical and physical phase transformations, electronic structure, and magnetic properties. Experimental stations for structural molecular biology at the NSLS are used for X-ray crystallography of proteins and other biological macromolecules and for studies of biochemical systems using far-ultraviolet radiation. The NSLS also serves as a training ground for future scientists. Between 1988 and 1999, over 600 students who earned doctorate degrees used the NSLS in their thesis research.

On the VUV ring, environmental research is focused on two IR BL stations, U2B and U10B. These lines are optimized for work into the far IR and are capable of achieving high spatial resolution (3-10 $\mu \mathrm{m})$. Beam lines on the X-ray ring operate in the soft and hard X-ray regimes. Soft X-ray research is conducted primarily at the X1A undulator BL station $(0.25-0.8 \mathrm{keV} ; 50$ $\mathrm{nm}$ spot) that houses a STXM instrument. Powder diffraction on environmental materials can be done at BL stations X3B1 and X7A (4-45 keV; $\mu \mathrm{m}$ spots). EXAFS analyses are conducted primarily at BL stations X11A, X18B, X19A, X23A2, and X23B. X19A is unique on the X-ray ring in providing access to absorption edges in the $2-8 \mathrm{KeV}$ range. $\mathrm{X} 26 \mathrm{~A}$ is the dedicated hard $\mathrm{X}$-ray microprobe (10 $\mu \mathrm{m}$ spot; $3-30 \mathrm{keV})$ for $\mu \mathrm{XRF}, \mu \mathrm{XAFS}$, and $\mu \mathrm{XRD}$. Microtomography is available at X27A.

\section{F. The Stanford Synchrotron Radiation Laboratory - Stanford Linear Accelerator Center}

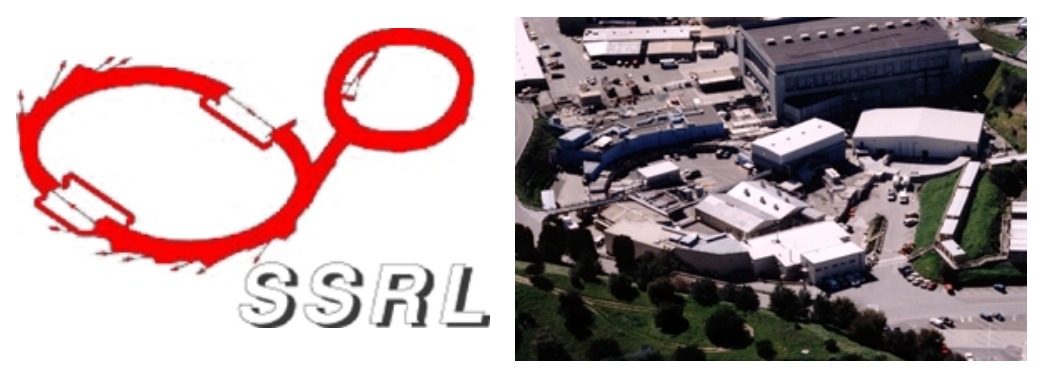

The Stanford Synchrotron Radiation Laboratory (SSRL) located at the Stanford Linear Accelerator Center (SLAC), Stanford University, was built in 1974 to take advantage of the intense synchrotron X-ray beams from the SPEAR storage ring that was originally built for high-energy particle physics research in the 1960's. Over the years, SSRL has been one of the main innovators in the production and use of SR, pioneering the development of wigglers and undulators that form the basis of all third generation SR sources. SSRL scientists have also pioneered the development of synchrotron methods such as (1) photoemission spectroscopy, which is widely used to study the electronic structure of solid surfaces, (2) X-ray absorption fine structure (XAFS) spectroscopy, which is broadly applied in many scientific fields to study the structural environments and bonding around selected elements, and (3) Multiple-Wavelength Anomalous Diffraction (MAD) phasing, which is rapidly becoming the main tool for solving the structures of complex biological molecules. SSRL is now comprised of 27 experimental stations and is used each year by over 900 on-site researchers from industry, government laboratories, and universities. These include astronomers, biologists, chemical engineers, chemists, electrical engineers, environmental scientists, geoscientists, materials scientists, medical scientists, soil scientists, and physicists. 
To meet the growing demand for beam time in the MES area, DOE Basic Energy Sciences funded a new BL optimized for XAFS spectroscopy studies of environmental samples. Based on a 26-pole 2.1 Tesla wiggler magnet, the BL (11-2) produces extremely high fluxes of X-rays over the energy range 5 to $38 \mathrm{keV}$. This BL is equipped with a highly stable scanned-energy monochromator, a 30-element Ge detector with digital signal processing, and a new grazingincidence (GI) spectrometer, which is available for X-ray reflectivity, X-ray standing wave, and GI-XAFS studies of dilute concentrations of adsorbates on surfaces under in situ conditions. A wavelength dispersive spectrometer and a $\mu$-focusing capability needed for $\mu$ XAFS studies are currently in commissioning stages. An integral part of this facility is a special sample handling hutch, adjoining the main experimental hutch, for the temporary storage and handling of radioactive samples, prior to and following XAFS experiments on radioactive samples.

Other SSRL BL stations on which MES research is done on a part-time, non-dedicated basis include 1-4 (SAXS), 2-1 (powder XRD), 2-3 (XAFS), 3-3 (NEXAFS, XSW), 4-1 (XAFS), 4-2 (XAFS, GIXAFS), 4-3 (XAFS), 6-2 (XAFS, GIXAFS, XSW), 7-2 (WAXS, surface X-ray scattering), 7-3 (XAFS), 8-1 (PES), 8-2 (NEXAFS, PES), 9-3 (XAFS, GIXAFS), 10-1 (NEXAFS, PES), and 10-2 (XAFS, GIXAFS).

\section{G. The Synchrotron Radiation Center - University of Wisconsin (Madison)}

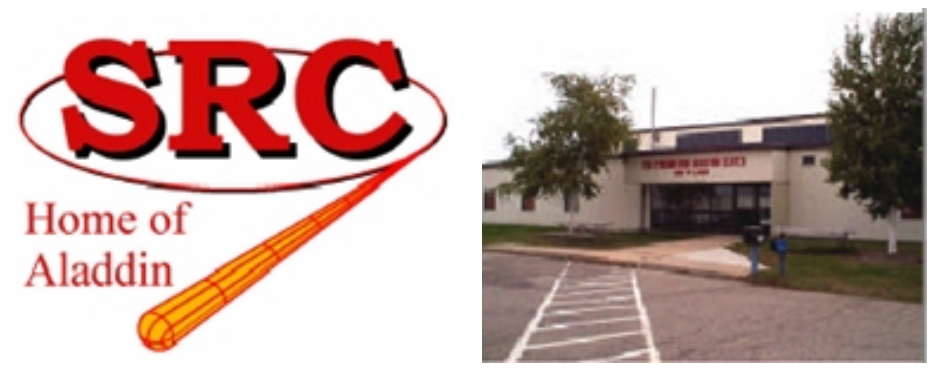

The Synchrotron Radiation Center (SRC) provides radiation in the $5 \mathrm{eV}$ $4000 \mathrm{eV}$ photon energy range and in the infrared from the $1 \mathrm{GeV}$ electron storage ring Aladdin. A variety of beam lines (25 total) are available that are optimized for angle-resolved photoemission, magnetic circular dichroism, core level spectroscopy, nanotechnology, and IR and soft X-ray microscopy. Staffsupported, state-of-the-art instrumentation is provided for user experiments. SRC is a user facility that connects users with other colleagues and instrumentation to accomplish their research, provides the management and resources to support multi-disciplinary research, and has the staff to instruct new users on the applications of the instrumentation.

Of particular interest to the MES community are the following SRC facilities:

(a) An X-ray Absorption Chamber (XAS) is offered for total electron yield measurements of solids in UHV. Special features include a load lock sample transfer system designed for rapid introduction of multiple samples. Planned upgrades to the system include the addition of fluorescence spectroscopy capabilities, partial electron yield detection, and the capability to gold coat the mesh detector used for signal normalization in situ.

(b) X-PEEM Spectromicroscopy is available for microchemical analysis of cells, tissues, minerals, or materials science specimens, with tens of nanometer spatial-chemical resolution.

(c) An IR microscope coupled to a FTIR BL is supported $\left(2-\mu \mathrm{m}\right.$ resolution, $650-8000 \mathrm{~cm}^{-1}$ spectral range). The IR microspectroscopy BL has been used to study the spatial localization of nutrient pools on veinal and interveinal surfaces of in vivo sapling leaves. IR images (maps) of single cells of microalgae have also been measured in order to study the distribution of the main 
metabolic pools (e.g., lipids, proteins, chlorophyll, and carbohydrates) with a few $\mu \mathrm{m}$ spatial resolution for individual algal cells.

A summary of BL facilities for MES research and the various SR techniques available at the seven U.S. SR sources is given in Table 1, and more detailed information on beam station facilities available at each source is provided in Appendix A.

Table 1. Summary of Facilities at U.S. SR Sources Used for MES Research

\begin{tabular}{|c|c|c|}
\hline Light Source & Beam Line Facilities & Techniques Available \\
\hline Advanced Light Source & $\begin{array}{l}\text { Beam line end stations: } 1.4 .3,6.1 .2 \text {, } \\
\text { 6.3.1, 7.0.1, 7.3.3, 8.0.1, 8.3.2, 9.3.1, } \\
9.3 .2,10.3 .1,10.3 .2,11.0 .2\end{array}$ & $\begin{array}{l}\text { XAFS, NEXAFS, and XES } \\
\text { spectroscopy, } \mu \text {-imaging: IR, PES, } \\
\text { SPEM; STXM, Hard X-ray } \mu \text {-probe } \\
\text { and } \mu \text { XAS, } \mu \text { XRD, } \mu \text {-tomography. }\end{array}$ \\
\hline Advanced Photon Source & $\begin{array}{l}\text { CAT facilities: SRI-CAT, DND- } \\
\text { CAT, MR-CAT, BESSR-CAT, } \\
\text { GSE-CARS, BIO-CAT, PNC-CAT }\end{array}$ & $\begin{array}{l}\text { XRF } \mu \text {-imaging, } \mu \text {-tomography, } \\
\text { Hard X-ray XAFS, XSW, SAXS, } \\
\text { WAXS, CTR-scattering, XES. }\end{array}$ \\
\hline $\begin{array}{l}\text { Center for Microstructures \& } \\
\text { Devices }\end{array}$ & Beam line ports: $4 \mathrm{~A}, 5 \mathrm{~A}, 5 \mathrm{~B}, 7 \mathrm{~A}$ & $\begin{array}{l}\mu \text {-tomography, XRF } \mu \text {-imaging, } \\
\text { XAFS, XRD, SAXS, reflectivity, } \\
\text { XPS }\end{array}$ \\
\hline $\begin{array}{l}\text { Cornell High Energy Synchrotron } \\
\text { Source }\end{array}$ & $\begin{array}{l}\text { Beam line end stations: A2, B2, C1, } \\
\text { D1, F3, G1, G2, G3 }\end{array}$ & $\begin{array}{l}\text { X-radiography, XRF } \mu \text {-imaging, } \mu \\
\text { XRD, XRD, SAXS, GISAXS, } \\
\text { reflectivity }\end{array}$ \\
\hline $\begin{array}{l}\text { National Synchrotron Light } \\
\text { Source }\end{array}$ & $\begin{array}{l}\text { Beam line end stations: U2B, U7A, } \\
\text { U10B, X1A, X3B1, X7A, X7B, } \\
\text { X11A, X15A, X18B, X19A, } \\
\text { X23A2, X23B, X26A, X27A }\end{array}$ & $\begin{array}{l}\text { IR spectroscopy, STXM, XAFS and } \\
\text { NEXAFS spectroscopy, XRD, hard } \\
\text { X-ray } \mu \text {-probe, } \mu \text {-imaging, } \mu \text { XRD, } \mu \\
\text {-tomography. }\end{array}$ \\
\hline $\begin{array}{l}\text { Stanford Synchrotron } \\
\text { Radiation Laboratory }\end{array}$ & $\begin{array}{l}\text { Beam line end stations: } 1-4,2-1,2-3 \text {, } \\
3-3,4-1,4-2,4-3,6-2,7-2,7-3,8-1 \text {, } \\
8-2,9-3,10-1,10-2,11-2 .\end{array}$ & $\begin{array}{l}\text { XAFS and NEXAFS spectroscopy, } \\
\mu X A F S, \text { XRD, XSW, WAXS, } \\
\text { SAXS, PES, XES. }\end{array}$ \\
\hline Synchrotron Radiation Center & $\begin{array}{l}\text { Instruments: HERMON, 10m TGM, } \\
\text { DCM, Grasshoppers (MKV, MKII), } \\
\text { FTIR, PGM }\end{array}$ & $\begin{array}{l}\text { XAFS, NEXAFS, X-PEEM, IR } \\
\text { spectroscopy }\end{array}$ \\
\hline
\end{tabular}

\section{The MES User Community and Community Building Activities}

The MES user community has continued to experience strong growth at U.S. SR laboratories in recent years. MES research now comprises 10-15\% of the total user base at SSRL and is approaching similar levels at ALS, APS, and NSLS. Figure 7 illustrates the rapid growth in MES activities at SSRL over the past ten years, as indicated by the steep rises in the number of beam time proposals submitted in the MES area, the number of 8-hour shifts awarded to MES researchers, and the number of publications resulting from this research. Figure 7 includes a timetable of key MES program-related activities at SSRL or sponsored by SSRL, which have helped define this field and have generated new users from diverse scientific and engineering communities such as soil science, plant biology, microbiology, and environmental engineering.

There have also been MES or MES-related workshops sponsored by the NSLS (e.g., Workshop on "Applications of Synchrotron Radiation to Earth Materials", NSLS, June 1992), the ALS (e.g., Workshops on "Soft X-ray Spectroscopy in Molecular Environmental Science at the ALS", LBNL, March 1997; "Scientific Directions at the Advanced Light Source”, LBNL, March 1998; 


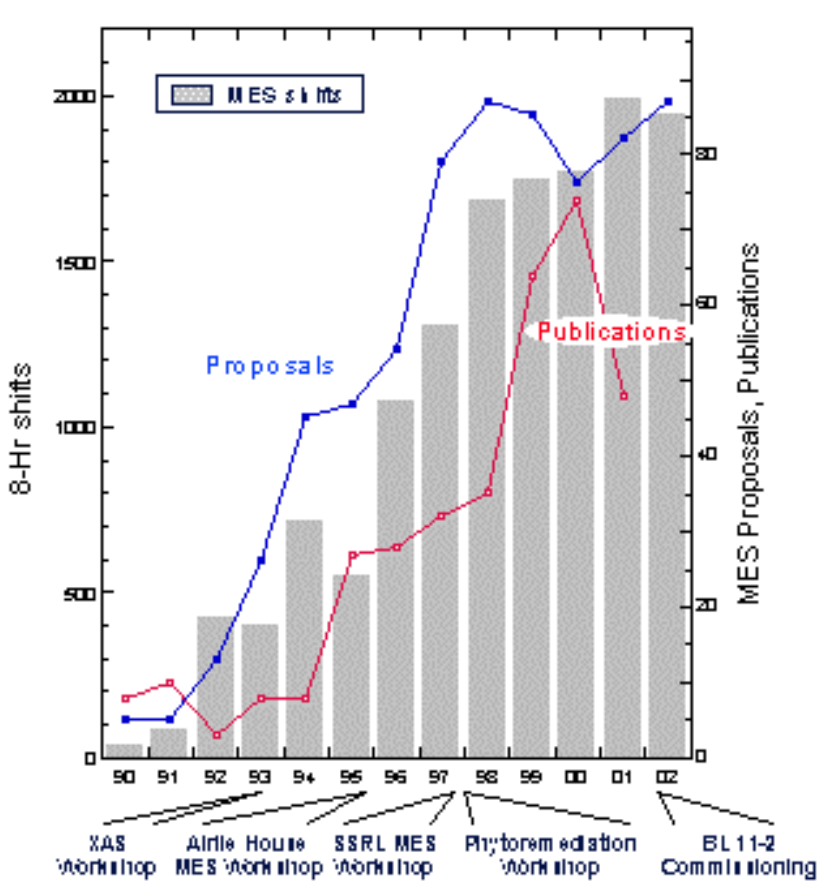

Figure 7. Growth of MES at SSRL over the past decade.
"Future Directions in Soft X-ray Molecular Environmental Science," Joint Workshop with SRRTNet on "Theory, Computation, and Synchrotron Radiation Experiments," ALS Users Meeting, LBNL, October 2001); CAMD ("Environmental Applications of Synchrotron Radiation", July 2002); the SRC ("Infrared Spectromicroscopy Workshop with Environmental Applications", May 2003); and the APS (e.g., the two "Synchrotron Environmental Science" (SES) meetings: SES-I in April 1999 and SES-II in May 2002). In addition, MES SR applications have been highlighted at the week-long Berkeley-Stanford Summer Schools in Synchrotron Radiation in July 2001, July 2002, and June 2003, which were co-sponsored by the ALS and SSRL. Each of these workshops, plus dozens of special symposia organized by EnviroSync members and held at national and international meetings, have attracted new MES SR users and have helped build the MES community over the past 10 years. The interest in this scientific area continues to be very strong, as indicated by the number of new workshops, short courses, and symposia at national and international meetings. For example, a short course on "Applications of Synchrotron Radiation to Low Temperature Geochemistry and Environmental Science", sponsored by the Mineralogical Society of America and the Geochemical Society, was held in Monterey, CA in December 2002. In addition, a symposium entitled "Applications of Synchrotron Radiation-based Techniques in the Environmental and Nuclear Sciences" was held at the $225^{\text {th }}$ American Chemical Society National Meeting in New Orleans, LA in March 2003, and MES was one of six areas highlighted at the $12^{\text {th }}$ International XAFS Conference, which was held in Malmo, Sweden in June 2003.

As shown in the upper panel of Figure 8, about half of SSRL's MES users are based at academic institutions, and about half are at national laboratories. The various disciplines comprising the MES community at SSRL are shown in the lower panel of Figure 8.

\section{MES Users Bv Home Institution}
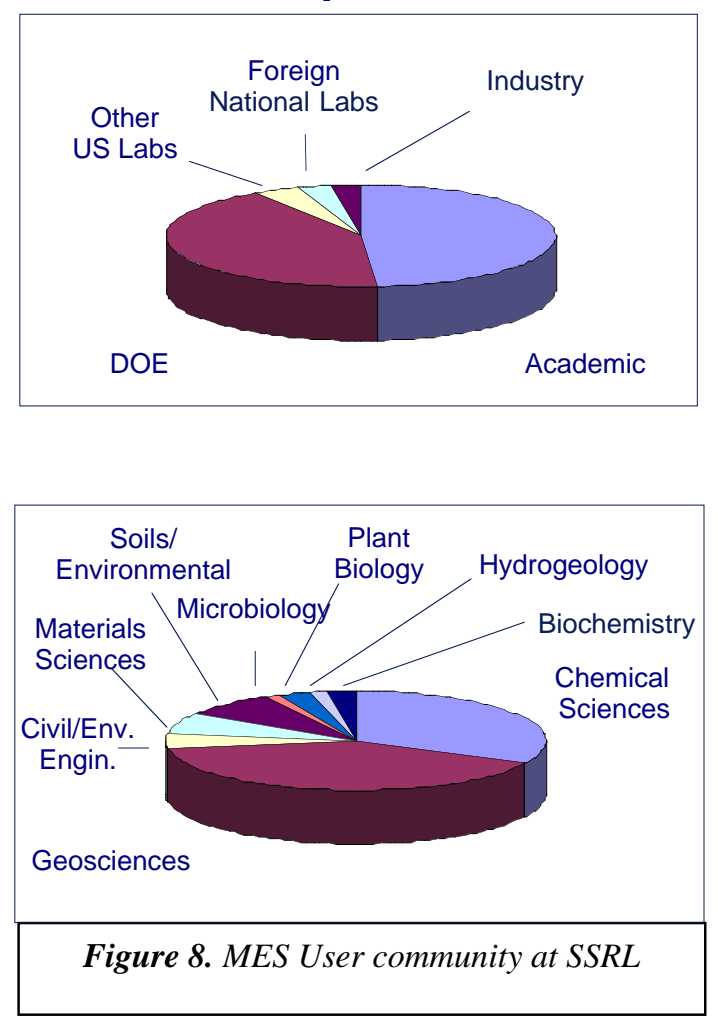


\section{Needs and Priorities of the MES Community}

\section{A. General Comments}

During the past several years, MES research at SR laboratories in the U.S. and other countries has continued to grow, as has the MES community. In addition, there has been a remarkable increase in the number of BL stations used in MES research since the 1995 Airlie Report [7], when only a half dozen BL stations were routinely used on a part-time basis by MES researchers. At that time, there were no beam lines optimized for MES research. There are now $12 \mathrm{BL}$ stations at the ALS, $15 \mathrm{BL}$ stations at the APS, 4 BL stations at CAMD, 8 BL stations at CHESS, 14 BL stations at the NSLS, 15 BL stations at SSRL, and 7 BL stations at SRC used by the MES community (see Appendix A). Two BL stations (BL 11-2 at SSRL and BL 11.0.2 at the ALS) are dedicated to and optimized for MES research, and a third BL station at the NSLS is currently being re-directed for MES studies. With the exception of the GSECARS-CAT at the APS, which serves a national group of earth science users including MES researchers, there are no PRT-style BL stations devoted primarily to MES research. We estimate that the equivalent of ten total BL stations, among these $75 \mathrm{BL}$ stations, were in full-time use by about $300 \mathrm{MES}$ researchers in 2002.

Most of the BL stations used for MES research are of the general-use type and have been optimized for other research areas. The problem of availability of general-use BL stations to MES researchers will be exacerbated over the next three years due to delays in upgrades of wiggler BL stations 4-1, 4-2, and 4-3 at SSRL following completion of the SPEAR storage ring upgrade to a $3^{\text {rd }}$-generation source. These three BL stations are among the most heavily used by MES researchers in the western U.S.. During this period, additional pressure will be placed on other SR laboratories by the dozens of MES researchers who commonly use these BL stations.

The demand for experimental time on BL stations suitable for MES research has continued to grow, and demand continues to outstrip availability of appropriate BL stations by a large margin. Many high-quality, peer-reviewed experimental programs in MES and other research areas do not receive access to SR beam time. In addition, many of the programs that do receive SR beam time do not receive sufficient experimental time on a regular basis to warrant the development of long-term research programs that require regular access to SR facilities. This problem has significant implications for graduate student research programs at U.S. universities as well as for research programs at national laboratories and should be addressed at the national level by appropriate committees representing all areas of science.

Another important observation pertains to the evolution of MES researchers from scientists whose research was conducted primarily in their individual research laboratories at universities or national labs to those who conduct a major portion of their research at one or more of the seven U.S. SR sources. This change in research style has had a major impact on the growth of the MES community because of (1) the need for shared national SR facilities, (2) the new research opportunities made possible by SR sources and techniques, and (3) the interdisciplinary collaborations and exchanges of knowledge these shared facilities have helped generate. In fact, nearly all of the research conducted at SR laboratories simply could not be done using conventional sealed-tube or rotating anode X-ray tubes in individual laboratories. This change in 
research style has also had a major impact on graduate and post-doctoral student training because these students are routinely exposed to research groups from other institutions and other disciplines from whom they learn new methods and approaches and with whom they share experiences. MES researchers also contribute to these other disciplines through fundamental studies that are broadly applicable to a variety of fields (e.g., XAFS studies of the hydrogen bonding network in water and of the nature of metal oxide/water interfaces) and the development of experimental methods and protocols for in situ studies of chemical reactions in aqueous/solid systems, microscale chemical analysis of heterogeneous materials, and nanoscale imaging of complex organic materials and microbial organisms. The learning experience and experimental success of MES students at SR labs are also dependent on the scientific and technical staff members who maintain and support beam lines. Without such BL maintenance and support, particularly for inexperienced students and research groups new to MES SR-based research, it is very unlikely that beam time will be used efficiently or that high quality data will be obtained during a typical 3- to 7-day SR experiment.

EnviroSync concludes that there are an insufficient number of dedicated and general-use MES BL stations available for MES research at this time, in spite of the recognized scientific merit and impact of results produced by MES researchers (see $\S \mathrm{V}$ for examples).

\section{B. Need for Infrastructure Support for Dedicated MES SR Facilities}

Overall support for MES BL facilities is low compared to that in other scientific fields. This is true for both staffing and equipment. For example, the current level of support for the 20+ BL stations dedicated to structural molecular biology at the four DOE SR sources and NSFsupported CHESS is approximately $\$ 750 \mathrm{~K}$ per BL station per year. In contrast, the current level of support for SR BL end stations or side stations, including general-use BL stations that are used by MES researchers (estimated to be the equivalent of $\sim 8$ full time BL stations) and the two dedicated BL stations (BL 11-2 at SSRL and BL 11.0.2 at the ALS), is less than \$350K per BL station per year. A significant portion of these annual operating costs for MES BL stations at SSRL, for example, goes to Environmental Safety and Health support required by State and Federal laws for receiving and handling environmental samples containing radioactive and/or toxic elements. This level of funding per BL station per year is not adequate to provide the level of user support required for optimal use of these unique national resources. As a consequence, the levels of staff and infrastructure support at all but a few beam lines (e.g., GSECARS-CAT) are inadequate. Currently, a number of BL stations are supported by one overworked staff member with responsibilities for more than one BL. This situation results in many periods during an experiment when no staff support is available, which translates into less than optimal experimental conditions and inefficient use of beam time in many cases.

EnviroSync concludes that there is a critical need for increased personnel and equipment support for all dedicated MES SR facilities in the U.S..

\section{Need for Infrastructure Support for Non-dedicated SR Facilities Essential to MES}

As mentioned previously, a large amount of MES research is done at BL stations that are not fully dedicated or fully optimized for MES research. Often the equipment and staff support 
available at these BL stations are not adequate for MES investigations. For example, EXAFS studies of very dilute MES samples require beam lines with very high fluxes and BL stations with expensive solid-state detectors that can be set up to isolate weak X-ray fluorescence signals for the element of interest from background scattering, which can be quite high. Only a few BL stations with these capabilities are available, resulting in extreme over-demand for these stations. In addition, the available support staff at general-use beam lines is frequently unfamiliar with MES samples or experimental protocols and needs, which places an extra burden on the few MES support staff at the seven U.S. SR laboratories who may be formally tasked elsewhere. The infrastructure required to support MES experiments at many desirable beam lines is lacking, and it is often difficult to assemble the needed equipment and technical support even when use of these beam lines is possible.

There are a number of BL stations where additional investment in MES staff support and specialized equipment would have a tremendous impact on MES research. Examples include BL stations 4-3, 6-2, and 11-2 at SSRL, where relatively modest investments could result in new $\mu$ XAFS capabilities that are badly needed by the MES community. Other examples include BL stations 1.4.3, 6.3.1, and 9.3.2 at the ALS; PNC-CAT, MR-CAT, and BESSRC-CAT at the APS; and BL stations X18B, X19A, X23A2, X26A at the NSLS. Such investments would result in improved capabilities and use of existing facilities already used in part for MES research. In other cases, such investments would provide new opportunities for MES research at some less utilized beam lines that could be modified for new capabilities. An example is the modification of bending magnet BL station 2-1 at SSRL for $\mu$ XRD, which is a technique that will grow in importance in MES research and other areas in the immediate future. Currently, there are only four beam lines at three of the seven U.S. SR sources where $\mu$ XRD is being done routinely (BL 7.3.3 at the ALS, BL's 2-ID-D and 20-ID at the ALS, and X26A at the NSLS). All are in overdemand, and only one is dedicated and properly staffed for $\mu$ XRD studies (BL 7.3.3 at the ALS). Another example is BL station X2A at the NSLS, which is currently being re-tasked for MES research. There are also SR techniques that are not as widely used currently as other techniques by MES researchers, thus do not justify fully dedicated MES BL stations. Examples of this are $\mathrm{X}$-ray reflectivity and X-ray standing wave studies, which are used to investigate the structure of solid surfaces and solid/water interfaces as well as adsorbate geometries and Photoemission Electron Microscopy (PEEM), which is used to determine the electronic structure (including oxidation state) of contaminant ions in nanoscale precipitates such as biominerals. In these cases, BL facilities shared among different disciplines are in order (e.g., BL 12-ID-D at the APS). However, the MES community has an obligation to help provide partial support for such shared facilities.

EnviroSync concludes that there is a critical need for increased levels of personnel and capital equipment support for a number of BL stations that are not dedicated to MES research but which are heavily used in such research. We also conclude that there are opportunities to re-task existing BL stations such that they will serve a broader scientific community, including MES. Example areas where this may be possible include additional $\mu$-focusing BL stations for XAFS and XRD and additional support for IR facilities. Such re-tasking is more realistic at a SR facility where the beam lines are under facility control (e.g., ALS and SSRL). 


\section{Need for New Non-Beam Line Facilities for MES Research}

The quality of scientific output from SR beam lines is often limited by the quality of materials investigated or by the ability to use particularly fresh or unique samples. Although this is true in most fields, in no other field is this consideration more critical than in MES where unique samples range from radioactive ones requiring special precautions and handling, to natural samples that must not be subjected to unnecessary preparation because of the possibility of alteration of their compositions or structures. MES samples are almost always extremely complex, as discussed in §I, consisting of mixtures of different phases, including amorphous and crystalline solids (often with nano-scale particle sizes) and aqueous solutions, microbial organisms, and plants in some cases. A key issue in most MES studies involving these types of samples concerns the spatial distribution and phase association of trace levels of contaminants. This problem is best addressed by SR techniques capable of $\mu \mathrm{m}$ and sub- $\mu \mathrm{m}$ resolution, and requires the use of $\mu \mathrm{XRF}, \mu \mathrm{XAFS}, \mu \mathrm{XRD}, \mu$-tomography, STXM, and PEEM. The infrastructure and support staff needed for these types of SR applications are essential for a growing number of MES research projects.

Another major, but often neglected, need of the MES community is suitable software for data collection and analysis. An example where this need has been satisfied are the user-friendly computer codes for analyzing EXAFS, including EXAFSPAK, FEFFIT, XAFS, and WinXAS, as well as the multiple scattering code FEFF, which is needed for theoretical simulation of XAFS spectra. Examples where improvements are needed involve computer codes for collecting and processing imaging data and $\mu$ XRD data. There are also critical needs for specialized equipment such as solid-state detectors, cryostats, and experimental rail systems that are essential for many MES SR applications.

Infrastructure facilities and capabilities often enable a class of experiments at a SR source across several beam lines. Particularly important examples in MES research are radioactive sample handling facilities in SR laboratories and nearby laboratory facilities in which biological specimens can be prepared and transported over a short distance to a beam line for experiments. Many biological samples cannot be transported via air carriers because of the need to examine fresh samples that have not been subjected to the handling and temperature variations that are difficult to avoid during air transport. These types of infrastructure capabilities are often particularly acute for MES work at beam lines that are not optimized for MES research. These critically important resources are under-supported at all SR sources and are needed at most.

EnviroSync concludes that there are critical needs for (1) personnel to provide software support for existing BL stations where MES research is done, (2) new state-of-the-art X-ray detectors, precision rail systems for GIXAFS, XSW, and X-ray reflectivity studies, and specialized spectrometers, such as X-ray emission spectrometers, needed for resolving interferences between X-ray fluorescence signals from different elements, (3) dedicated facilities for handling and temporary storage of radioactive and toxic environmental samples, and (4) near-by laboratory facilities for preparing biological samples for SR studies. 


\section{E. New Beam Line Facilities and Capabilities}

Over-subscription of beam lines used in MES research is great and growing. The challenge is to develop new beam lines, enhance the capabilities of existing beam lines, and provide enhanced infrastructure support to meet the current and future needs of the MES community in a coherent and responsible manner. Because of the several year time period required to design and construct new state-of-the-art beam lines, advanced planning is essential for developing the case and funding for new BL facilities that will serve the MES community. The main problems faced by the MES community in this context are (1) the high costs of building new beam lines $(\$ 5 \mathrm{M}-$ $\$ 8 \mathrm{M})$, (2) the lack of appropriate funding sources for their construction and the continuing costs of personnel to operate them, (3) the diminishing opportunities for new beam lines because of the fact that there is limited floor space at the seven U.S. SR sources, and (4) the competing funding needs of existing BL stations dedicated to or heavily used in MES research. Cost-effective ways of increasing the number of SR beam lines optimized for MES research include upgrading existing beam lines that are underutilized (although there are not many) and re-directing beam lines for which an historical use has been de-emphasized.

Requests for improvements to existing SR facilities, re-direction of existing SR facilities, or the construction of new SR facilities for MES research should be evaluated in the context of the current state of existing facilities and those under development. The EnviroSync organization should provide guidance in setting the priorities of the MES community in each of these areas by gathering the necessary information on (1) MES user statistics, (2) the adequacy of existing SR beam lines in meeting the needs of the MES community, and (3) the adequacy of infrastructure support at SR sources for this community. Such a community-wide user survey was conducted in 1995 as part of the Airlie Report [7], so this is a continuing mission of EnviroSync.

\section{F. Recommendations}

(1) EnviroSync should work with the Directors of the seven U.S. SR sources to seek increased operations funding (for support staff, capital equipment, equipment upgrades, and maintenance) for beam lines dedicated to or used heavily by the MES community from the current level $(<\$ 350 \mathrm{~K}$ per $\mathrm{BL}$ station per year) to a level approaching that of the Structural Molecular Biology community ( $\$ 750 \mathrm{~K}$ per BL station per year). This recommendation is projected to cost on the order of $\$ 7.5 \mathrm{M}$ per year for the 10 full time equivalent BL stations currently used by the MES community. In addition to DOE-BES and DOE-BER, federal agencies such as EPA and USDA that do not normally provide much support for SR facilities but whose constituencies benefit from the facilities should be approached for this type of support. Although certain NSF programs (e.g., NSF-EARIF and NSF-CHE) provide some support of this type, increased participation by NSF in providing infrastructure funding and the funding required to redirect BL stations to MESrelated activities should also be sought.

(2) EnviroSync should work with the Directors of the seven U.S. SR sources to identify existing BL stations that could be re-directed to MES activities and to help secure the funding needed to upgrade these BL stations and to provide the necessary scientific and engineering staff to support MES and other users of these re-directed BL stations. 
(3) EnviroSync should work with the Directors of the seven U.S. SR sources to improve access of the MES community to BL stations that provide innovative new methods such as Photoelectron Electron Microscopy and other micro-imaging techniques.

(4) EnviroSync should work with the Directors of the seven U.S. SR sources to approach appropriate funding agencies to seek new funding for dedicated facilities, where needed, for radioactive sample handling and preparation of biological samples.

(5) EnviroSync should conduct another mail survey of the MES community to determine the highest priorities and needs for (1) infrastructure support of existing BL stations, (2) capital equipment needs, and (3) needs for new BL stations dedicated to MES research.

(6) EnviroSync should continue to function as an advisory group to the federal agencies that fund SR sources and BL stations and infrastructure, providing advice on priorities for redirection of existing BL stations and construction of new beam lines optimized for MES research, and organizing workshops that focus on accomplishments and needs of the MES community as well as new research opportunities.

(7) A national-level committee should be appointed to examine the long-term consequences of limited access to SR facilities by university- and national lab-based research programs and to make recommendations on how this access can be improved.

Appendix B includes a brief history of the National Molecular Environmental Science Synchrotron User Organization known as EnviroSync, as well as a list of current members of the EnviroSync Steering Committee. 


\section{MES Research Highlights at Seven U.S. SR Facilities}

The 22 examples of MES research discussed below were selected by the EnviroSync Steering Committee from among many different MES studies by a number of research groups over the past five years. They are intended to highlight the importance of fundamental and targeted research involving environmental materials and to show that the impact of this research extends beyond the field of molecular environmental science.

A. Hydrogen Bonding Configurations of Liquid Water [S.C.B. Myneni (Princeton University and LBNL), A. Nilsson, P. Wernet (SSRL and University of Stockholm), L.G.M. Pettersson, Y. Luo, M. Cavalleri, A. Pelmenschikov (University of Stockholm), L.A. Näslund, L. Ojamäe, H. Ogasawara, P. Väterlein (University of Uppsala), Z. Hussain, C. Heske (ALS); Research conducted at the ALS] [9]

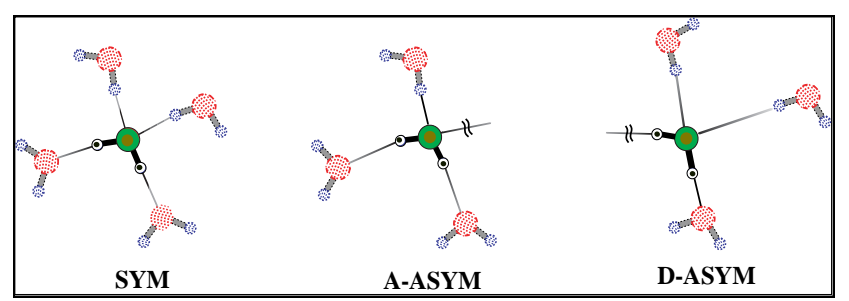

Figure 9. Typical local structures of H-bonding in liquid water: fully coordinated, symmetric $H$-bonded species (SYM), and broken asymmetric H-bond networks (A-ASYM, D-ASYM). (from [9])
One of the fundamental issues in complex environmental systems is the interaction of water at interfaces with solids. The basic nature of water in the bulk and adsorbed on surfaces is being studied at a local level using $\mathrm{X}$-ray spectroscopy and density functional theory (DFT) calculations. The hydrogen bond (H-bond) in liquid water holds the key to its peculiar behavior, with implications for biological, chemical and geological processes. It mediates the interactions of bioorganic and water molecules and thus strongly influences their function. In liquid water, the dynamical motion of atoms at the picosecond time-scale causes the H-bonds to break and reform resulting in a statistical distribution of different coordinations for the water molecules (Fig. 9). What is the nature of the H-bonding in terms of changes in the electronic structure? In liquid and solid phases, water molecules exhibit two types of $\mathrm{O}-\mathrm{H}$ interactions - strong covalent $\mathrm{H}$-bonds within the water molecule and relatively weak H-bonds between the molecules. In ice, each water molecule is coordinated by four neighboring waters through $\mathrm{H}$-bonds (two H-bonds to the oxygen atom and one to each hydrogen). Although liquid water primarily exhibits the same coordination environment, experimental (vibrational spectroscopy, neutron and X-ray diffraction) and theoretical (molecular dynamics) studies indicate that liquid water contains a fraction of water molecules with broken H-bonds. However, little specific information on the local coordination structure of the H-bond environment has been obtained from previous investigations. Using X-ray absorption spectroscopy at the oxygen K-edge, the empty electronic states are investigated and local nature of $\mathrm{H}$-bonding is identified through the large effect of chemical bonding on the valence orbital structure of the molecules. O K-edge XANES spectra of liquid water were measured using the beam line 8.0 at the ALS. These spectra (Fig. 10) showed different $\mathrm{H}$-bonding configurations in the liquid phase. Since the X-ray absorption process is faster than a femtosecond, it allows probing of the molecular orbital structure of frozen, local geometries of water molecules. These results indicate that the electronic structure of liquid water is significantly different from that of the solid and gaseous forms, with a pronounced pre-edge feature below the main absorption edge. DFT calculations of these spectra suggest that this pre- 


\section{Observed Spectra}

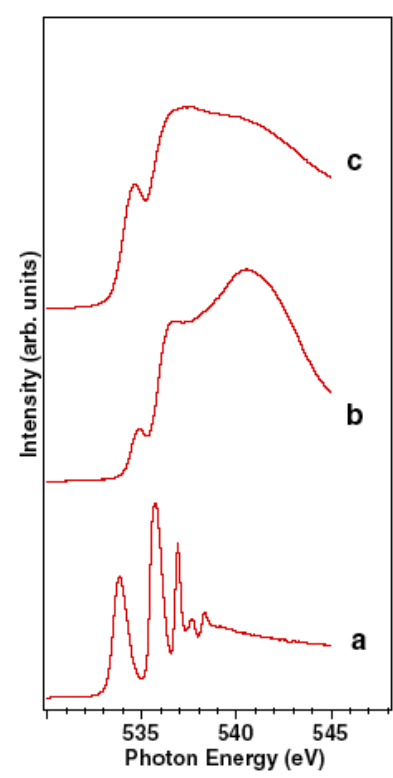

Calculated Spectra

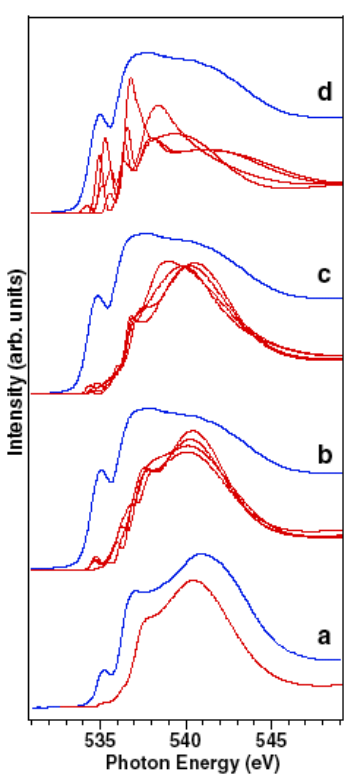

Figure 10. (left) Oxygen K-edge XANES spectra of liquid water(c), ice (b), and water vapor (a); (right) Calculated oxygen K-edge XANES spectra of ice $(a)$ and $(b-d)$ three different structural models of water corresponding to (b) SYM, (c) A$A S Y M$, and (d) D-ASYM. The calculated spectrum of D-ASYM is the best match with the experimental oxygen K-XANES spectrum of liquid water (see Fig. 9 for definitions of D-ASYM, A$A S Y M$, and $S Y M$ ). (from [9])

edge feature originates from specific configurations of water, for which the $\mathrm{H}$ bonding is unsaturated and strongly asymmetric (Fig. 10). The results show that an unsaturated H-bonding environment exists for a significant fraction of water molecules in liquid water.

B. Structure of the Hydrated $\alpha-\mathrm{Al}_{2} \mathrm{O}_{3}(0001)$ Surface [P.J. Eng (University of Chicago); T.P. Trainor and G.E. Brown, Jr. (Stanford University); G.A. Waychunas (LBNL); M. Newville, S.R. Sutton and M.L. Rivers (University of Chicago); Research conducted at the APS] [10]

The interaction of liquid water with the surfaces of natural solids is one of the most fundamental chemical reactions occurring in nature. Its importance extends from geochemical processes such as mineral dissolution and sorption/desorption reactions, which play major roles in chemical weathering, contamination of ground waters, environmental restoration, and the biogeochemical cycling of elements, to the growth of crystals and partitioning and sequestration of trace elements and toxic species under low temperature conditions. The reactivity of metal oxide surfaces depends on the type(s) of functional groups exposed at the surface, which is strongly influenced by the degree of surface hydroxylation. Therefore, it is important to determine the structures and compositions of hydrated metal oxide surfaces directly. This problem was addressed employing the technique of crystal truncation rod (CTR) diffraction on the ID-13 GSECARS beam line at the APS. This first of its kind study determined the 3-D atomic arrangement of single crystal, metal oxide surfaces under ambient or in situ conditions (i.e., in the presence of bulk solution at ambient temperature). The $\alpha-\mathrm{Al}_{2} \mathrm{O}_{3}$ (0001) surface was chosen for study because of its importance as a model system for understanding the reactivity of naturally abundant phases of Al-containing (hydr)oxides such as gibbsite or aluminosilicate clays. Furthermore, knowledge of the structure of hydrated metal oxide surfaces is required for testing models of the structure, reactivity, and charging behavior of metal-(hydr)oxide surfaces. The main finding of this study, depicted in Figure 11, is that unlike the vacuum-prepared clean surface where Al-terminated (e.g., Guenard et al. [11]) or mixed Al/O-terminated surfaces are reported, the hydrated surface is oxygen terminated with a $53 \%$ contracted double aluminum layer directly below. A disordered oxygen layer at $\approx 2.3 \AA$ above the terminal oxygen layer was interpreted as sorbed water. 


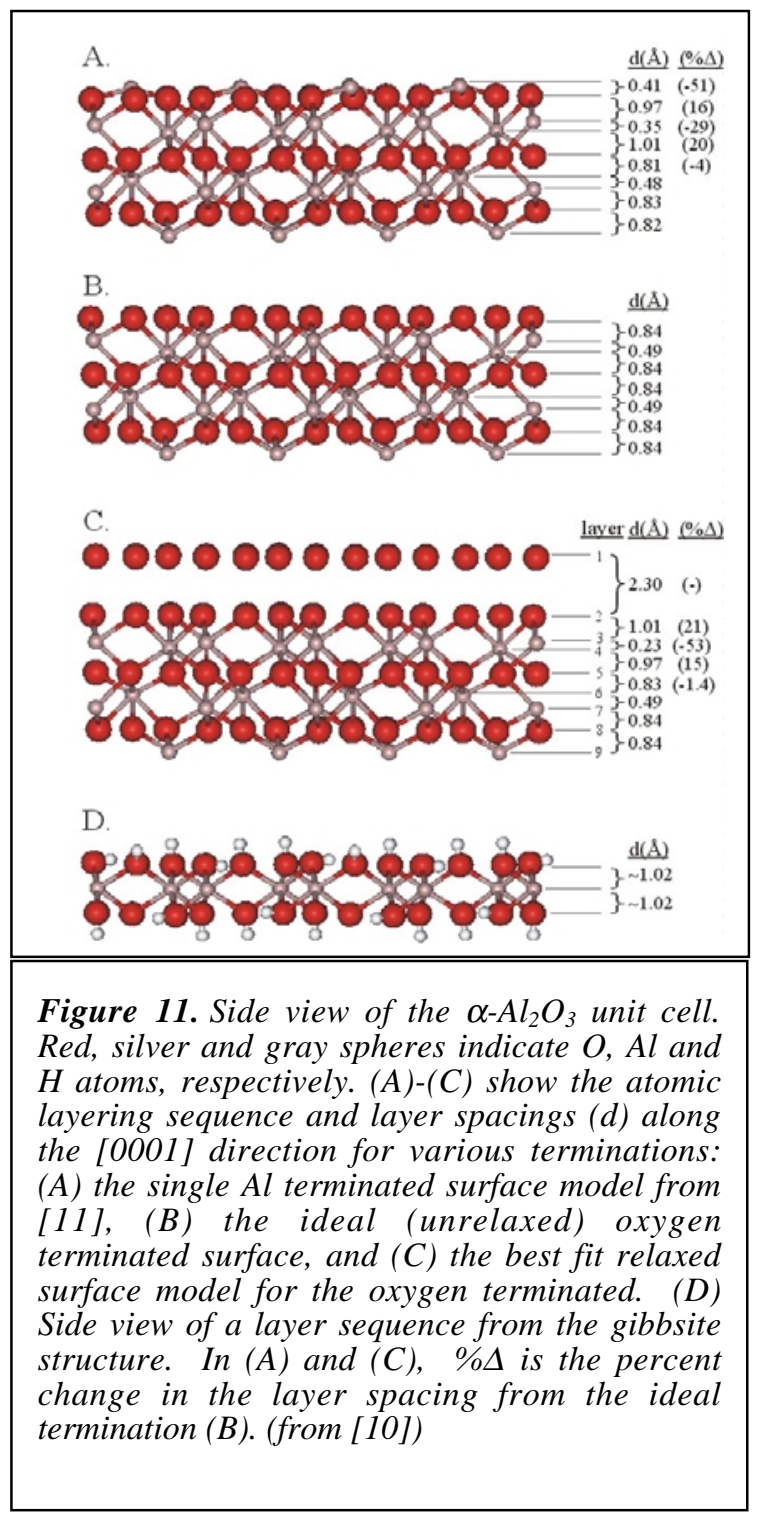

These results provide a firm experimental basis for understanding the reactivity and properties of the hydrated $\alpha-\mathrm{Al}_{2} \mathrm{O}_{3}$ (0001) surface. Furthermore, they provide a starting point for further firstprinciples theoretical studies of the interaction of water with the $\alpha-\mathrm{Al}_{2} \mathrm{O}_{3}$ (0001) surface and for future exploration of other surface orientations of $\alpha-\mathrm{Al}_{2} \mathrm{O}_{3}$, and other metal oxide-water interfaces, which should lead to a broader understanding of aqueous-solid interactions in the natural environment.

C. Dissolution Mechanisms at Feldspar-Water Interfaces [Paul Fenter(Argonne National Laboratory), H. Henry Teng (The George Washington University), Likwan Cheng (Argonne National Laboratory), and Neil C. Sturchio (The University of Illinois at Chicago); Research conducted at the APS] $[12,13]$

Weathering influences global cycling of $\mathrm{Si}, \mathrm{Al}$, and alkali and alkaline earth metals; atmospheric $\mathrm{CO}_{2}$ concentration; natural water composition; and soil formation [14]. Despite the extensive investigation of this subject in the past several decades, the mechanisms of silicate dissolution remain controversial. The first application of synchrotron X-ray reflectivity to probe mineral dissolution, in situ, and in real time is shown in Figure 12. Data are shown as a function of $\mathrm{pH}$ and temperature during dissolution of the (001) cleavage surface of orthoclase $\left(\mathrm{KAlSi}_{3} \mathrm{O}_{8}\right)$. The measured X-ray reflectivity did not decrease monotonically with time during dissolution, as would be characteristic of random dissolution (e.g., where all exposed tetrahedral sites dissolve at the same rate). Instead, the reflectivity exhibited an oscillatory pattern at both acidic and alkaline $\mathrm{pH}$ values. This observation implies that two distinct reactive sites (e.g., terrace and step sites) are found in each $\mathrm{pH}$ regime, and that the relative reactivities of these sites differ substantially at the two extreme $\mathrm{pH}$ values. We find that dissolution at alkaline $\mathrm{pH}$ is fully stoichiometric and dominated by lateral dissolution processes producing layer-by-layer dissolution, while dissolution at acidic $\mathrm{pH}$ is a more random process in which the orthoclase surface is substantially disrupted and roughened. "Snapshots" of the dissolution process were also obtained through high-resolution X-ray reflectivity measurements of previously reacted surfaces (Fig. 13). 


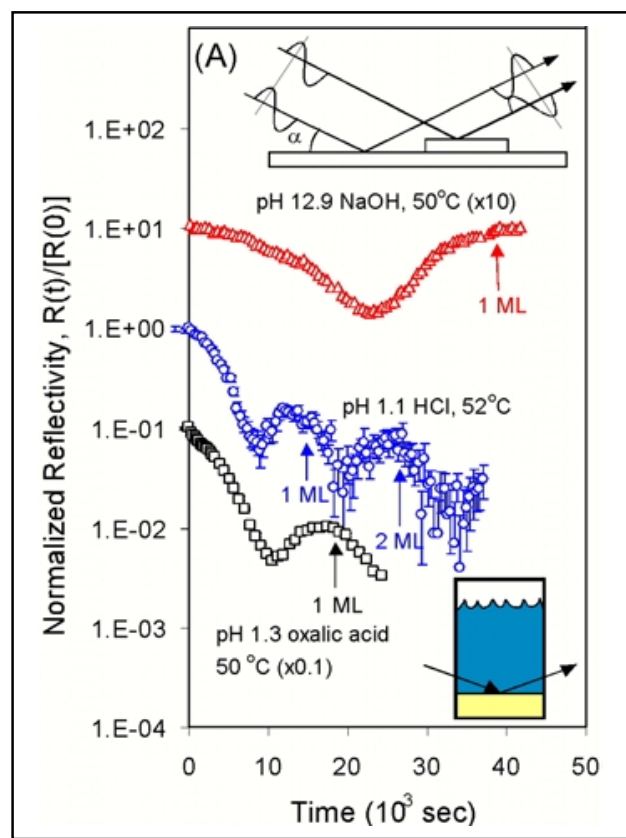

Figure 12. In situ $X$-ray reflectivity versus time (measured at the anti-Bragg condition, shown inset at top) during dissolution at extreme $\mathrm{pH}$. The removal of successive monolayers (ML) is noted for each set of data. (from [12])

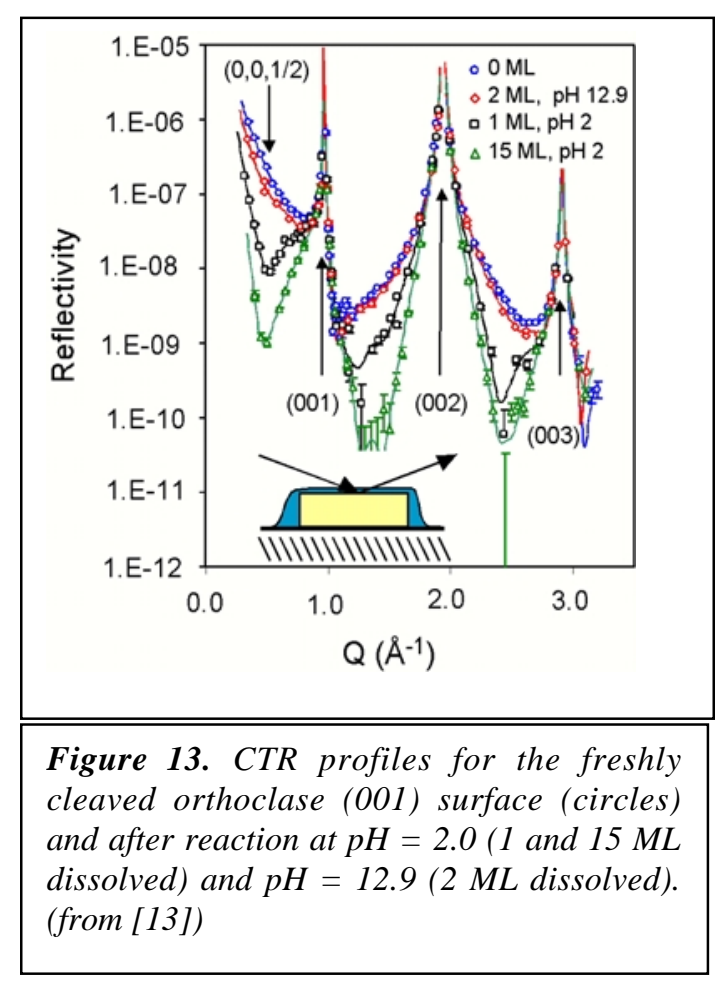

Crystal truncation rod (CTR) data were obtained for a freshly cleaved orthoclase surface, after dissolution of approximately 1 and 15 monolayers at $\mathrm{pH}=2.0$, and after dissolution of 2 monolayers at $\mathrm{pH}=12.9\left(1\right.$ monolayer $\left.=5.7 \times 10^{-10} \mathrm{~mol} \mathrm{~cm}^{-2}\right)$. All CTR measurements were performed in deionized water in a "thin-film" cell (Fig. 13, inset). The acid-reacted surfaces showed substantial changes in surface termination, including step proliferation and local etching that is nonstoichiometric in only the outermost unit cell. In contrast, the alkaline-reacted surface was essentially unchanged with respect to the freshly cleaved surface, with only a small increase in the surface step density.

These observations clarify differences in orthoclase dissolution mechanisms as a function of $\mathrm{pH}$ and place new constraints on the understanding of alkali feldspar weathering processes. We have distinguished the separate roles of steps/defects versus terraces in orthoclase dissolution at different $\mathrm{pH}$ conditions, providing direct evidence for distinct elementary dissolution reactions and reaction sites. By probing the systematic variation of absolute dissolution rates as a function of $\mathrm{pH}$, temperature, solution composition, cleavage plane, and feldspar mineral phase, we expect to gain a truly fundamental understanding of these molecular-scale dissolution and weathering processes. These results demonstrate the capability of X-ray scattering techniques to directly probe mineral reactivity in situ with real-time measurements and highlight the unique information that this approach yields. 
D. Macromolecular Structure of Natural Organic Matter [S.C.B. Myneni (Princeton University and LBNL), J.T. Brown, G.A. Martinez, and W. Meyer-Ilse (LBNL); Research conducted at the ALS] [15]

Little is known from direct observation under in situ conditions about the macromolecular structure of natural organic matter (NOM) or how it changes as solution conditions are changed. An in situ X-ray spectromicroscopy study at the ALS by Myneni and others has provided some of the first information of this type. Figure 14 shows that the solution structure of Suwannee River fulvic acid (one of the standard NOM's provided by the International Humic Substance Society) changes dramatically depending on the solution $\mathrm{pH}$, ionic strength, and presence of other cations. This observation implies that, compared to typical biofilms, which have relatively well-defined structural units (the microbial cell), typical NOM's such as humic and fulvic acids may vary dramatically in their permeability to pollutants as their 3-D structure changes as a function of solution conditions.

\section{E. Surface Site Control on Uptake of Dissolved} Contaminants [R.J. Reeder and E.J. Elzinga (SUNYStony Brook); A. Lanzirotti (University of Chicago); Research conducted at the NSLS] [16,17]
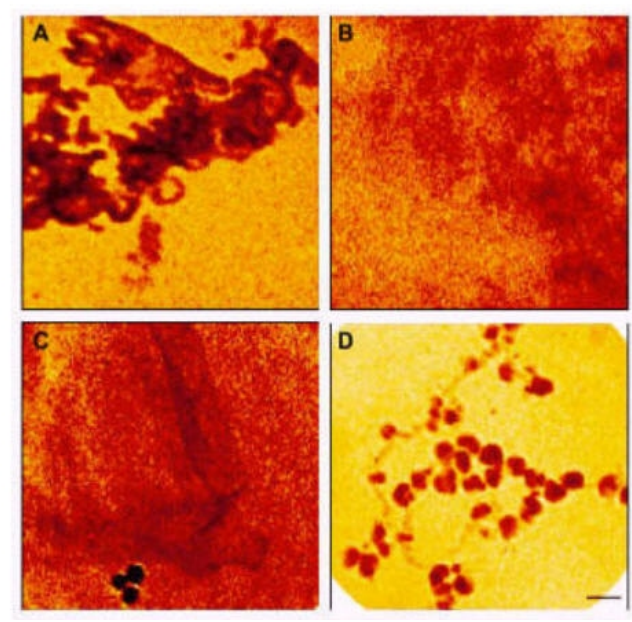

Figure 14. $X$-ray transmission microscope images taken at the carbon K-edge on ALS BL 6.1.2 showing the macromolecular structure of Suwannee River fulvic acid (from the International Humic Substance Society) in aqueous solution as a function of $p H$ and ionic strength $(\boldsymbol{A}: \mathrm{pH}=3.0 ; \boldsymbol{B}$ : $p H=9.0 ; C: p H=4.0$ and $\left[\mathrm{Ca}^{2+}\right]=0.018$ $\mathrm{M} ; \mathrm{D}: \mathrm{pH}=4.0$ and $\left[\mathrm{Fe}^{3+}\right]=0.001 \mathrm{M}$ ). The scale bar in the lower right panel is $500 \mathrm{~nm}$ and is representative of the scales in the other panels. (from [15])

Knowledge of the structure, distribution, and reactivity of different surface sites on minerals is essential for understanding interactions involving dissolved contaminants and solids in the environment. Differences in coordination among surface binding sites and their availability have an impact of the effectiveness of metal uptake in soils, aquifer, and sediments, thereby influence contaminant mobility. A challenge in distinguishing among multiple binding sites at mineral surfaces has been the difficulty in segregating similar sites to permit their study. A novel approach for studying metal interactions at distinct sites on the common (1014) surface of calcite $\left(\mathrm{CaCO}_{3}\right)$ has been developed using the $\mu$-beam X-ray fluorescence and X-ray absorption capabilities at BL X26A at the NSLS. This surface of calcite commonly grows by the spiral mechanism, which segregates nonequivalent sites into growth steps composing distinct "vicinal" regions of the spiral. Growth in the presence of various contaminant metals results in differential uptake between these regions, which provides a direct measure of the surface site preferences.

A series of experiments conducted at NSLS on BL X26A have revealed that divalent metal ions (e.g., $\mathrm{Co}, \mathrm{Cu}, \mathrm{Mn}, \mathrm{Zn}, \mathrm{Cd}$, and $\mathrm{Sr}$ ) show distinct preferences for different surface sites according to their size and coordination within the sites. 
Figure 15 shows distributions of $\mathrm{Co}$ and $\mathrm{U}$ at the calcite (1014) surface, revealing the correspondence of metal concentration with site distribution. The magnitude of differential uptake may exceed a factor of ten for some metals, which implies that differences in the availability of sites could change sorption characteristics of a mineral by a similar degree. One striking finding of this work is that metals with similar size and charge may exhibit markedly different preferences for sites. Other studies have shown that anions, including $\mathrm{AsO}_{4}{ }^{3-}$, $\mathrm{SeO}_{4}{ }^{2-}$, and $\mathrm{UO}_{2}\left(\mathrm{CO}_{3}\right)_{3}{ }^{4-}$, also show distinct preferences for different surface sites, further indicating that uptake of toxic species and radionuclides is controlled by the coordinative aspects of surfaces. These fundamental data will allow environmental scientists to include site preference information into molecular models of contaminant uptake.

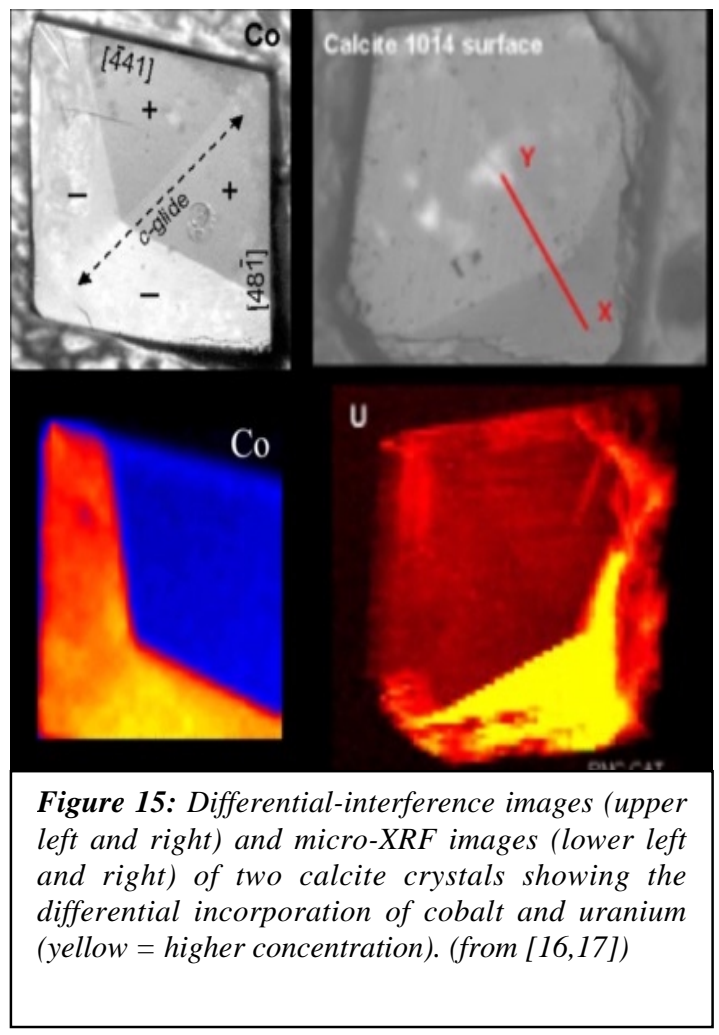

F. Role of Biofilms in Heavy Metal Uptake by Mineral Surfaces. [Alexis S. Templeton, T.P. Trainor, G.E. Brown, Jr., and A.M. Spormann (Stanford University) and S.J. Traina (University of California, Merced); Research conducted at SSRL] [18]

Microbial biofilms are widespread in soils and form microenvironments in which aqueous chemical conditions differ from those of the host ground water. Reactive functional groups on bacterial surfaces and in extracellular ligands provide a large array of binding sites for metals, posing the question of whether or not bacterial biomass plays a dominant role in controlling metal ion migration in soils and aquifers. Such processes could have major implications for ground water quality, as the migration and toxicity of heavy metal contaminants in the environment are controlled by interactions between the metal solutes, aqueous solutions, and soil materials.

Templeton et al. [18] used SSRL-based X-ray standing wave-fluorescence yield measurements coupled with grazing-incidence XAFS to probe the distributions of $\mathrm{Pb}(\mathrm{II})$, a common toxic soil contaminant, within a Burkholderia cepacia/alumina/water system (Fig. 16). In situ measurements were performed on $B$. cepacia biofilms grown on single-crystal $\alpha-\mathrm{Al}_{2} \mathrm{O}_{3}$ surfaces, subsequently reacted with dilute $\left(10^{-5}\right.$ and $\left.10^{-6} \mathrm{M}\right) \mathrm{Pb}(\mathrm{II})$-containing aqueous solutions. Longperiod X-ray standing wave results (Fig. 16) show that the biofilms do not passivate the underlying oxide surface and that the same high-energy sites which uptake $\mathrm{Pb}$ (II) on the biofilm-free oxide surface also play the dominant role in the mixed biofilm-mineral system. These results emphasize the importance of mineral surfaces as sinks for heavy metals in natural environments 
and raise questions about conventional assumptions that biofilm and organic coatings on mineral surfaces can change the way in which aqueous heavy metals interact with these surfaces.
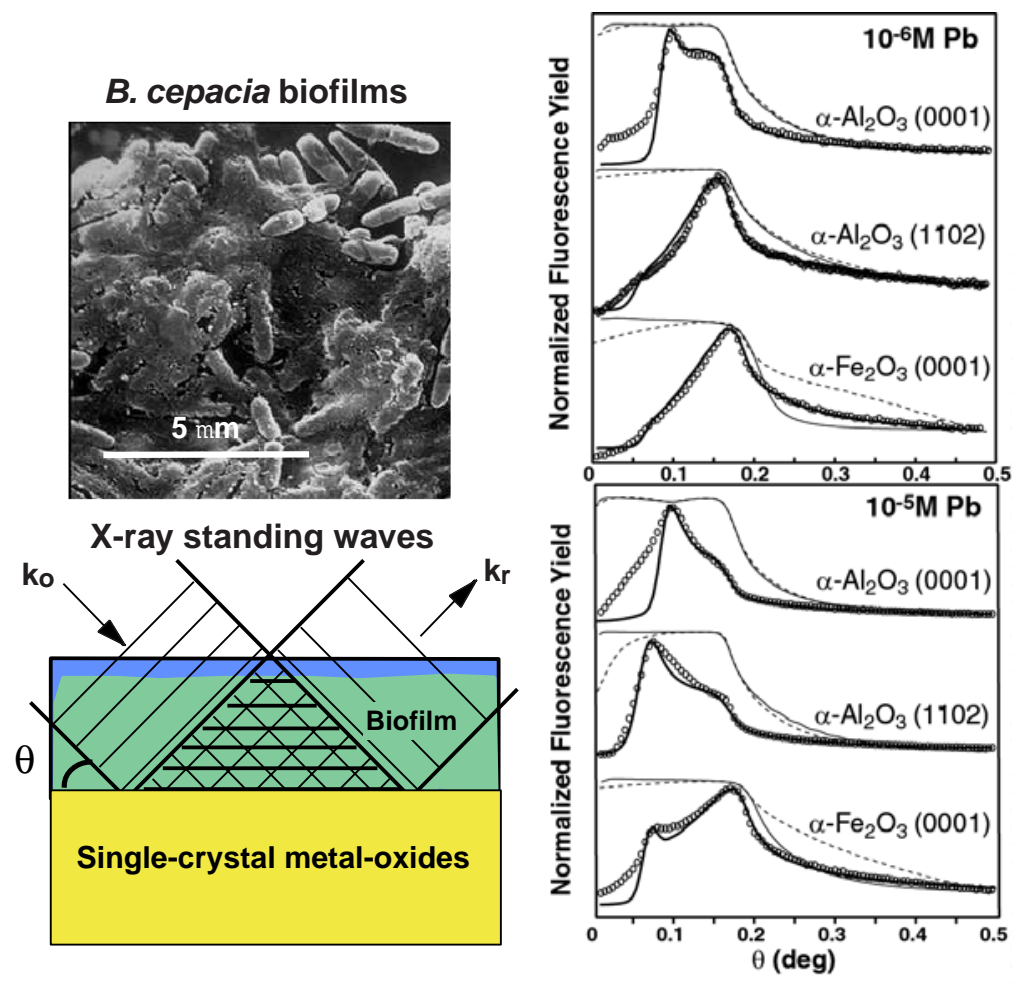

Figure 16. (top left panel): Environmental SEM image of a Burkholderia cepacia biofilm grown on an $\mathrm{Al}_{2} \mathrm{O}_{3}$ single crystal substrate. (bottom left panel): Schematic diagram showing a biofilm of $B$. cepacia (1-2 $\mu m$ thick) grown on an $\alpha-\mathrm{Al}_{2} \mathrm{O}_{3}$ (1-102) substrate and the generation of $X$-ray standing waves used to probe the position of metal ions after their interaction with the biofilm-mineral sample. (right panels): X-ray reflectivity data (dashed lines) and fits (light solid lines) and fluorescence-yield XSW data (circles) and fits (heavy solid lines) for $B$. cepacia-coated Al- and Fe-oxide surfaces exposed to two different concentrations of $\mathrm{Pb}(\mathrm{II})$ in aqueous solution. The XSW-FY data for the $10^{-6}$ and $10^{-5} \mathrm{MPb}$ on $\alpha-\mathrm{Al}_{2} \mathrm{O}_{3}$ (0001) show a maximum at $\approx 80 \mathrm{mdeg}$, indicating that $\mathrm{Pb}(\mathrm{II})$ occurs predominantly in the biofilm, whereas the $X S W-F Y$ data for $10^{-6} \mathrm{M}$ $\mathrm{Pb}$ on the $\mathrm{B}$. cepacia-coated $\alpha-\mathrm{Al}_{2} \mathrm{O}_{3}$ (1-102) and $\alpha-\mathrm{Fe}_{2} \mathrm{O}_{3}(0001)$ samples have their maxima at $\approx 165$ mdeg, indicating that the $P b(I I)$ is predominantly located at the substrate surface. At $10^{-5} \mathrm{MPb}$, only the more reactive $\alpha-\mathrm{Fe}_{2} \mathrm{O}_{3}(0001)$ sample shows $\mathrm{Pb}(\mathrm{II})$ predominantly at the substrate surface. (from [18])

G. Iron Valence Heterogeneity in the Strong Reducer, Green Rust [K.H. Pecher, B. Tonner (Dept. of Physics, University of Central Florida, Orlando, FL), H.-Ch. Hansen (Chemistry Department, Kemisk Institut, Frederiksberg, Denmark), E. Kneedler (Surface/Interface Inc., Sunnyvale, CA); Research conducted at the ALS] [19]

Green Rust (GR) is the name for a class of mixed valence iron compounds that have recently gained recognition as being strong reducing agents for organic as well as inorganic pollutants in anoxic environmental compartments. For example, real-time XAFS spectroscopy studies at SSRL by Myneni et al. [20] showed that aqueous $\mathrm{Se}(\mathrm{VI})$ is reduced abiotically to $\mathrm{Se}(\mathrm{IV})$ and $\mathrm{Se}(0)$ by GR at rates comparable to those observed in bacterial reduction of $\mathrm{Se}(\mathrm{VI})$. The crystal structure of GR is defined by brucite-like sheets of $\mathrm{Fe}(\mathrm{II})$ and $\mathrm{Fe}(\mathrm{III})$ octahedrons being intercalated by charge compensating anions and water molecules. Different forms of GR with a wide range of $\mathrm{Fe}(\mathrm{II}) / \mathrm{Fe}$ (III) ratios and interlayer spacings have been identified, mainly depending on anions used during synthesis or anions present in soil or sediment pore waters. To date rather incomplete information is available on the electronic structure of such compounds. The sub- $\mu \mathrm{m}$ distribution of charge states of iron in single platelets of sulfate GR has been determined using scanning transmission X-ray spectromicroscopy (STXM) collected on BL 7.0.1 at the ALS (Fig. 17). NEXAFS spectra collected from different areas of the sample could be fit using a linear combination of single iron valence model spectra as $\mathrm{Fe}$ (II) and Fe(III). Mapping of the $\mathrm{Fe}(\mathrm{II}) / \mathrm{Fe}(\mathrm{III})$-ratio of a single hexagonal platelet of $\mathrm{SO}_{4}{ }^{-} \mathrm{GR}$ revealed considerable heterogeneity and deviation from the expected ratio of $\mathrm{Fe}(\mathrm{II}): \mathrm{Fe}(\mathrm{III})$ of 2 in this type of GR, 
especially near the particle edges, where Fe(III) dominates. These findings suggest that Fe(III) surface sites probably control the surface reactivity of this environmentally important solid.

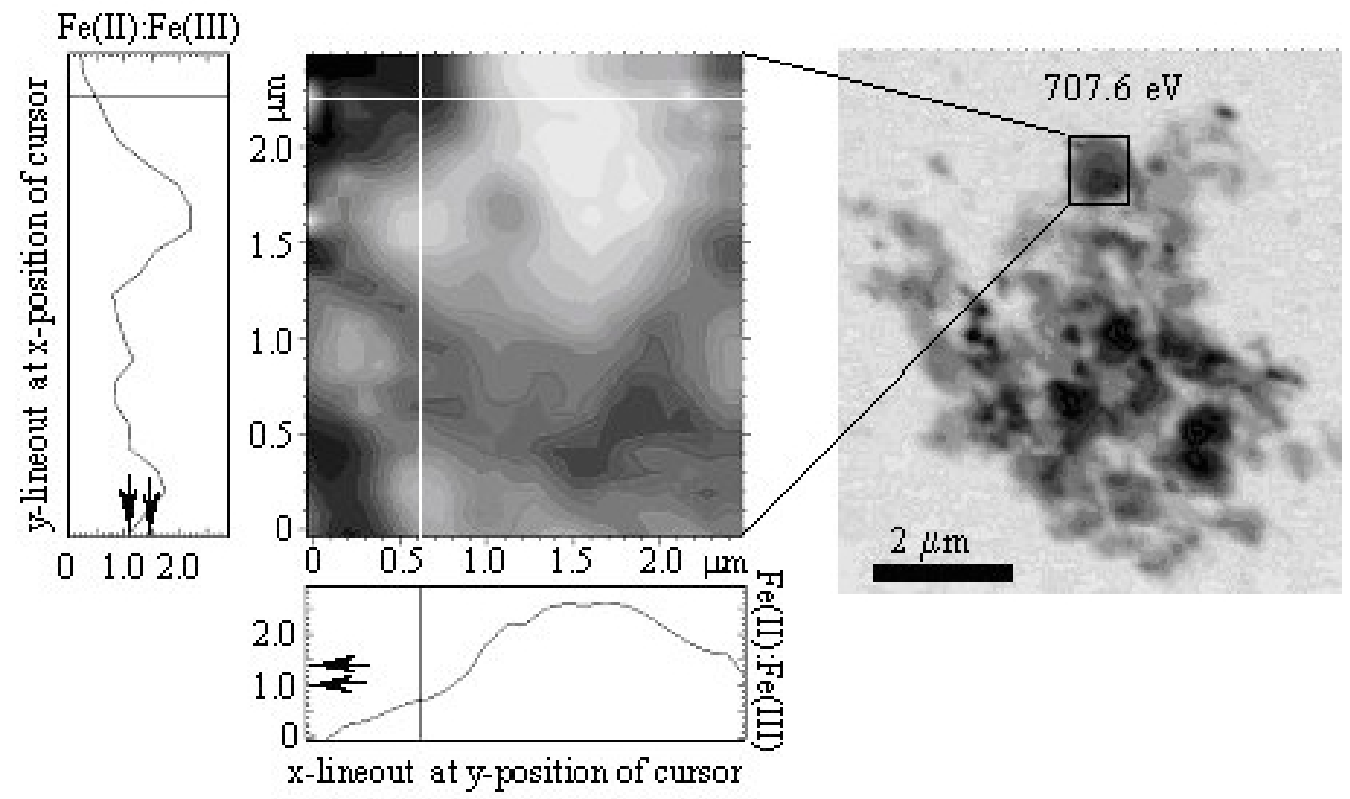

Figure 17: Spatial distribution of $\mathrm{Fe}(\mathrm{II}) / \mathrm{Fe}(\mathrm{III})$-ratio in a single particle of $\mathrm{SO}_{4}$-Green Rust (field of view corresponds to the rectangle shown on the right hand side). The $x$ - and $y$-lineout plots are along the respective lines in the charge state ratio plot. The arrows correspond to the mean charge state ratios fitted from XANES averaged over larger areas. (from [19])

H. Microbial Reduction of Iron-Bearing Clays. [W.F. Bleam (University of WisconsinMadison); Research conducted at SRC]

Anaerobic bacteria and actinomycetes in the environment rely upon electron acceptors other than molecular oxygen for respiration. Certain microbes utilize iron-bearing minerals as electron acceptors, reducing ferric iron to ferrous iron in the process. The microbial reduction of iron-rich layer silicates has been explored using x-ray photoelectron emission microscopy (X-PEEM) to image clay films exposed to anaerobic bacteria capable of growing when the only electron acceptor is iron-rich layer silicate clay. Unlike other oxide minerals, which dissolve as ferric iron is reduced to ferrous iron at the mineral surface, iron-bearing layer silicates resist dissolution and undergo crystallographic changes to accommodate the larger ferrous ions produced upon electron transfer. Preliminary X-PEEM images of microbially reduced clay films suggest there is little electron transfer between clay particles, yielding a mixture of ferric-rich and ferrous-rich clay particles rather than homogeneous reduction of all clay particles. Definitive proof, however, must await further study of reference minerals because current theoretical analysis is unable to explain observed iron L-edge XANES spectra.

I. Manganese Oxide Biomineralization by Spores of Bacillus SG-1 [K.H. Pecher (University of Central Florida), M.D. McCubbery (Oregon Graduate Institute), J.R. Bargar (Stanford Synchrotron Radiation Laboratory), and B.M. Tebo (Scripps Institution of Oceanography); Research conducted at the ALS and SSRL] [21] 
Biogenic Mn oxides are produced catalytically by bacteria, which oxidize soluble, ground waterborne $\mathrm{Mn}(\mathrm{II})$ and produce insoluble $\mathrm{Mn}(\mathrm{IV})$. They occur throughout the environment as finely dispersed nanoparticles and grain coatings and have a profound effect on contaminant degradation, carbon, and nutrient cycling in the environment because of their high capacity to sequester heavy-metal contaminants and to oxidatively degrade recalcitrant organic carbon and inorganics. There is great interest in utilizing these processes for in situ immobilization of contaminants such as uranium, cobalt, and lead in the oxic subsurface. The catalytic and degradative capacities of Mn oxides have already been used in heterogeneous catalysis, and $\mathrm{Mn}$ (II) oxidation is of practical concern in agriculture, industry, and drinking water treatment. Knowledge of the Mn-oxidizing mechanisms and their controls is desired so Mn-oxide precipitation can be induced in the subsurface for the purposes of in situ remediation.

Relatively little is understood about the pathways by which bacteria oxidatively transform Mn(II) to $\mathrm{Mn}(\mathrm{III} / \mathrm{IV})$. Molecular genetics studies have shown that Mn-oxidizing activity is associated with a multi-copper oxidase enzyme (or enzyme complex), which oxidizes substrates via successive one-electron steps. In contrast, some researchers have suggested that biogenic Mn(II) oxidation proceeds via a direct two-electron transfer mechanism.

The charge-state evolution of Mn reacted with spores of the Mn-oxidizing marine bacterium Bacillus sp., strain SG-1, was measured using the STXM at ALS beam station 7.0.1. Mn oxidation states were determined in situ in wet samples by analysis of the $\mathrm{Mn} \mathrm{L}_{2,3}$-edge x-ray absorption spectrum. The STXM provides $30 \mathrm{~nm}$ spatial resolution allowing the distribution of $\mathrm{Mn}$ to be mapped across and between individual spores. The time-dependence of Mn oxidation states in samples reacted with $10 \mu \mathrm{M} \mathrm{Mn}(\mathrm{II})$ is shown in Figure 18. $\mathrm{Mn}$ (III) increased to $\sim 35 \%$ of total Mn between 30 and $40 \mathrm{hr}$ of reaction time, but then rapidly decreased as Mn(IV) grew to the $90 \%$ level. Thus, the reaction products produced after $50 \mathrm{hr}$ of reaction have a spore-scale oxidation state consistent with that of monoclinic birnessite,

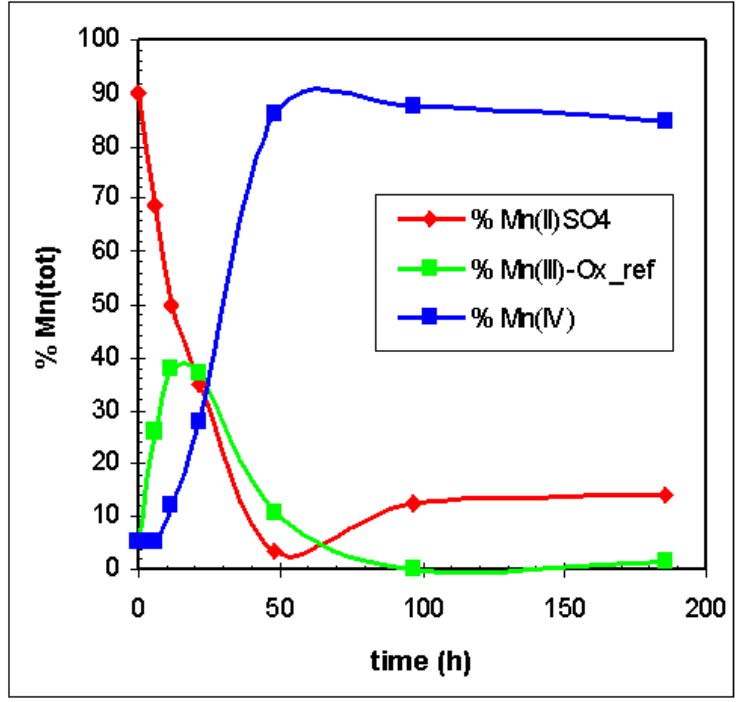

Figure 18. Variation of Mn oxidation state as a function of time of interaction of Mn-oxidizing bacteria with Mn-bearing minerals. (from [21]) a common soil mineral. In addition, the temporal behavior of $\mathrm{Mn}(\mathrm{III})$ in this system is suggestive of a $\mathrm{Mn}(\mathrm{III})$-containing internediate phase, the exact chemical structure of which is still unknown and requires further investigation by submicron spectromicroscopy. Mn(III)-bearing species were not detected in K-edge measurements performed at SSRL on BL 11-2, indicating that Mn(III) is not present below the $\sim 10 \%$ bulk composition detection limit. Very low levels of $\mathrm{Mn}$ (III) would be expected if it were present as an enzyme-associated reaction intermediate. These results lend weight to the presence of an enzymatic, successive one-electron transfer mechanism. Practical consequences of such a mechanism include the possibility of stimulating biogenic Mn-oxide production via introduction of complexed $\mathrm{Mn}(\mathrm{III})$ to the oxic subsurface. 
J. Plutonium Sorption onto Yucca Mountain Tuff [Martine C. Duff, Paul M. Bertsch, Douglas B. Hunter (Savannah River Ecology Laboratory, Univ. of Georgia); Peter J. Eng, Matthew Newville, Steven R. Sutton (University of Chicago and GSECARS); Research conducted at the APS and NSLS] [5,6]

The distribution and speciation of plutonium was studied in a natural core sample taken from 450 $m$ depth at the proposed high-level radioactive waste repository in Yucca Mountain, NV (Fig. 19). The core sample (from the Topopah Spring Tuff site at Yucca Mountain) was exposed to an aqueous solution of ${ }^{239} \mathrm{Pu}^{5+}$ for XRF and EXAFS studies [5,6]. Studies on the redox and speciation chemistry of $\mathrm{Pu}$ in synthetic and natural waters suggest $\mathrm{Pu}$ can be present in four oxidation states (III, IV, V, VI) simultaneously. Pu(V) usually dominates in oxic neutral to basic natural waters, and synthetic Yucca Mountain groundwaters. The goal of this work was to determine where in the soil and rock at the nuclear repository site Pu contaminants would sorb or concentrate and what chemical phases of plutonium would be present. All of these factors (location, sorption sites, chemical speciation) greatly affect the transport of $\mathrm{Pu}$ in groundwater, and little is known about the fate of aqueous Pu species in heterogeneous environments.

Using the optics of the GSECARS microprobe, a $200 \mu \mathrm{m} \times 200 \mu \mathrm{m}$ beam was focused to $4 \mu \mathrm{m} \times 7 \mu \mathrm{m}$ at the sample position. X-ray fluorescence maps were made, giving the relative concentrations of $\mathrm{Mn}, \mathrm{Fe}, \mathrm{Zn}, \mathrm{As}, \mathrm{Pb}, \mathrm{Sr}, \mathrm{Y}$, and $\mathrm{Pu}$ over a 150 $\mu \mathrm{m} \times 150 \mu \mathrm{m}$ patch of the natural rock. The $\mathrm{Pu}$ is highly associated with Mn-rich smectite phases and all but absent in the zeolitic and iron oxide grains, which dominate the rock (Fig. 4). Bulk X-ray diffraction data on a piece of tuff from the same core sample showed the Mn-rich phase to be the highly disordered, high-surface area mineral rancieite. XANES and first shell EXAFS were measured on the highest concentration $\mathrm{Pu}$ spots (estimated to be $\sim 2000 \mathrm{ppm}$ in a $10 \mu \mathrm{m} \times 10 \mu \mathrm{m}$ spot) at the $\mathrm{Pu} \mathrm{L}_{3}$ edge using a $\mathrm{Si}(\mathrm{Li})$ solid-state fluorescence detector $[5,6]$.

EXAFS of $\mathrm{Pu}$ shows six oxygen atoms coordinating $\mathrm{Pu}$ at $2.25 \AA$, which is consistent with both $\mathrm{Pu}^{4+}$ and $\mathrm{Pu}^{5+}$

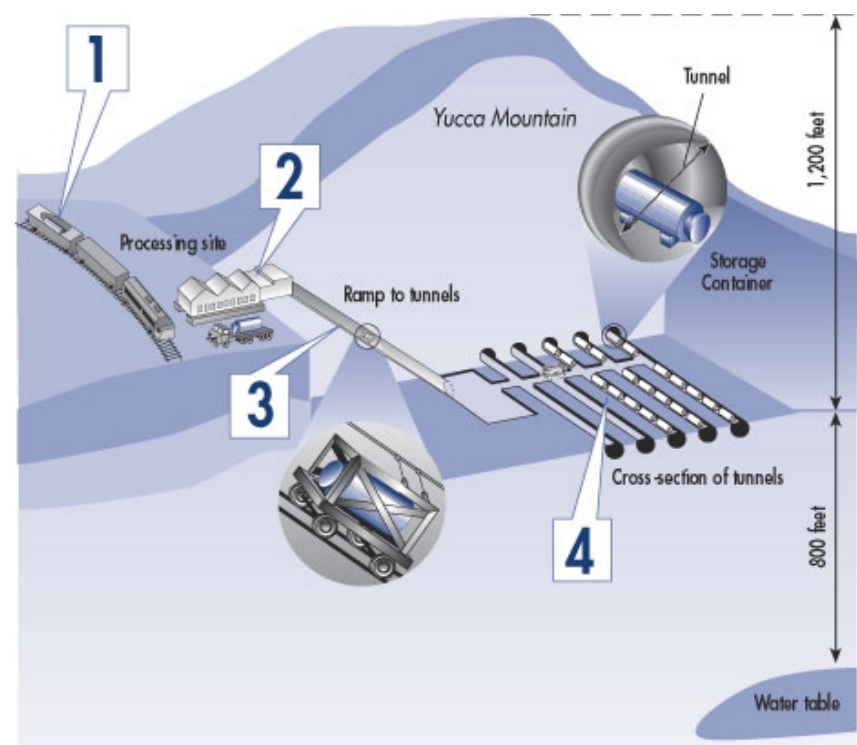

Figure 19: Yucca Mountain Repository Conceptual Design. (1) Canisters of waste, sealed in special casks, are shipped to the site by truck or train. (2) Shipping casks are removed, and the inner tube with the waste is placed in a steel, multilayered storage container. (3) An automated system sends storage containers underground to the tunnels. (4) Containers are stored along the tunnels, on their side. compounds. The lack of a broad shoulder on the main absorption peak in the XANES, and the lack of a short $\mathrm{Pu}-\mathrm{O}$ bond (at distances shorter than $\sim 2.0 \AA$ ) strongly suggest that there is essentially no $\mathrm{Pu}^{6+}$. This is consistent with the expectation that $\mathrm{Pu}$ would not be oxidized when in contact with a $\mathrm{Mn}$ mineral phase. In fact, $\mathrm{Mn}$ minerals would tend to reduce the $\mathrm{Pu}$ from $\mathrm{Pu}^{5+}$ to $\mathrm{Pu}^{4+}$. These results are consistent with this scenario. 
No clear EXAFS signal was observed from $\mathrm{Pu}-\mathrm{Pu}$ or $\mathrm{Pu}-\mathrm{Mn}$ correlations in a second coordination shell. This suggests that the $\mathrm{Pu}$ is in a highly disordered local environment, is not tightly bound to a single site on the Mn mineral, and is not present in a single type of Pu complex on the surface. Because of the poor crystallinity and high surface area of the underlying $\mathrm{Mn}$ mineral, it is reasonable to assume that the $\mathrm{Pu}$ has sorbed from solution onto (or been intercalated into) the Mn mineral at a variety of surface sites, which is consistent with the XANES and EXAFS results.

\section{K. Characterization of Fe Plaque and Associated Metals on the Surface of Aquatic Plant} Roots by Fluorescence X-ray Tomography [Colleen M. Hansel, Scott E. Fendorf (Stanford University) and Steven R. Sutton and Matthew Newville (GSECARS, University of Chicago); Research conducted at the APS and SSRL] [22,23]

Defining mechanisms involved in metal accumulation and tolerance is essential for discerning physiological adaptations by plants to metal contaminated soils, for defining the bioavailability of attenuated contaminants, and for exploiting specific plant attributes to maximize metal binding efficiency. Iron-(hydr)oxide plaques on roots are suspected to limit the uptake of toxins; yet, mechanisms of contaminant immobilization are unresolved. To elucidate metal sequestration processes at the soil-root interface, we examined the roots of Phalaris arundinacea, a common, indigenous aquatic plant, using X-ray fluorescence $\mu$-tomography and X-ray absorption spectroscopy (XAS).

Phalaris arundinacea samples were obtained from a mine waste-impacted wetland in the Coeur d'Alene Basin of northern Idaho. X-ray fluorescent computed microtomography (FCMT) was performed on undulator BL 13ID-C at the Advanced Photon Source, Argonne National Laboratory. For FCMT, the intact, unaltered root was mounted on the rotation axis of an $x$-y-theta stepping motor stage. Fluorescence data were collected with a solidstate energy dispersive X-ray detector that allows multiple elements to be detected simultaneously. The FCMT data (Fig. 20) were obtained by translating the root through the X-ray beam and collecting fluorescence at each $2 \mu \mathrm{m}$ step. At each position, the fluorescence signal from a given element is proportional to the integrated number of atoms of that element along the ray transected by the beam. The sample is then rotated by $0.5^{\circ}$ about
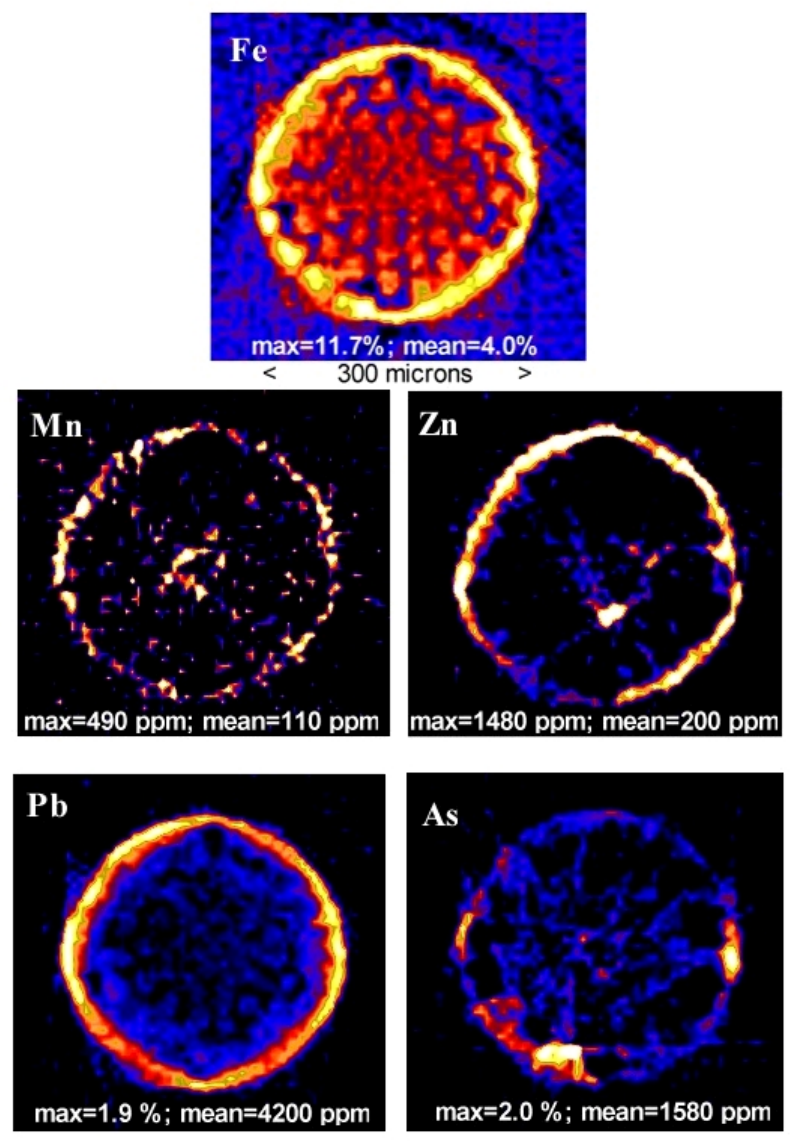

Figure 20: Metal distributions on and within grass roots as depicted by fluorescence microtomography. The spatial distribution of $\mathrm{Fe}, \mathrm{Pb}, \mathrm{Mn}$, $\mathrm{Zn}$, and As within a cross-sectional slice of the grass root is illustrated. (from [22]) 
the vertical axis and the line scan repeated. The process is continued until the particle has been rotated through a total of $180^{\circ}$ at the end of which a 2D plane has been sampled. XAFS analysis was conducted on BL 4-3 at SSRL.

Root tissue concentrations for $\mathrm{Fe}, \mathrm{Pb}, \mathrm{As}, \mathrm{Mn}$, and $\mathrm{Zn}$ are 58600, 1160, 150, 500, and $950 \mathrm{mg}$ $\mathrm{kg}^{-1}$, respectively. Scanning electron microscopy (SEM) disclosed heterogeneous precipitates, or plaque, on the exterior of the roots. As revealed by FCMT images, Fe and $\mathrm{Pb}$ are correlated within a continuous rind on the root surface (Fig. 20). Based on linear-combination XAS fits, the Fe rind is composed dominantly of ferrihydrite (63\%) with lesser amounts of goethite (32\%), and minor levels of siderite (5\%). Although $\mathrm{Pb}$ is associated with $\mathrm{Fe}$ on the root surface, it is complexed by organic functional groups, consistent with those of bacterial biofilms. Arsenic exists as a combination of two sorbed As species, being comprised predominantly of arsenate $(82 \%)$ with lesser amounts $(18 \%)$ of As(III)-iron (hydr)oxide complexes. While the Fe(hydr)oxide deposits form a continuous surficial rind around the root, As exists in isolated regions on the exterior and interior of the root. Root surface-associated As generally is found in regions of high Fe levels and may therefore occur as a direct consequence of Fe phase heterogeneity and preferential As sorption reactions. In contrast, $\mathrm{Mn}$ and $\mathrm{Zn}$ exist as discrete, isolated mixed-metal carbonate (rhodochrosite/hydrozincite) nodules on the root surface. Accordingly, external exclusion of $\mathrm{Fe}, \mathrm{Pb}, \mathrm{As}, \mathrm{Mn}$, and $\mathrm{Zn}$ at the root surface explains the anomalously high concentrations of metals associated with aquatic plants and thus provides insight into the biogeochemical cycling of these metals within anaerobic systems. As such, hydrated iron oxides, bacterial biofilms, and metal carbonates will influence the availability and mobility of metals within the rhizosphere of aquatic plants.

L. Metal Localization and Speciation in Hyperaccumulating Plants [D.B. Hunter, P.M. Bertsch and S. B. Clark (University of Georgia), K.M. Kemner (Argonne National Laboratory); Research conducted at the NSLS] [24]

The health and productivity of wetlands has received much attention in the past decade in regard to their critical role in regulating water quality, and as rapidly disappearing habitats for a variety of biota, including reptiles and amphibians, as well as migrating birds. Another threat to wetlands is contamination from agricultural and industrial discharges. In the U.S. nearly 80 million MT of coal combustion waste is disposed of annually by burial in landfills or by pumping into settling basins. At the DOE's Savannah River Site (near Aiken, SC) a coal-fired electrical power plant has operated since 1952. Coal combustion waste (fly ash) enriched in heavier metals and metalloids has been directly deposited from the plant to open water adjacent to riparian wetlands. Runoff from these fly ash basins has led to accumulation of toxic metals and metalloids in several trophic levels of the food chain in these surrounding wetlands. Knowledge of the bioaccumulation of these metals by floating aquatic plants is lacking but there is some evidence of hyperaccumulation of a number of metals and metalloids commonly enriched in fly ash. Thus, these aquatic plants represent potential species for phytoremediation of contaminated aquatic systems. Some of these organisms represent the smallest members of the flowering plants, measuring no more than 1-2 $\mathrm{mm}$ in breadth, which makes metal uptake studies in individuals difficult. Despite their small size, these plants constitute a significant portion of the biomass in wetland areas. 
Micro-XRF analyses provide an excellent way to perform in situ measurements of heavier metal accumulation. Salvinia rotundiflora, Wolffia brasiliensis, Lemna minor (duckweed) and Azolla caroliniana (water fern) were investigated for their ability to accumulate trace levels of the oxyanions: selenate $[\mathrm{Se}(\mathrm{VI})]$ and chromate $[\mathrm{Cr}(\mathrm{VI})]$. Micro-XRF measurements showed a thousand-fold concentration in the contaminants in localized regions within the roots and leaves (Fig. 21). The Se accumulated in roots of Lemna was localized in $\sim 50 \mu \mathrm{m}$ regions corresponding to cell nuclei, whereas the $\mathrm{Cr}$ accumulated in localized $\sim 50-75 \mu \mathrm{m}$ aggregates in Salvinia roots that were distinctly non-nuclear in nature and completely reduced to $\mathrm{Cr}$ (III), a relatively innocuous form of $\mathrm{Cr}$. The $\mathrm{Cr}$-rich aggregates in the cytoplasm resembled distinct structures, such as vacuoles, which are thought to be common storage sites for toxic metals in plants. Spatially-resolved Se K $\alpha$ XANES spectra revealed that the Se accumulated in the nuclei of the Lemna root cells was predominantly in the hexavalent oxidation state, whereas Se was reduced in the veins of Lemna leaves suggesting significant incorporation of Se into proteins. Such information is valuable in delineating physiological mechanisms of metal accumulation and transformation, and for evaluating the efficacy of bioremediation strategies

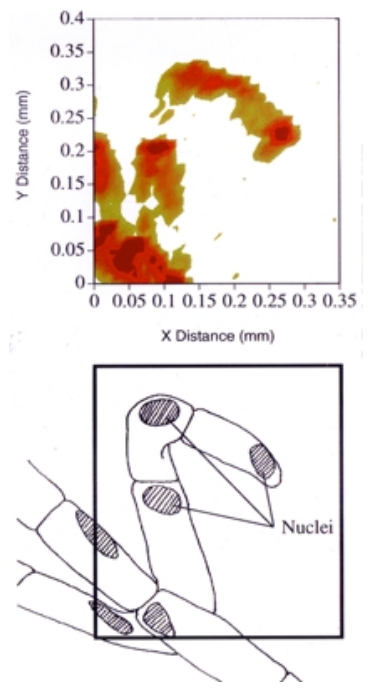

a.

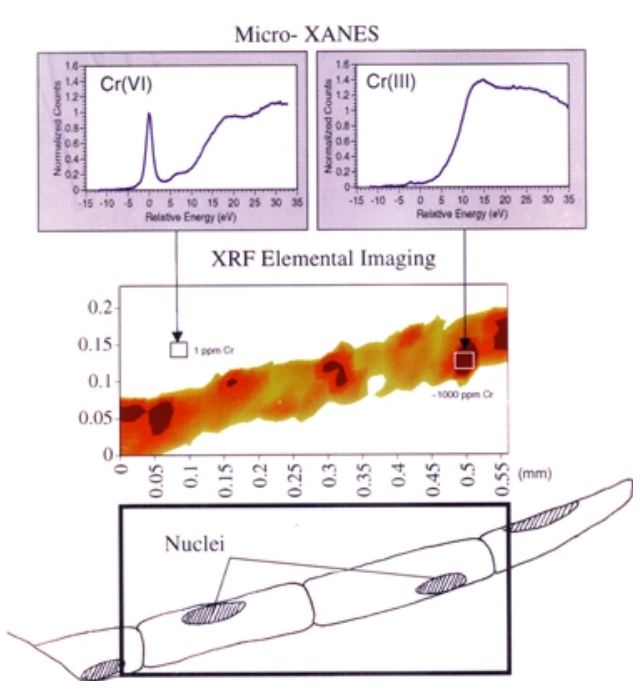

b.
Figure 21. Micro-XRF image of (a) the selenium distribution and $(b)$ the chromium distribution within rootlets of the hyperaccumulating aquatic plant, Salvinia rotundifolia. Plants were exposed to dilute levels of $\mathrm{Se}(\mathrm{VI})$ and $\mathrm{Cr}(\mathrm{VI})$, toxic forms of $\mathrm{Se}$ and $\mathrm{Cr}$, and they had accumulated in excess of $10^{5}$ times the solution $\mathrm{Se}$ and $\mathrm{Cr}$ in localized areas in single cells. Micro-XANES demonstrated that Se accumulated in the nuclei of root cells and that it remained in the $\mathrm{Se}$ (VI) form. In contrast, $\mathrm{Cr}$ accumulated in the cytoplasm of the root cells and was reduced to $\mathrm{Cr}(\mathrm{III})$, a less toxic form of chromium, which suggests a detoxification mechanism. (from [24])

M. Interaction of Uranium with Zeolites at the Yucca Mountain Site [R.J. Reeder, M. Nugent (SUNY Stony Brook), R.T. Pabalan (Southwest Research Institute); Research conducted at the NSLS] [25]

Ensuring that long-lived radionuclides remain isolated and immobile after burial at the Yucca Mountain repository (Fig. 22) is critical for future use of nuclear power. Clinoptilolite is one of the dominant minerals in the unsaturated zone below the repository at Yucca Mountain, and released radionuclides such as $\mathrm{U}(\mathrm{VI})$ are expected to interact with this mineral. The structure of clinoptilolite has large open tunnels in which fully hydrated heavy metal cations could be trapped (i.e., outer-sphere sorption mechanisms). Cations can also lose part of their hydration spheres and bond directly to structural $\mathrm{AlO}_{4}$ or $\mathrm{SiO}_{4}$ units. EXAFS characterization of U(VI) sorption complexes indicate that a strongly bound, inner-sphere surface complex forms at the near-neutral 
pH conditions expected (Fig. 22), but under acidic conditions an outer-sphere complex dominates. This direct spectroscopic information supports the view that radionuclide mobility may be limited by sorption interactions with clinoptilolite under the near-neutral $\mathrm{pH}$ conditions of the Yucca Mountain site.

N. Freezing Tolerance in Plant Tissues $[\mathrm{P} . \mathrm{L}$. Steponkus, M. Uemura, R. A. Joseph, S. J. Gilmour (Cornell University) and M. F. Thomashow (Michigan State University); Research conducted at CHESS] [26]

The ability to endure low temperatures and freezing is a

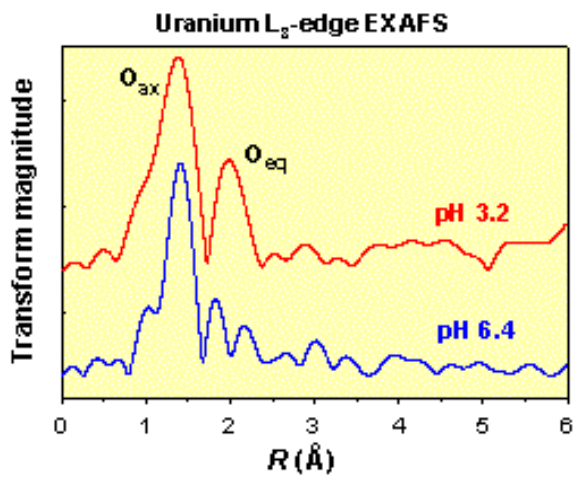

Figure 22. Fourier transforms of EXAFS spectra from $U(V I)$-reacted clinoptilolite. (from [25]) major determinant of the geographical distribution and productivity of agricultural crops. Even in areas considered suitable for the cultivation of a given species, decreases in yields and crop failure frequently occur as a result of aberrant freezing temperatures. In spite of attempts to minimize damage to freezing-sensitive crops - primarily by using energy-costly practices to modify the microclimate - substantial economic losses resulting from freezing are incurred annually in a diverse array of agricultural crops. This research has recently provided the first direct evidence that expression of COR (cold regulated) genes are functionally involved in cold acclimation. Simply stated, freezing injury is a consequence of freeze-induced cell dehydration, which results in several different lesions in the plasma membrane. In nonacclimated leaves of herbaceous species, the primary lesion is the result of lamellar-tohexagonal II phase transitions (Fig. 23) in the molecular structure of the plasma membrane, most often near the chloroplast envelope, as a result of freeze-induced cell dehydration. Freezeinduced formation of the hexagonal II phase disrupts both the physical continuity and semipermeable characteristics of the plasma membrane such that the cells become leaky and

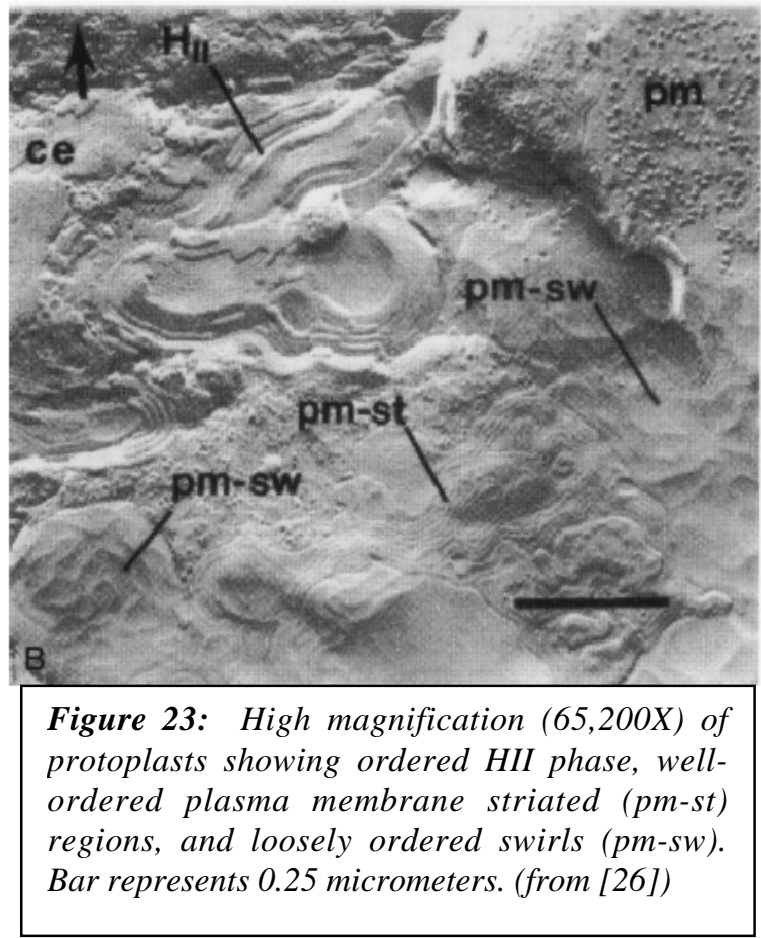

Figure 23: High magnification $(65,200 X)$ of protoplasts showing ordered HII phase, wellordered plasma membrane striated (pm-st) regions, and loosely ordered swirls (pm-sw) Bar represents 0.25 micrometers. (from [26])

flaccid. Studies using NMR, freeze-fracture electron microscopy, and x-ray diffraction have shown that COR15a alters the intrinsic curvature of the inner membrane of the chloroplast envelope and thereby alters the phase transitions of the membranes. X-ray measurements were used to determine the structural phases and lattice constants of the membrane walls. These studies establish that expression of the COR15a gene decreases the propensity for freeze-induced lesions, and improves the freezing tolerance, of nonacclimated leaves of A. thaliana and winter cereals such as rye, wheat, barley, and oat. 
O. Chemical Speciation of Chromium in Hanford Tank Farm Vadose Zone Sediments. [J.G. Catalano, J.A. Warner, and G.E. Brown, Jr., (Stanford University), J.M. Zachara, C.C. Ainsworth (Pacific Northwest National Laboratory), and S.J. Traina (U.C. Merced); Research conducted at SSRL and the APS] [27]

$\mathrm{Cr}^{6+}$ is highly toxic and mobile in groundwater, whereas when in the $3+$ form, it is non-toxic and forms insoluble solids, thus is immobile. Chromium is present at concentrations of up to 37,000 ppm in sediments beneath the Hanford Tank Farm in Washington State as a result of leakage of effluent from the tanks and spills (Fig. 23). Although present primarily as $\mathrm{Cr}(\mathrm{VI})$ in the tank wastes, its chemical form in the vadose zone beneath the tanks is not generally known.

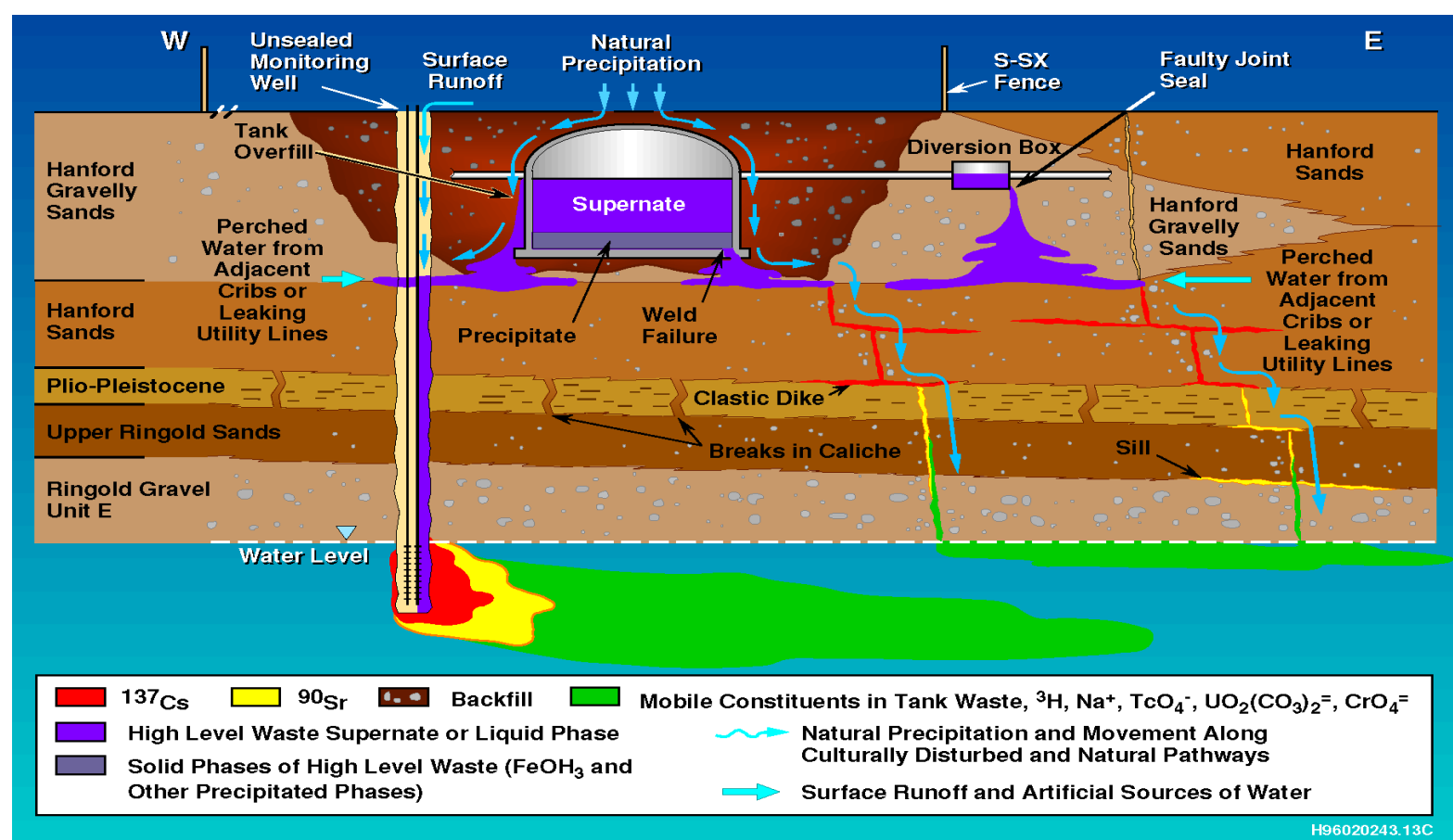

Figure 23. Hypothetical pathways for movement of S-SX Tank Farm leachates in the Hanford vadose zone.

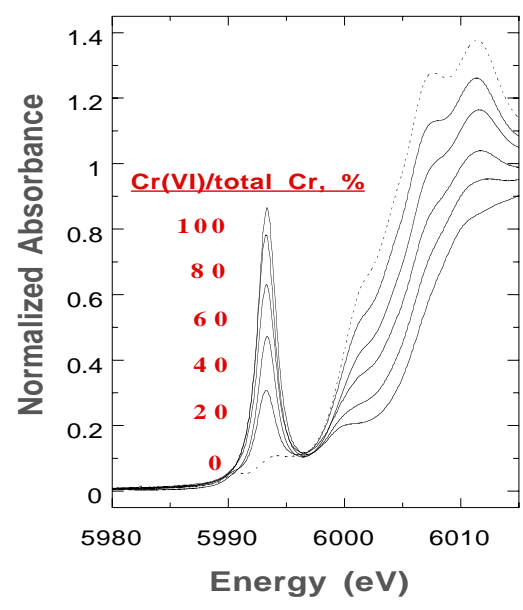

Figure 24 (Left). Cr K-edge XANES spectra of mechanical mixtures of $\mathrm{Cr}(\mathrm{VI})$ and $\mathrm{Cr}(\mathrm{III})$ used to calibrate pre-edge feature (from [4]).

Figure 25 (Right). Normalized $\mathrm{Cr}$ $K$-edge XANES spectra of Hanford $S$-SX Tank Farm contaminated sediment samples taken at SSRL. From top to bottom: 41-09-397ABC (58\% Cr(VI)), 41-09-39-6AB (51\% Cr(VI)), SX-108-8A $(53 \%$ $C r(V I))$, $S X-108-7 A(25 \% \operatorname{Cr}(V I))$. (from [27])

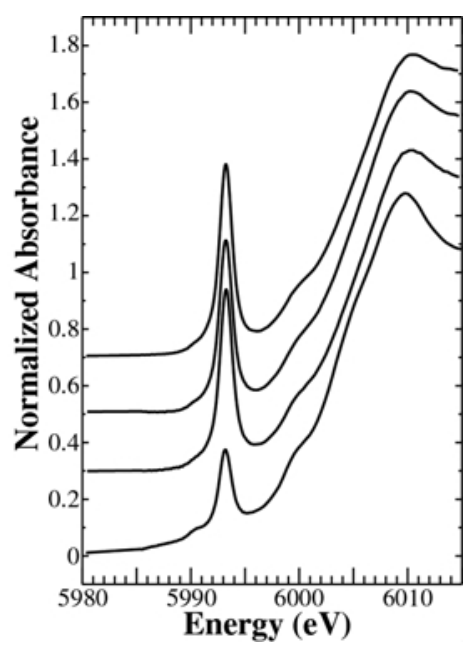


To address this important issue, XAFS spectroscopy was used to analyze the speciation of $\mathrm{Cr}$ in nine contaminated sediment samples from two Hanford S-SX Tank Farm boreholes. Figure 24 shows the change in pre-edge feature height as a function of $\mathrm{Cr}(\mathrm{VI}) /$ total $\mathrm{Cr}$. XAFS spectroscopy (Fig. 25) showed that a number of these samples contain > 50\%, $\mathrm{Cr}(\mathrm{VI})$, whereas one sample (SX-108-7A) contains about $25 \% \mathrm{Cr}(\mathrm{VI})$. $\mu$ XRF mapping showed little association of $\mathrm{Cr}$ with $\mathrm{Fe}$ - and $\mathrm{Mn}$-oxides. These results indicate that although significant reduction of $\mathrm{Cr}(\mathrm{VI})$ to $\mathrm{Cr}(\mathrm{III})$ has occurred in the Hanford vadose zone, neither the reduction of $\mathrm{Cr}(\mathrm{VI})$ nor the sorption of $\mathrm{Cr}$ to Fe- or Mn-oxide particles is sufficient to limit its mobility in the subsurface at Hanford.

\section{P. Remediation of Pu in Soils and Concrete at Rock Flats Environmental Technology Site} (RFETS), Colorado [M.P. Neu, W.H. Runde, D.L. Clark, S.D. Conradson, D.E. Efurd, D.R. Janecky, J.P. Kaszuba, C.D. Tait, R.G. Haire (Los Alamos National Laboratory); Research conducted at SSRL] [28]

The risk associated with trace Pu contamination in soils at RFETS is fundamentally related to its speciation (i.e., physical form, local/molecular structure and composition, oxidation state, hostphase identity). In general, insoluble phases pose less risk to humans, wildlife, and water supplies because the rate of metal ion release is slow, sometimes nonexistent. Readily leachable phases pose the greatest short-term threat to environmental health. $\mathrm{Pu} \mathrm{L}_{\mathrm{II}}$-edge EXAFS studies performed at SSRL indicate that $\mathrm{Pu}$ in soils at the 903 drum storage site (Fig. 26) is predominantly present as $\mathrm{PuO}_{2}(\mathrm{~s})$. This phase is known to be highly insoluble under soil water
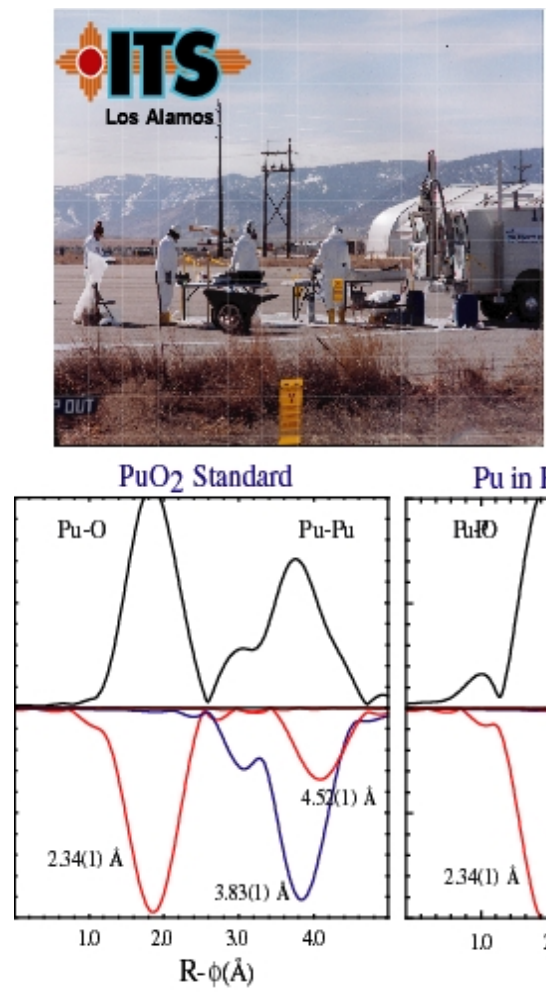

$\mathrm{Pu}$ in RFETS Concrete

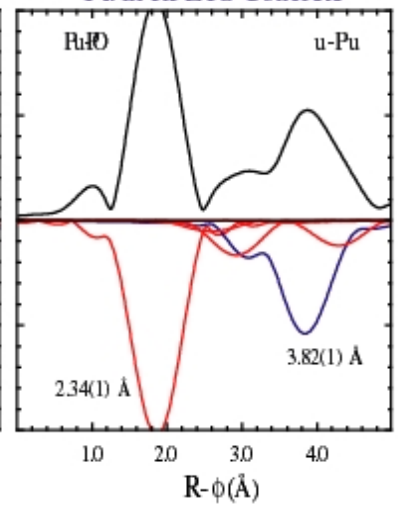

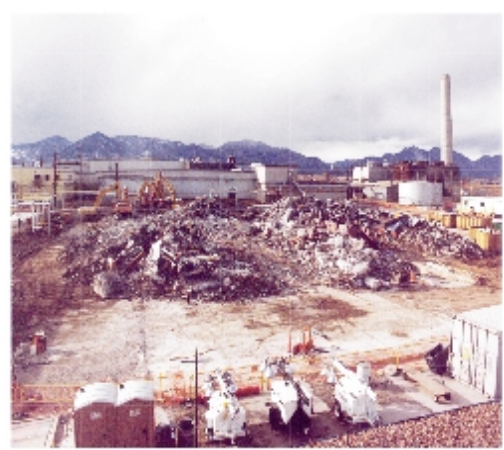

Pu in RFETS Soil

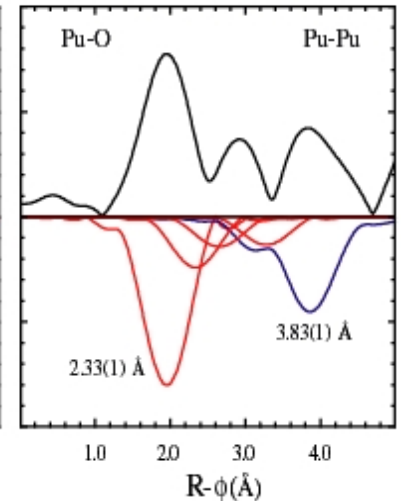

Figure 26. (upper left panel) Collection of Pu-contaminated soil at Rocky Flats Environmental Technology Site (RFETS). (upper right panel) Pu-contaminated concrete at RFETS. (lower panels) Fourier transforms of Pu $L_{I I^{-}}$ EXAFS spectra of (left) $\mathrm{PuO}_{2}$ standard, (middle) Pu in RFETS concrete, (right) Pu in RFETS soil. (from [28]) 
conditions. This work backs up the earlier assessment that soluble transport models are not applicable to $\mathrm{Pu}$ migration in RFETS soils. Other work has demonstrated that particulate (i.e., erosion) transport is the dominant transport mechanism for $\mathrm{Pu}$ migration at the site, and the identification of $\mathrm{PuO}_{2}$ associated with the soil particles further indicates that erosion modeling is critical for the assessment of long-term surface water quality. This prediction translates directly into very substantial cost savings. This work has allowed the site to focus efforts toward erosion modeling, and future land configuration studies to control particulate transport. It will also help define cleanup levels in compliance with the Rocky Flats Compliance Agreement. Thus Pu XAFS measurements have developed into a decision-making tool for Kaiser-Hill LLC, saved the company millions of dollars by focusing site-directed efforts in the correct areas, and will aid the DOE in its efforts to clean up and close the RFETS by 2006.

Q. Tank Waste Np and Pu Separations Technology Development. [D.L. Clark, S.D. Conradson, D.W. Keogh, D.E. Morris, M.P. Neu, R.J. Donohoe (Los Alamos National Laboratory); Research conducted at SSRL] [29-32]

More than 300 million gallons of fission-product-bearing tank waste exist within the DOE nuclear weapons complex. The requirement of cleaning up these facilities is driving development of technologies that can separate high-level radionuclides, to be vitrified for disposal, from benign tank waste components such as Al-oxide (Fig. 27). One key problem with the proposed alkaline $(2.5 \mathrm{~N} \mathrm{NaOH})$ sludge-washing process, designed to remove amphoteric $\mathrm{Al}$ from the tank sludges, is co-removal of $\mathrm{Pu}$ and $\mathrm{Np}$. EXAFS measurements performed at SSRL have been fundamental in establishing the molecular structures and compositions of dissolved $\mathrm{Np}$, and $\mathrm{Pu}$ species in sludge wash solutions, namely $\left[\mathrm{AnO}_{2}(\mathrm{OH})_{4}\right]^{2-}$ and $\left[\mathrm{AnO}_{2}(\mathrm{OH})_{5}\right]^{3-}(\mathrm{An}=\mathrm{Np}, \mathrm{Pu})$. Although $\mathrm{U}$ does not form these amphoteric complexes in $\mathrm{NaOH}$ solution, EXAFS studies by Los Alamos National Laboratory scientists have shown that $\mathrm{Np}$ and $\mathrm{Pu}$ form highly soluble anionic species (Fig. 28) under these tank waste conditions. The discovery and characterization of these anionic species are requisite fundamental steps leading to modeling and design of enhanced chemical separations processes. Proper design of such processes will save taxpayers money and natural resources.
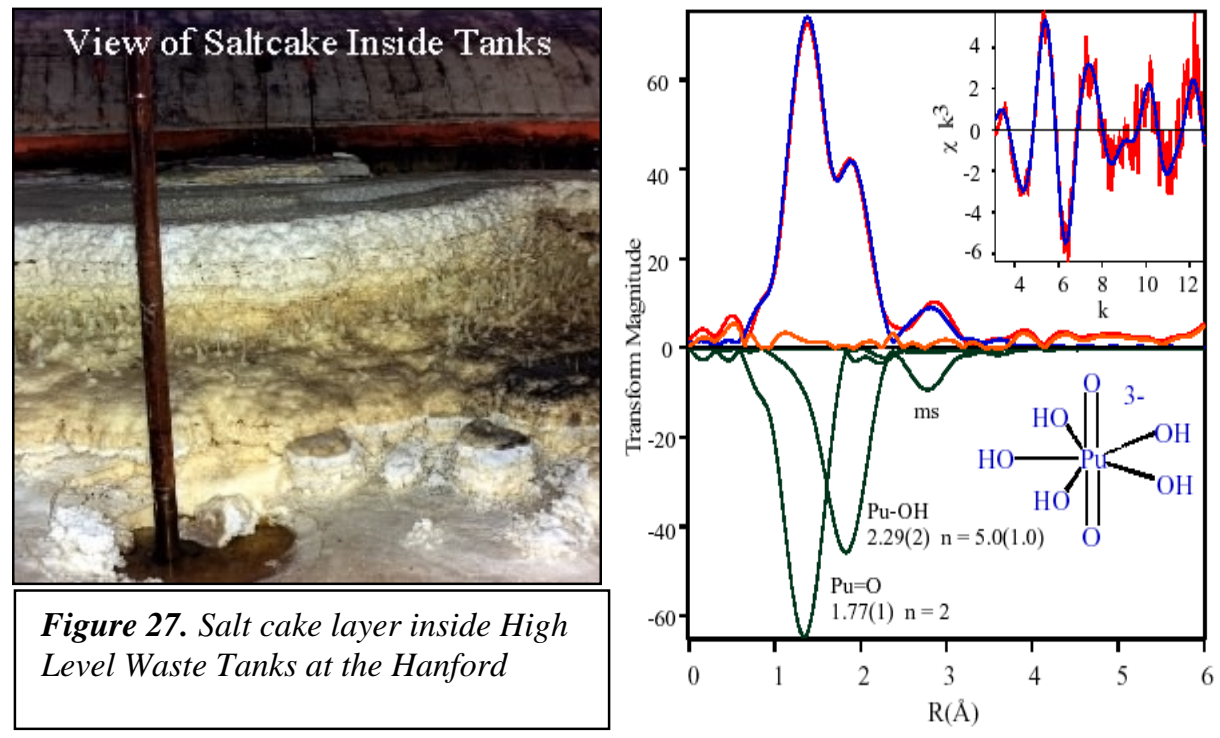

Figure 28. Plutonium $L_{I I I^{-}}$ EXAFS spectrum (upper right inset) and Fourier transform (FT) (main figure) of $\mathrm{PuO}_{2}{ }^{2+}$ in $3.5 \mathrm{M}$ TMAOH solution. The FT has been fit with two main features (shown pointing downward) corresponding to two $\mathrm{Pu}-\mathrm{O}$ pair correlations at $1.77 \AA$ and five $\mathrm{Pu}-\mathrm{OH}$ pair correlations at $2.29 \AA$. The structure of the $\mathrm{PuO}_{2}{ }^{2+}$ aqueous species is shown in the lower right inset drawing. The EXAFS data were taken on SSRL BL 4-2. (from [31]) 


\section{R. Permeable Reactive Barrier Technology Demonstration for Remediation of Uranium-} Contaminated Ground Water at Fry Canyon, Utah [C.C. Fuller, J.A. Davis, and M.J. Piana (U.S. Geological Survey), J.R. Bargar, (SSRL); Research conducted at SSRL] [33,34]

The shallow alluvial aquifer at Fry Canyon, Utah, is contaminated with up to $17 \mathrm{mg} / \mathrm{L}$ uranium leached from processed tailings at an ore upgrader processing plant that was operated in the 1950s and 1960s. A partnership was formed in June of 1996 between the DOE (Grand Junction Office), U.S. EPA, Interior Department, Geological Survey (USGS), Bureau of Land Management (BLM), and the Utah Department of Environmental Quality for the purposes of demonstrating in situ treatment technologies, notably permeable reactive barriers (PRBs) (Fig. 29), for removing dissolved radionuclides and metals from ground water. PRBs are trenches or "fencepost" structures emplaced in the subsurface at depths up to 100 feet (excavation) or deeper (soil mixing, deep tool emplacement in non-pumping wells), to intercept the hydraulic flow path [35]. They are filled with reactive materials capable of sequestering dissolved radionuclides from contaminated ground water via adsorption or mineral precipitation mechanisms. In essence, PRBs act as filters to clean ground water.

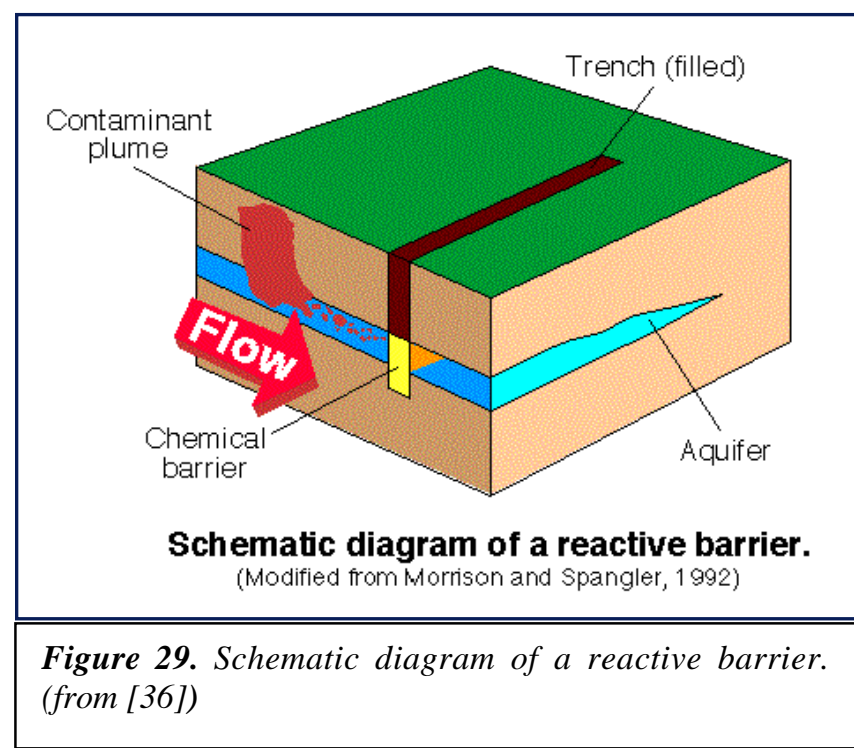

Commercial apatite $\left(\mathrm{Ca}_{5}\left(\mathrm{PO}_{4}\right)_{3} \mathrm{OH}\right)$, was investigated for use at Fry Canyon. Apatite is soluble in groundwater. When dissolved it releases phosphate, which can react with soluble hexavalent uranium $(\mathrm{U}(\mathrm{VI}))$ to form autunite. The relatively low solubility of autunite has led some to propose that it could be a good "inert" host for in situ sequestration of U(VI). This general chemical strategy has previously been shown to have a high capacity for attenuating lead- and cadmium contamination. EXAFS and SR-XRD measurements of U(VI)-reacted apatites conducted on BL 4-3, 11-2, and 2-3 at SSRL showed that U(VI)-phosphate solids were not present in the reacted apatite materials, and that $\mathrm{U}(\mathrm{VI})$ was not absorbed into the apatite structure. Furthermore, the EXAFS-derived local molecular structure of U(VI) in the reacted apatites was consistent with the structure expected for $\mathrm{U}(\mathrm{VI})$ adsorbed (chemically bonded) to external apatite surfaces. These measurements show that uranium attenuation in the barriers will occur primarily through adsorption on PRB material surfaces, as opposed to precipitation of $\mathrm{U}(\mathrm{VI})$-phosphate phases. This conclusion was confirmed by EXAFS measurements of materials extracted directly from the Fry Canyon barrier after 18 months of operation. As is the case with all PRB designs, the barrier will require monitoring to insure that re-release of U(VI) does not occur due to changes in ground-water chemistry or saturation of its U(VI)-binding capacity. These results have the important implication that permeability will remain high in the apatite PRB. It should be possible to recover adsorbed uranium from the apatite material by washing, which suggests apatite may be appropriate for use in retrievable barriers. Furthermore, uranium thus trapped cannot be remobilized by oxidation in ground water (because it is already present as 
the oxidized, hexavalent form), which is a major concern with zero-valent iron-based PRBs that attenuate uranium by reducing $\mathrm{U}(\mathrm{VI})$ to $\mathrm{U}(\mathrm{IV})$.

S. Chemical Behavior of Technetium in Nuclear Wastes [W.W. Lukens, D.K. Shuh, J.J. Bucher, and N.M. Edelstein (Lawrence Berkeley National Laboratory); Research conducted at SSRL] [37,38]

Technetium $\left({ }^{99} \mathrm{Tc}, \tau_{1 / 2}=213,000 \mathrm{yr}\right)$ is an abundant product of ${ }^{235} \mathrm{U}$ fission and is an element of concern due to its long half-life and the high solubility and high environmental mobility of pertechnetate, $\mathrm{TcO}_{4}^{-}$, which is the stable form of Tc in aerobic environments. Considerations of Tc release often drive environmental remediation activities because Tc concentration in ground water is often the first to approach regulatory limits. Cement has been chosen as one waste form for long-term storage of Tc and other low-level nuclear waste materials. However, pertechnetate is readily leached from cement waste forms; Tc can be immobilized as tetravalent $\mathrm{TcO}_{2} \bullet \mathrm{xH}_{2} \mathrm{O}$ or $\mathrm{TcS}_{2}$, both of which have low solubilities and low environmental mobilities. For this reason, understanding the redox chemistry of Tc in these systems is crucial for predicting the long-term behavior of Tc in cementitious waste forms.

The speciation of Tc in cement was investigated using XAFS spectroscopy. The Tc K-XANES spectra of a series of cement samples were fit using a linear combination of Tc K-XANES spectra of Tc species present (Fig. 30). In samples that were not sealed, the Tc initially present as $\mathrm{Tc}(\mathrm{IV})$ was steadily oxidized to $\mathrm{TcO}_{4}{ }^{-}$; in constrast, Tc remained reduced in sealed samples until the samples were opened as illustrated in Figure 30 (right). These results show that atmospheric oxygen is responsible for oxidizing Tc(IV) in cement waste forms and that the nitrate present in the waste is unreactive towards Tc(IV).
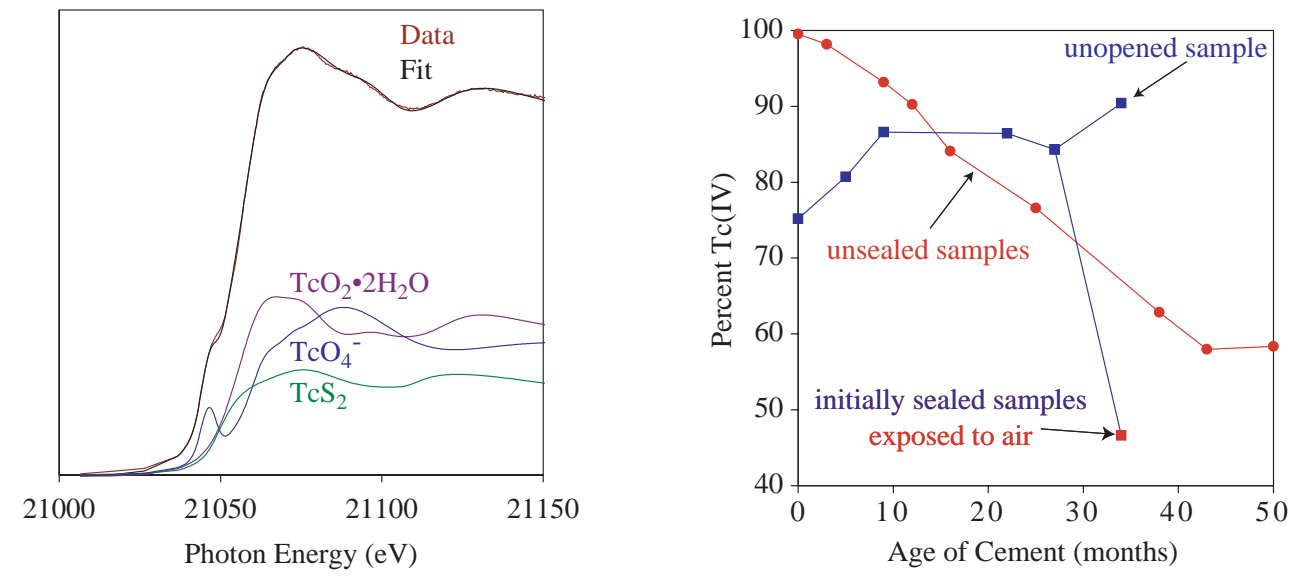

Figure 30. (left) Deconvolution of Tc speciation in a cement sample from Tc K-XANES spectra. (right) Evolution of Tc speciation in two sets of cement samples: sealed and unsealed. (from [38])

Technetium chemistry also complicates the treatment of Hanford's high-level waste (HLW) in specific tanks. Separation of $80 \%$ of the Tc is required under one remediation scenario and is based upon ion exchange of pertechnetate, $\mathrm{TcO}_{4}{ }^{-}$. However, certain waste tanks - the Complexant Concentrate (CC) or Envelope C tanks - contain a large percentage of a soluble, lower-valent Tc species, which is not removed by ion exchange. While this species has not been identified, XANES results suggest that the lower-valent Tc species is tetravalent [38]. 
The products of reduction of pertechnetate in alkaline solution in the presence of components of HLW were investigated using Tc K-edge EXAFS as shown in Figure 31 [39]. In the presence of carboxylate ligands such as citrate or EDTA, only $\mathrm{TcO}_{2} \cdot \mathrm{xH}_{2} \mathrm{O}$ was observed; however, in the presence of compounds possessing more than one alcohol group - polyols - soluble Tc(IV) complexes were observed. None of the Tc K-XANES spectra of the soluble Tc(IV) alkoxide complexes is similar to those reported earlier for the non-pertechnetate species in HLW. Although these Tc(IV) complexes can be created in alkaline solution, they are not the problematic species in Hanford HLW. These species are currently under investigation.

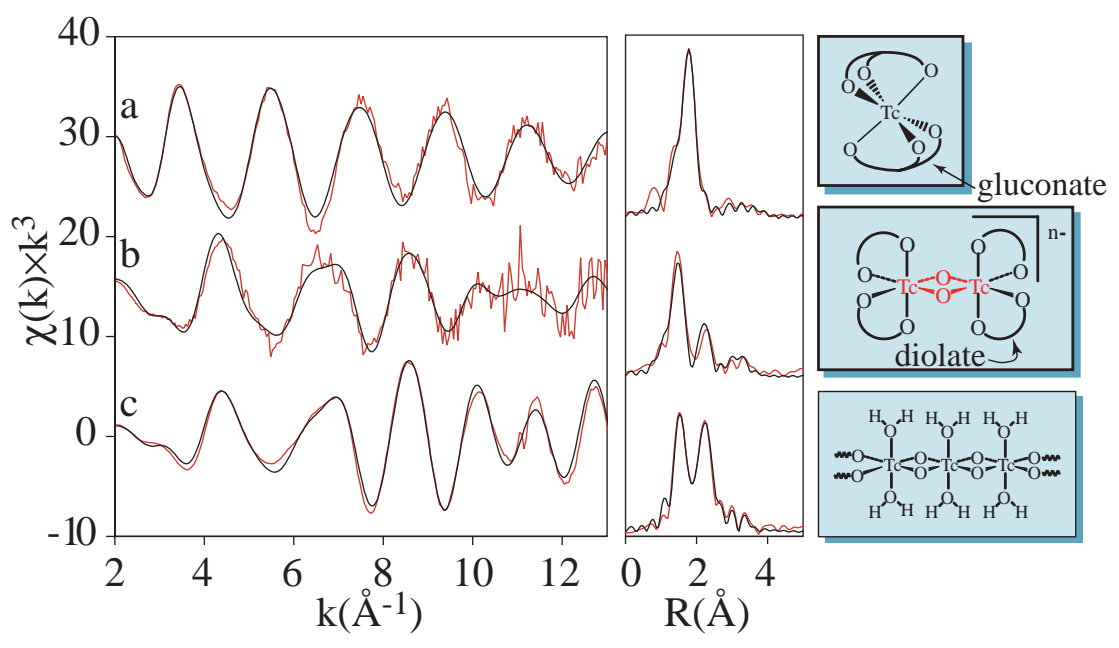

Figure 31. (left) EXAFS spectra and (center) Fourier transforms of pertechnetate reduced in $1 M \mathrm{NaOH}$ in the presence of (a) gluconate, (b) glyoxylate, and (c) EDTA. Data are shown in red, fits are shown in black. (right) Structures deduced from the EXAFS results. (from [39])

\section{T. Formation of Sphalerite (ZnS) Deposits in Natural Biofilms of Sulfate-Reducing Bacteria}

[M. Labrenz, G.K. Druschel, T. Thomsen-Ebert, B. Gilbert, S. A. Welch, K.M. Kemner, G.A. Logan, R.E. Summons, G. De Stasio, P.L. Bond, B. Lai, S.D. Kelly, and J.F. Banfield (University of California, Berkeley and Argonne National Laboratory); Research conducted at the APS] [40]

This work showcases the strength of combining X-ray and electron microscopies for the study of mineral-microbe interactions. Biofilms were collected from a flooded $\mathrm{Pb}-\mathrm{Zn}$ deposit known as the Tennyson Mine in Wisconsin, USA. The predominant bacterial species identified was Desulfobacteriaceae, which is an aerotolerant sulfate-reducing bacteria (SRB). X-ray fluorescence microprobe analysis (XRFMA) and energy dispersive X-ray analysis (Fig. 32) indicate that the biofilm concentrates $\mathrm{Zn}$ in the form of sphalerite $(\mathrm{ZnS})$ at a level $10^{6}$ times greater than in the mine solutions. High-resolution transmission electron microscopy (Fig. 32) showed that larger $\mu \mathrm{m}$-sized precipitates consist of $\sim 3 \mathrm{~nm}$ sized particles. XRFMA (Fig. 32) showed that $\mathrm{Zn}$ occurs in $\sim 1 \mu \mathrm{m} \mathrm{ZnS}$ precipitates, which is consistent with $55 \%$ porosity indicating a semi-random packing of $\sim 3 \mathrm{~nm}$ sized aggregates. There are $\sim 1$ billion $3 \mathrm{~nm}$ particles in a $\mu \mathrm{m}$-sized precipitate. XRFMA (Fig. 32) also showed that $\mathrm{ZnS}$ precipitates concentrate As (0.01 wt \%) and Se (0.004 wt \%) but not $\mathrm{Pb}$. 
The ability of the aerotolerant sulfate-reducing bacteria to grow under moderately reducing conditions is central to explaining the near exclusive precipitation of sphalerite. Zn influx in the mine waters prevents an accumulation of sulfide due to the precipitation of sphalerite $(\mathrm{ZnS})$ and thus inhibits the later formation of FeS (mackinawite). Additionally, removal of sulfide by $\mathrm{ZnS}$ formation prevents the development of highly reducing conditions needed for the growth of anaerobic groups of sulfate reducing bacteria. Besides playing a role in the fate and transport of contaminant metals like As and Se as shown in this work, this biomineralization process may be relevant to the early stages of formation of the large sediment-hosted $\mathrm{Pb}-\mathrm{Zn}$ deposits from brines, exhalative fluids, or basinal fluids, and other low-temperature $\mathrm{ZnS}$ deposits.

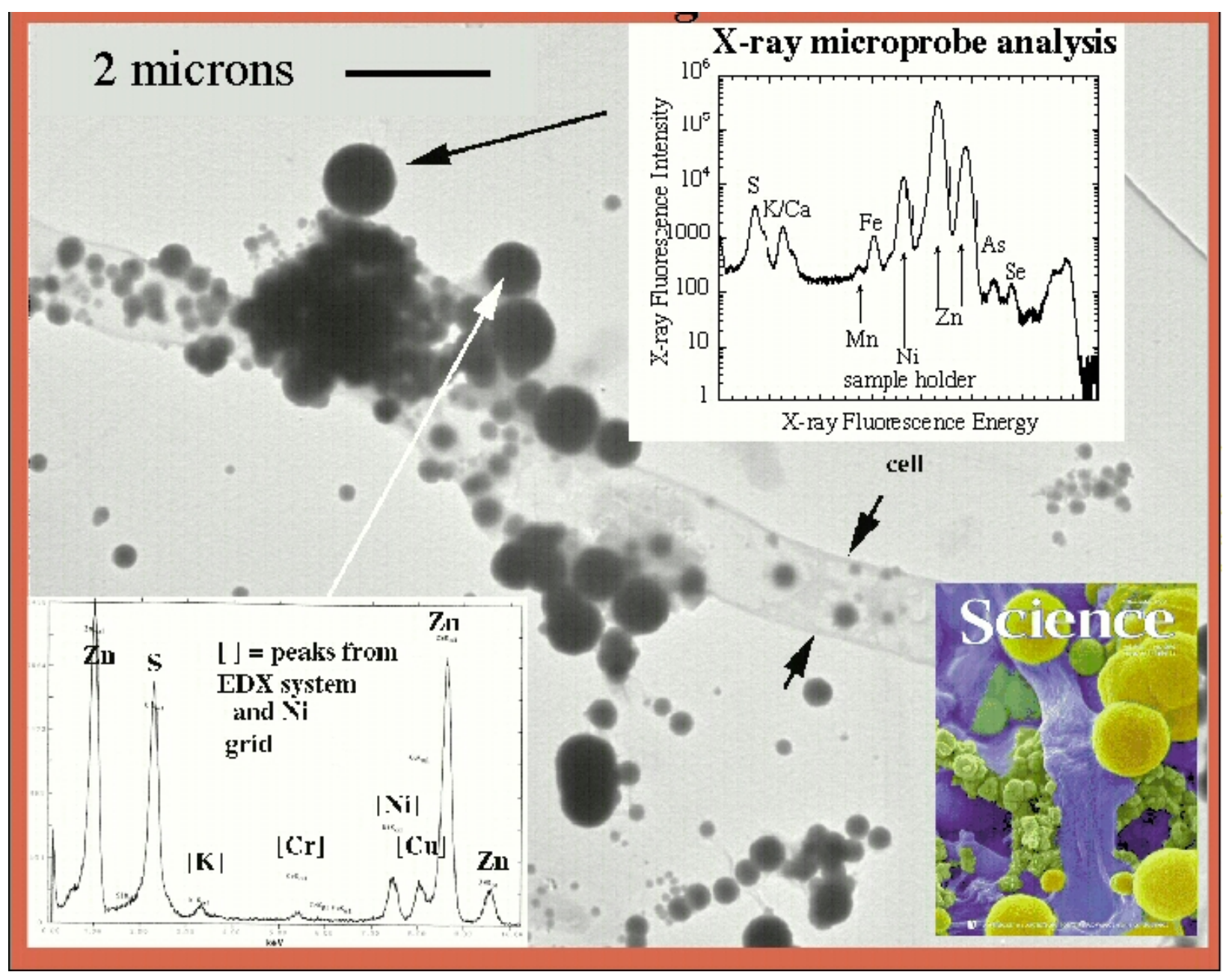

Figure 32. X-ray fluorescence trace metal microanalysis of sulfate-reducing bacteria. (from [40])

U. Environmental Leachability of Electric Arc Furnace Dust [J. A. Stegemann and R. J. Caldwell (Water Technology International Corp., Burlington, ON), A. Roy, P. J. Schilling, and R. Tittsworth (Louisiana State University); Research conducted at CAMD] [41]

Dust from the production of steel in electric arc furnaces (EAF) contains a mixture of elements (e.g., $\mathrm{Cr}, \mathrm{Ni}, \mathrm{Zn}, \mathrm{Cd}$, and $\mathrm{Pb}$ ) that pose a challenge for both recovery and disposal. This investigation examined the correlation between leachability, mineralogy, and chemical speciation of six Canadian EAF dusts. Four different leach tests were conducted: distilled water, 
Ontario Regulation 347 Leachate Extraction Procedure, Amount Available for Leaching (AALT) and $\mathrm{pH} 5$ Stat. Mineralogy was determined by XRD, and XANES spectra were collected at CAMD. SEM images showed that the EAF dust is dominated by solid spherical agglomerates in the tens of $\mu \mathrm{m}$ size range and fine-grained irregular particles below $1 \mu \mathrm{m}$ in size (Fig. 33).

XANES spectra yielded the following results: $\mathrm{Cr}$ : Only insoluble $\mathrm{Cr}^{3+}$ species were observed; no significant chromate $\left(\mathrm{Cr}^{6+}\right)$ species were present at a detection limit of about $0.5 \%$. $\mathrm{Zn}: \mathrm{ZnCl}_{2}$ dominated two dusts and $\mathrm{ZnO}$ the others. Pb: Dominant species was $\mathrm{PbO}$. $\mathrm{Ni}$ : $\mathrm{NiO}$ (bunsenite) was observed at levels undetectable by XRD. Nickel chloride was present only in negligible amounts. Cd was below detection limits.

Chromium and nickel contaminants in EAF dust are largely unleachable, as they are found with the predominant spinel ferrite phase in EAF dust. However, even a small proportion of chromium speciated as chromate can result in significant leachate concentrations. The leachability of zinc, lead and cadmium can be significant, as large fractions of these contaminants are found as chlorides and oxides. Leaching of metals is largely controlled by $\mathrm{pH}$. The acid neutralization capacity of the EAF dusts appears to be controlled by dissolution of lime and zincite, which are present in variable amounts. Results from the regulatory leaching tests can be misleading because the variable acid neutralization capacity can lead to very different final leachate pHs. A more informative approach would be to evaluate the total amounts of contaminants available in the

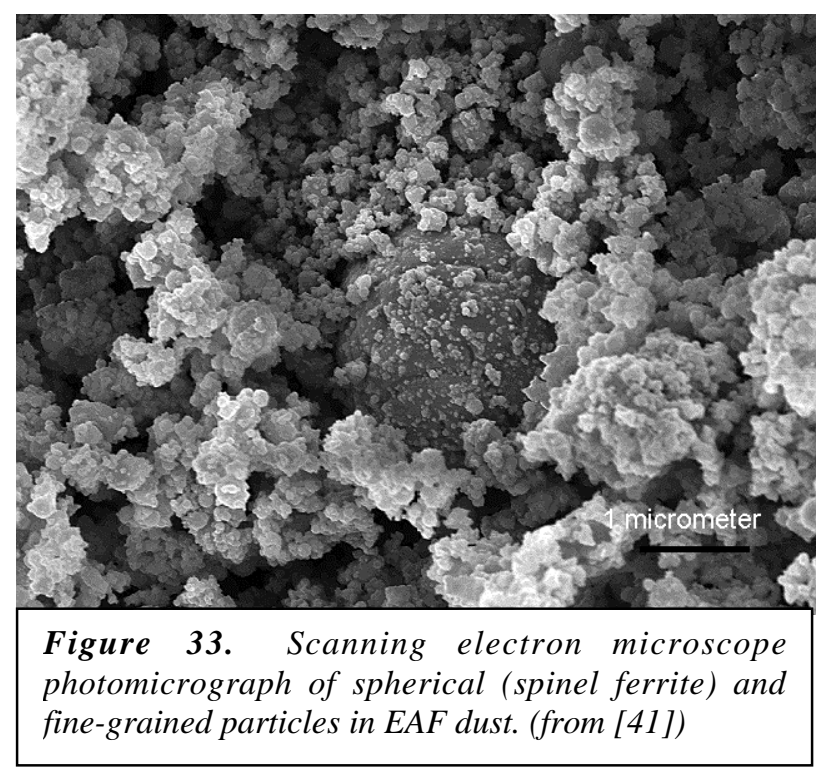
long term and the acid neutralization capacity.

V. Quantitative Speciation of Heavy Metals in Soils and Sediments by Combining X-ray Fluorescence, Absorption, and Diffraction at Micrometer Scales of Resolution [A. Manceau (University J. Fourier and CNRS, Grenoble, France), M.A. Marcus, N. Tamura, H.A. Padmore, Advanced Light Source, LBNL); Research conducted at the ALS] [42-44]

Remediation of metal contaminants in soils, sediments, and subsurface waters is a major goal of the U.S. Department of Energy. Because less-soluble forms of metals tend to be less toxic and more mobile, the human and ecological impacts of hazardous heavy metals and metalloids can be reduced by transforming soluble species to sparingly soluble forms, either in situ or in landfills after excavation. To this end, quantitative determination of all the forms of potentially toxic metals in soils, sediments, and solid wastes is key to assessing the initial risk, formulating efficient remediation strategies, and assessing the effectiveness of remediation efforts. This objective was achieved for $\mathrm{Ni}$ - and $\mathrm{Zn}$-contaminated soils from the Morvan region of France using three non-invasive SR techniques (X-ray fluorescence ( $\mu \mathrm{SXRF}), \mu \mathrm{XRD}$ and $\mu$-scanning $\mathrm{XRD}$, and $\mu \mathrm{XAFS})$, all applied at the $\mu \mathrm{m}$ resolution scale without disrupting the soil matrix. The 
$\mathrm{Ni}$ and $\mathrm{Zn}$ were found to be concentrated in ferromanganese nodules, which consist of sub- $\mu \mathrm{m}$ to nm-sized particles with varying structures and compositions.

Figure 34 shows the $\mu \mathrm{SXRF}$ elemental maps of $\mathrm{Fe}, \mathrm{Mn}, \mathrm{Ni}$, and $\mathrm{Zn}$, which are unevenly distributed at the $\mu \mathrm{m}$ scale. $\mathrm{Ni}$ and $\mathrm{Zn}$ are both strongly correlated with $\mathrm{Mn}$ but not with Fe. The highest $\mathrm{Zn}$ and $\mathrm{Ni}$ concentrations were observed in the Mn-rich core. The partial Ni-Mn association suggests that $\mathrm{Mn}$ is present in at least two forms, with only one containing $\mathrm{Ni}$. Comparison of $\mu \mathrm{SXRF}$ and $\mu \mathrm{SXRD}$ maps clearly shows that Ni and lithiophorite have the same distribution, indicating that $\mathrm{Ni}$ is exclusively bound to this Mn phase. The $\mu$ SXRD map for goethite $(\alpha-\mathrm{FeOOH})$ does not match the $\mathrm{Zn}$ elemental map, indicating that $\mathrm{Zn}$ is not associated with goethite.

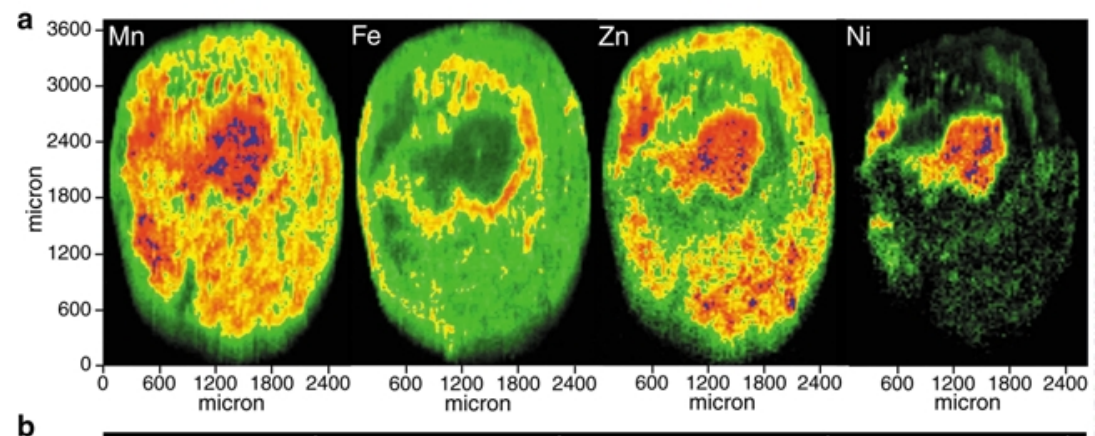

Figure $34 . \quad$ Combined
fluorescence (a) and
diffraction (b) measurements
recorded on a soil
ferromanganese nodule. The
four top images are elemental
maps obtained by $\mu$ SXRF, and
the four images on the bottom
are mineral species maps
obtained by rastering the
sample in an XY pattern,
collecting point XRD patterns,
and integrating the diffracted
intensity of the relevant (hkl)
reflections (d-spacings in
parenthesis). (from [42])

The sequestration mechanism of $\mathrm{Ni}$ inferred from $\mu \mathrm{SXRF}-\mu \mathrm{SXRD}$ was confirmed by Ni K-edge $\mu$ EXAFS measurements from selected regions of interests in this nodule, others from the same soil, and representative soils from continents (Figs. 35a,b). Nickel was demonstrated to substitute for $\mathrm{Mn}^{3+}$ in the manganese layer of lithiophorite, which is consistent with the small difference $(\Delta \mathrm{r}=7 \%)$ in their radii values.

Unlike $\mathrm{Ni}$, the $\mathrm{Zn}$ elemental map does not resemble any of the four mineral species maps, nor can it be reconstructed by a combination of several elemental maps (Fig. 34). Therefore, some $\mathrm{Zn}$-containing species are missing, and the nature and proportion of the $\mathrm{Zn}$ host phases were determined by EXAFS. The five $\mu$ EXAFS spectra recorded in different spots chosen so as to vary the proportions of component species, look like a linear combination of two end-members (Fig. 35c). However, least-squares fitting analysis indicated the presence of three predominant species, lithiophorite, birnessite, and poorly-crystallized Fe oxide (e.g., ferrihydrite), with the proportion of the third species being constant throughout the nodule. 

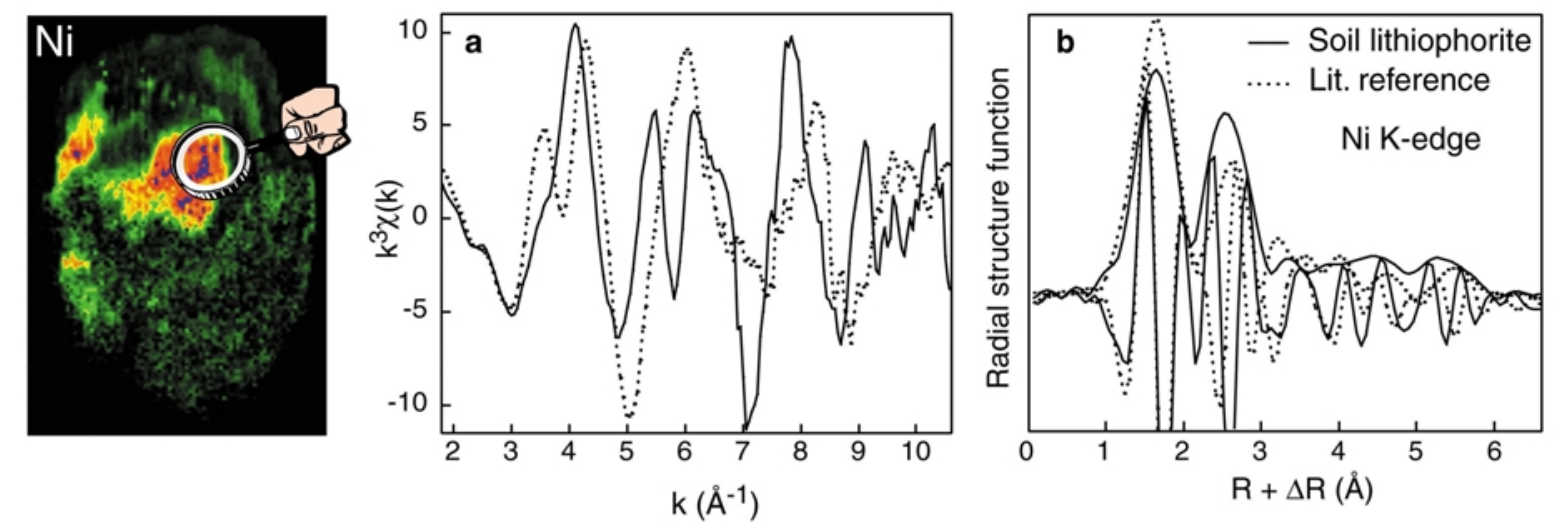

Lithiophorite reference

Soil lithiophorite

Zn-sorbed birnessite
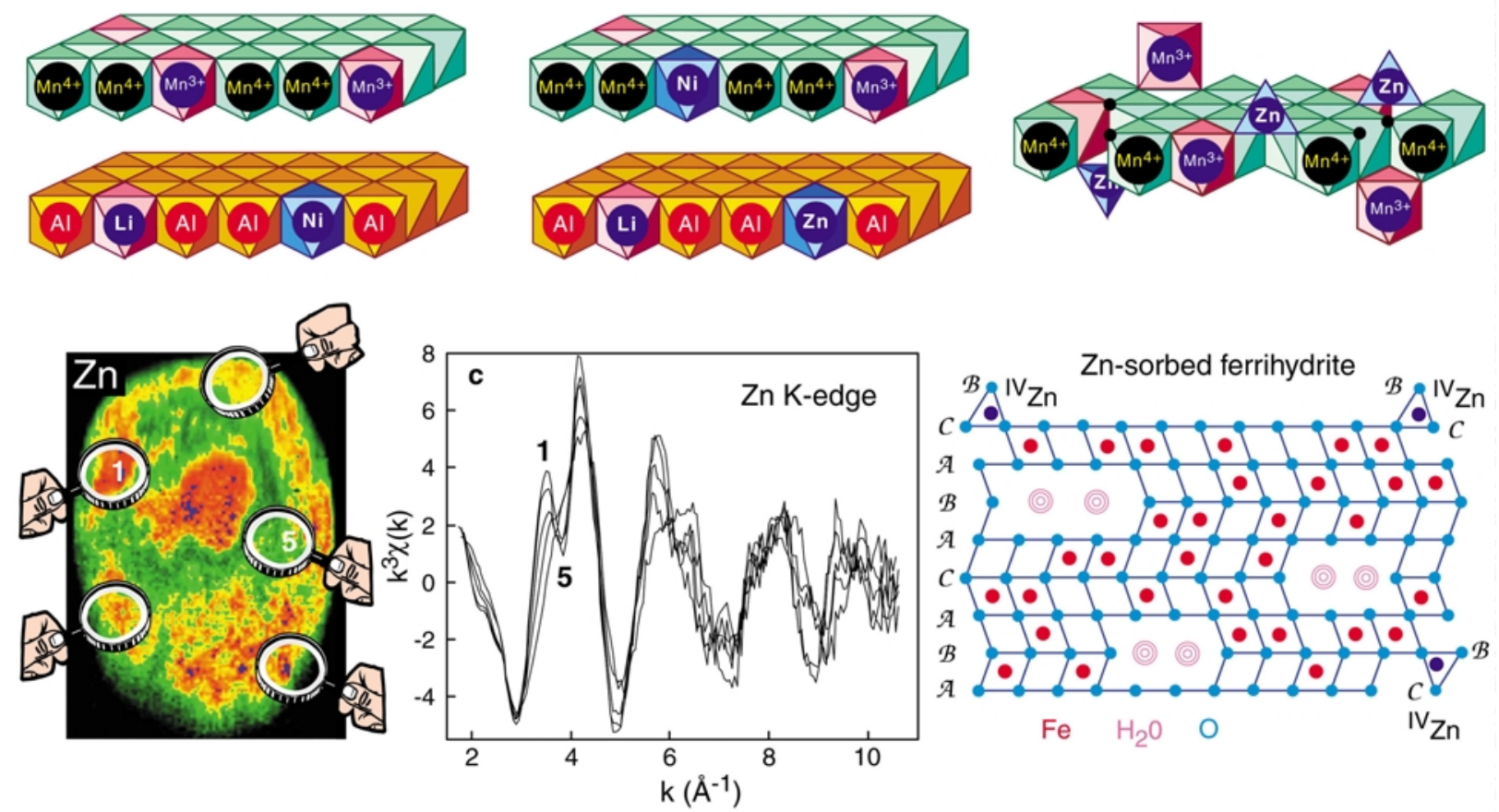

Figure 35. Molecular-level sequestration mechanism of $\mathrm{Ni}$ and $\mathrm{Zn}$ in a soil ferromanganese nodule. a,b) Ni $\mathrm{K}$ edge $\mu E X A F S$ spectrum and radial distribution function from a nodule core Ni 'hot spot', compared to a Nicontaining lithiophorite reference, in which $\mathrm{Ni}$ substitutes for $\mathrm{Li}$ in the $\mathrm{Al}(\mathrm{OH})_{3}$ layer. In the soil lithiophorite, $\mathrm{Ni}$ substitutes for $\mathrm{Mn}^{3+}$ in the $\mathrm{MnO}_{2}$ layer. c) Zn K-edge $\mu$ EXAFS spectra collected in five points-of-interests having variable $\mathrm{Mn} / \mathrm{Fe}$ ratio. $\mathrm{Zn}$ is bound to three minerals: lithiophorite, birnessite and poorly crystalline Fe oxide (ferrihydrite is used as a proxy). (from [42-44]) 


\section{Acknowledgments}

We wish to thank Dr. Alain Manceau (University J. Fourier and CNRS, Grenoble, France) for contributing a research highlight to this report. We also wish to thank all of the individuals involved in the research summarized in the twenty-four research highlights that illustrate the breadth and high quality of research being carried out by the MES community at the seven U.S. synchrotron radiation facilities. The seven U.S. synchrotron radiation user facilities are thanked for providing staff support and high quality X-ray beams that made this research possible. Profs. Keith Hodgson and Burton Richter of the Stanford Synchrotron Radiation Laboratory and the Stanford Linear Accelerator Center, respectively, are acknowledged for reviewing the final draft of this report. Finally, we wish to thank the funding agencies, particularly DOE and NSF, for supporting the SR facilities used by the MES community in the U.S. and the research reported herein.

\section{References}

[1] Brown, G.E., Jr., Henrich, V.E., Casey, W.H., Clark, D.L., Eggleston, C., Felmy, A., Goodman, D.W., Grätzel, M., Maciel, G., McCarthy, M.I., Nealson, K., Sverjensky, D.A., Toney, M.F., Zachara, J.M., Metal oxide surfaces and their interactions with aqueous solutions and microbial organisms. Chem. Rev. 1999, 99, 77-174.

[2] Brown, G.E., Jr., Sturchio, N.C., An overview of synchrotron radiation applications to low temperature geochemistry and environmental science. Rev. Mineral. Geochem. 2002, 49, 1-115.

[3] Brown, G.E., Jr., Foster, A.L., Ostergren, J.D., Mineral surfaces and bioavailability of heavy metals: a molecular-scale perspective. Proc. Nat. Acad. Sci. USA, 1999, 96, 3388-3395.

[4] Peterson, M.L., Brown, G.E., Jr., Parks, G.A., Direct XAFS evidence for heterogeneous redox at the aqueous chromium/magnetite interface. Colloids and Surfaces 1996, 107, 77-88.

[5] Duff, M.C., Newville, M., Hunter, D.B., Bertsch, P.M., Sutton, S.R., Triay, I.R., Vaniman, D.T., Eng, P., Rivers, M.L. Micro-XAS studies with sorbed plutonium on tuff. J. Synchrotron Rad. 1999, 6, 350-352.

[6] Duff, M.C., Hunter, D.B., Triay, I.R., Bertsch, P.M., Reed, D.T., Sutton, S.R., Shea-McCarthy, G., Kitten, J., Eng, P., Chipera, S.J., Vaniman, D.T., Mineral associations and average oxidation states of sorbed Pu on tuff. Environ. Sci. Technol. 1999, 33, 2163-2169.

[7] Molecular Environmental Science: Speciation, Reactivity, and Mobility of Environmental Contaminants. An Assessment of Research Opportunities and the Need for Synchrotron Radiation Facilities. Report of the DOE Molecular Environmental Science Workshop, July 5-8, 1995, Airlie Center, VA, SLAC-R-95-477, 125 p.

[8] Molecular Environmental Science and Synchrotron Radiation Facilities: An Update of the 1995 DOE Airlie Workshop on Molecular Environmental Science. Report of a DOE Workshop held at SSRL on January 17-18, 1997, Stanford, CA, SLAC-R-97-517, 59 p.

[9] Myneni, S.C.B., Luo, Y., Naslund, L.A., Cavalleri, M., Ojamae, L., Ogasawara, H., Pelmenschikov, A., Wernet, Ph., Vaterlein, P., Heske, C., Hussain, Z., Pettersson, L.G.M., Nilsson, A., Spectroscopic probing of local hydrogen-bonding structures in liquid water. J. Phys. Condensed Matter 2002, 14, L213-L219.

[10] Eng, P.J., Trainor, T.P., Brown, G.E., Jr., Waychunas, G.A., Newville, M., Sutton, S.R., Rivers, M.L., Structure of the hydrated $\alpha-\mathrm{Al}_{2} \mathrm{O}_{3}$ (0001) surface. Science 2000, 288, 1029-1033.

[11] Guenard, P. Renaud, G. Barbier, A., Gautier-Soyer, M., Determination of the $\alpha-\mathrm{Al}_{2} \mathrm{O}_{3}(0001)$ surface relaxation and termination by measurements of crystal truncation rods. Surf. Rev. Lett. 1997, 5, 321-324.

[12] Teng, H.H., Fenter, P., Cheng, L., Sturchio, N.C., Resolving orthoclase dissolution processes with atomic force microscopy and X-ray reflectivity. Geochim. Cosmochim. Acta 2001, 65, 3459-3474.

[13] Fenter, P., Teng, H., Geissbuhler, P., Hanchar, J.M., Nagy, K.L., Sturchio, N.C., Atomic-scale structure of the orthoclase (001)-water interface measured with high-resolution X-ray reflectivity. Geochim. Cosmochim. Acta 2000, 64, 3663-367.

[14] Berner RA, Lasaga AC, Garrels RM, The carbonate-silicate geochemical cycle and its effect on atmospheric carbon dioxide over the past 100 million years. Am. J. Sci. 1983, 283, 641-683. 
[15] Myneni, S.C.B., Brown, J.T., Martinez, G.A., Meyer-Ilse, W., Imaging of humic substance macromolecular structures in water and soils. Science 1999, 286, 1335-1337.

[16] Reeder, R.J., Nugent, M., Tait, C.D., Morris, D.E., Heald, S.M., Beck, K.M., Hess, W.P., and Lanzirotti, A., Coprecipitation of uranium(VI) with calcite: XAFS, micro-XAS, and luminescence characterization. Geochim. Cosmochim. Acta 2001, 65, 3491-3503.

[17] Elzinga, E.J., Reeder, R.J., EXAFS study of $\mathrm{Cu}^{2+}$ and $\mathrm{Zn}^{2+}$ adsorption complexes at the calcite surface Implications for site-specific metal incorporation preferences during calcite crystal growth. Geochim. Cosmochim. Acta 2002 66, 3943-3954.

[18] Templeton, A.S., Trainor, T.P., Traina, S.J., Spormann, A.M., Brown, G.E., Jr., Pb(II) distribution at biofilmmetal oxide interfaces. Proc. Nat. Acad. Sci. USA 2001, 98, 11897-11902.

[19] Pecher, K., Kneedler, E., McCubbery, D., Meigs, G., Tonner, B., Characterization of reactive transition metal precipitates using scanning transmission x-ray microscopy (STXM). Preprints of Extended Abstracts presented at the ACS National Meeting, American Chemical Society, Division of Environmental Chemistry 2000, $40(2), 323-325$.

[20] Myneni, S.C.B., Tokunaga, T.K., Brown, G.E., Jr., Abiotic selenium redox transformations in the presence of Fe(II,III) hydroxides. Science 1997, 278, 1106-1109.

[21] Bargar, J.R., Tebo, B.M., Pecher, K.H., Chiu, V., Villinski, J.E., Tonner, B.P., Kinetics and products of Mn oxide biomineralization by spores of the marine Bacillus sp. strain SG-1. Preprints of Extended Abstracts presented at the ACS National Meeting, American Chemical Society, Division of Environmental Chemistry 2000, 40(2), 491-493.

[22] Hansel, C.M., Fendorf, S., Sutton, S., Newville, M., Characterization of Fe plaque and associated metals on the roots of mine-waste impacted aquatic plants. Environ. Sci. Technol. 2001, 35, 3863-3868.

[23] Hansel, C.M., LaForce, M.J., Fendorf, S.E., Spatial and temporal association of Fe and As species on minewaste impacted aquatic plant roots. Environ. Sci. Technol. 2002, 36, 1988-1994.

[24] Hunter, D.B., Bertsch, P.M., Kemner, K.M., Clark, S.B., Distribution and chemical speciation of metals and metalloids in biota collected from contaminated environments by spatially resolved XRF, XANES, and EXAFS. J. Phys. IV 1997, 7 (Colloque C2, X-ray Absorption Fine Structure, Vol. 2), 767-771.

[25] Reeder, R.J., Nugent, M., Pabalan, R.T., Local structure of uranium(VI) sorbed on clinoptilolite and montmorillonite. In: Cidu, R. (ed.), Water-Rock Interaction, A.A. Balkema Publishers, Lisse, The Netherlands, pp 423-426, 2001.

[26] Steponkus, P.L., Uemura, M., Joseph, R.A., Gilmour, S.J., Thomashow, M.F., Mode of action of the COR15a gene on the freezing tolerance of Arabidopsis thaliana. Proc. Nat. Acad. Sci. 1998, 95, 14570-14575.

[27] Zachara, J.M., Ainsworth, C.C., Brown, G.E., Jr., Catalano, J.G., McKinley, J.P., Oafoku, O., Smith, S.C., Szecsody, J.E., Traina, S.J., Warner, J.A., Chromium speciation and mobility in a high level nuclear waste vadose zone plume. Geochim. Cosmochim. Acta 2003 (in press).

[28] Neu, M.P., Runde, W.H., Clark, D.L., Conradson, S.D., Efurd, D.W., Janecky, D.R., Kaszuba, J.P., Tait, C.D., Haire, R.G., Plutonium speciation and its effects on environmental migration. Book of Abstracts, 218th ACS National Meeting, New Orleans, LA, Aug. 22-26, 1999.

[29] Clark, D.L., Conradson, S.D., Donohoe, R.J., Keogh, D.W., Morris, D.E., Palmer, P.D., Rogers, R.D., Tait, C.D., Chemical speciation of the uranyl ion under highly alkaline conditions. Synthesis, structures, and oxo ligand exchange dynamics. Inorg. Chem. 1999, 38, 1456-1466.

[30] Clark, D.L., Conradson, S.D., Neu, M.P., Palmer, P.D., Runde, W., Tait, C.D., XAFS structural determination of $\mathrm{Np}$ (VII). Evidence for a trans dioxo cation under alkaline solution conditions. J. Am. Chem. Soc. 1997, $119,5259-5260$.

[31] Neu, M.P., Clark, D.L., Conradson, S.D., Donohoe, R.J., Gordon, J.C., Keogh, D.W., Morris, D.E., Rogers, R.D., Scott, B.L., Tait, C.D., Structure and stability of actinides (U, Np, Pu) under strongly alkaline radioactive waste tank conditions. Book of Abstracts, 218th ACS National Meeting, New Orleans, LA, Aug. 22-26, 1999.

[32] Tait, C.D., Clark, D.L., Conradson, S.D., Donohoe, R.J., Gordon, J.C., Gordon, P.L., Keogh, D.W., Konze, W.V., Morris, D.E., Effect of aluminate on the speciation of the actinides under tank waste conditions. Abstracts of Papers, 222nd ACS National Meeting, Chicago, IL, August 26-30, 2001.

[33] Fuller C.C., Bargar, J.R., Davis, J.A., Piana, M.J., Mechanisms of uranium interactions with hydroxyapatite: Implications for groundwater remediation. Environ. Sci. Technol. 2002, 36, 158-165. 
[34] Fuller, C.C., Bargar, J.R., Piana, M.J., Davis, J.A., Molecular-scale characterization of uranium sorption by apatite materials from a permeable reactive barrier demonstration. Environ. Sci. Technol. 2002 (submitted).

[35] Freethey, G.F., Naftz, D.L., Rowland, R.C., Davis, J.A. Deep Aquifer Remediation Tools: Theory, Design, and Performance Modeling; Naftz, D.L., Morrison, S.J., Davis, J.A. and Fuller, C.C. (Eds.), Academic Press, San Diego, 2002, pp 133-163.

[36] Morrison, S.J., Spangler, R.R. Chemical barriers for controlling groundwater contamination. Environ Progress 1992, 12, 175-181.

[37] Allen, P.G., Siemering, G.S., Shuh, D.K., Bucher, J.J., Edelstein, N.M., Langton, C.A. Clark, S.B., Reich, T., MA Denecke, M.A., Technetium speciation in cement waste forms determined by X-ray absorption fine structure spectroscopy, Radiochimca Acta 1997, 76, 77-86.

[38] Lukens, W.W., Jr., Bucher, J.J., Edelstein, N.M., Shuh, D.K., Products of pertechnetate radiolysis in highly alkaline solutions: Structure of $\mathrm{TcO}_{2} \bullet \mathrm{xH}_{2} \mathrm{O}$. Environ. Sci. Technol. 2002, 36, 1124-1129.

[39] Blanchard, D.L., Brown, G.N., Conradson, S.D., Fadeff, D.K., Golcar, G.R., Hess, N.J., Klinger, G.S., Kurath, D.E., Technetium in Alkaline, High-Salt, Radioactive Tank Waste Supernate: Preliminary Characterization and Removal, PNNL-11386, 1995, PNNL, Richland, WA.

[40] Labrenz, M., Druschel, G.K., Thomsen-Ebert, T., Gilbert, B., Welch, S.A., Kemner, K.M., Logan, G.A., Summons, R.E., De Stasio, G., Bond, P.L., Lai, B., Kelly, S.D., Banfield, J.F., Formation of sphalerite (ZnS) deposits in natural biofilms of sulfate-reducing bacteria. Science 2000, 290, 1744-1747.

[41] Stegemann, J. A., Roy, A., Caldwell, R. J., and Schilling, P. J., Understanding environmental leachability of electric arc furnace dust. J. Environ. Eng. 2000, 126, 112-20.

[42] Manceau, A., Tamura, N., Marcus, M.A., MacDowell, A.A., Celestre, R.S., Sublett, R.E., Sposito, G., Padmore, H.A., Deciphering Ni sequestration in soil ferromanganese nodules by combining X-ray fluorescence, absorption and diffraction at micrometer scales of resolution, Am. Mineral. 2002, 87, 1494-1499.

[43] Manceau, A., Marcus, M.A., Tamura, N., Quantitative speciation of heavy metals in soils and sediments by synchrotron X-ray techniques. In: Applications of Synchrotron Radiation in Low-Temperature Geochemistry and Environmental Science, P. Fenter, S. Sutton, M. Rivers, N.C. Sturchio (eds.), Rev. Mineral. Geochem. 2002, 49, 341-428.

[44] Manceau, A., Tamura, N., Celestre, R.S., MacDowell, A.A., Sposito, G., Padmore, H.A., Molecular-scale speciation of $\mathrm{Zn}$ and $\mathrm{Ni}$ in soil ferromanganese nodules from loess soils of the Mississippi Basin. Environ. Sci. Technol. 2003, 37, 75-80. 


\section{Appendix A. Description of MES-related Beam Lines at Synchrotron Radiation Labs}

\section{Advanced Light Source}

Lawrence Berkeley National Laboratory, Berkeley, CA 94720

Home Page: http://www-als.lbl.gov

Beamline Specifications Page: http://www-

als.lbl.gov/als/als users bl/bl table.html

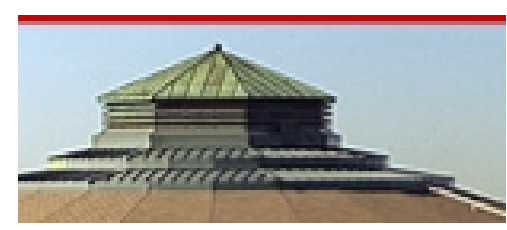

\begin{tabular}{|c|c|c|c|}
\hline Beamline & Techniques & Beam Characteristics & Contact \\
\hline 1.4 .3 & Infrared Spectromicroscopy & $\begin{array}{l}\text { Bend, } 0.05-1.0 \mathrm{eV}, \sim 1 \mu \mathrm{m} \text { spatial, } 0.125 \\
\mathrm{~cm}^{-1} \text { energy res., reflection/transmission }\end{array}$ & $\begin{array}{l}\text { Michael Martin } \\
\text { MCMartin@lbl.gov } \\
510-495-2231\end{array}$ \\
\hline 6.1 .2 & $\begin{array}{l}\text { Spectromicroscopy/NEXAFS } \\
\text { imaging }\end{array}$ & $\begin{array}{l}\text { Bend, } 300-900 \mathrm{eV}, 1 \mathrm{k}^{2} \text { pixels, } 1 \mathrm{k} \mathrm{ph} / \text { pixel, } \\
\text { in } 3 \mathrm{~s} \text { at } 517 \mathrm{eV}\end{array}$ & $\begin{array}{l}\text { Gregory Denbeaux } \\
\text { GPDenbeaux@lbl.gov } \\
\text { 510-486-4051 }\end{array}$ \\
\hline 6.3 .1 & XAFS & Bend, $500-2000 \mathrm{eV}, 10^{11} \mathrm{ph} / \mathrm{s}$ & $\begin{array}{l}\text { Rupert Perera } \\
\text { rcperera@ } 1 \text { lbl.gov } \\
510-495-2062\end{array}$ \\
\hline 7.0 .1 & $\begin{array}{l}\text { Soft X-ray emission, SPEM, } \\
\text { PES, ultraESCA, NEXAFS }\end{array}$ & $\begin{array}{l}\text { Undulator; } 60-1200 \mathrm{eV}, 40 \mathrm{~nm} \text { spatial res. } \\
\text { and } \mathrm{E} / \Delta \mathrm{E}=\sim 3000,10^{12} \mathrm{ph} / \mathrm{s} \text { at } 0.01 \% \mathrm{BW}\end{array}$ & $\begin{array}{l}\text { Eli Rotenberg } \\
\text { erotenberg@1bl.gov } \\
510-486-5975\end{array}$ \\
\hline 7.3 .3 & $\mu \mathrm{XRD}$ & Bend, $6-12 \mathrm{KeV}, 10^{9} \mathrm{ph} / \mathrm{s}, 1 \mu \mathrm{m}$ spot & $\begin{array}{l}\text { Nobumichi Tamura } \\
\text { Ntamura@1bl.gov } \\
510-486-6189\end{array}$ \\
\hline 8.0 .1 & $\begin{array}{l}\text { Imaging photoelectron } \\
\text { spectroscopy/soft X-ray } \\
\text { emission }\end{array}$ & $\begin{array}{l}\text { Undulator, } 65-1400 \mathrm{eV}, 10^{11}-10^{15} \mathrm{ph} / \mathrm{s} \text { per } \\
\text { res. and energy, } 100 \mu \mathrm{m} \text { spot }\end{array}$ & $\begin{array}{l}\text { Jonathan Denlinger } \\
\text { JDDenlinger@lbl.gov } \\
\text { 510-486-5648 }\end{array}$ \\
\hline 8.3 .2 & Tomography & $\begin{array}{l}\text { Superbend, } 3-45 \mathrm{KeV}, 10^{11} \mathrm{ph} / \mathrm{s} @ 10 \mathrm{KeV} \text {, } \\
0.1-0.6 \times 6 \mathrm{~cm}\end{array}$ & $\begin{array}{l}\text { Malcom Howells } \\
\text { MRHowells@lbl.gov } \\
510-486-4949 \\
\end{array}$ \\
\hline 9.3 .1 & NEXAFS/Photoemission & Bend, 2.2-6.0 KeV: $10^{11} \mathrm{ph} / \mathrm{s}$ & $\begin{array}{l}\begin{array}{l}\text { Fred Schlachter } \\
\text { fsschlachter@lbl.gov }\end{array} \\
510-486-6499\end{array}$ \\
\hline 9.3 .2 & XAFS & Bend, $30-1400 \mathrm{eV}: 10^{11} \mathrm{ph} / \mathrm{s}$ & $\begin{array}{l}\text { Fred Schlachter } \\
\text { fsschlachter@1bl.gov } \\
510-486-6499\end{array}$ \\
\hline 10.3 .1 & $\mu \mathrm{XRF}$ & $\begin{array}{l}\text { Bend, } 3-20 \mathrm{KeV}, 3 \times 10^{10} \mathrm{ph} / \mathrm{s} \text {, at } 12.5 \\
\mathrm{KeV}, 1 \mu \mathrm{m} \text { spot }\end{array}$ & $\begin{array}{l}\text { Al Thompson } \\
\text { ACThompson@lbl.gov } \\
510.486 .5590\end{array}$ \\
\hline 10.3 .2 & $\mu \mathrm{XAFS}$ & $\begin{array}{l}\text { Bend, } 3-17 \mathrm{KeV}, 10^{10} \mathrm{ph} / \mathrm{s} / 0.03 \% \mathrm{BW}, 5 \\
\mu \mathrm{m} \text { spot }\end{array}$ & $\begin{array}{l}\text { Matthew Marcus } \\
\text { MAMarcus@1bl.gov } \\
510.486 .587\end{array}$ \\
\hline 11.0 .2 & $\begin{array}{l}\text { Soft X-ray Fluorescence } \\
\text { Spectroscopy/Photoemission/ } \\
\text { NEXAFS (MES beam line) }\end{array}$ & $\begin{array}{l}\text { EP Undulator, } 75-2000 \mathrm{eV}, 10^{12} \mathrm{ph} / \mathrm{s}, 5 \mathrm{x} \\
15 \mu \mathrm{m} \text { spot }\end{array}$ & $\begin{array}{l}\text { David Shuh } \\
\text { DKShuh@lbl.gov } \\
510.486 .6937\end{array}$ \\
\hline
\end{tabular}

NEXAFS = Near-Edge X-ray Absorption Fine Structure Spectroscopy

$\mathrm{XAFS}=\mathrm{X}$-ray Absorption Spectroscopy

$\mathrm{XRF}=\quad \mathrm{X}$-ray Fluorescence

SPEM $=$ Scanning photoemission microscope

$\mathrm{ESCA}=\quad$ Electron spectroscopy for chemical analysis 


\section{Advanced Photon Source}

Argonne National Laboratory, Argonne, IL 60440

Home Page: http://www.aps.anl.gov

Beamline Specifications Page:

http://www.aps.anl.gov/aps/frame_beamtime.html

\begin{tabular}{|c|c|c|c|}
\hline Beamline & Techniques & Beam Characteristics & Contact \\
\hline 2-ID-D (XOR) & $\begin{array}{l}\mu \mathrm{XRF}, \mu \mathrm{XRD} \\
\mu \mathrm{XANES}\end{array}$ & $\begin{array}{l}\text { Undulator, } 2-32 \mathrm{KeV}, 10^{11} \mathrm{ph} / \mathrm{s} \\
\text { @ } 10 \mathrm{KeV}, 100 \mathrm{~nm} \text { beam spot. }\end{array}$ & $\begin{array}{l}\text { Barry Lai (blai@aps.anl.gov) } \\
\text { 630-252-6405 }\end{array}$ \\
\hline 2-ID-E (XOR) & $\mu \mathrm{XRF}$ & $\begin{array}{l}\text { Undulator, } 7-12 \mathrm{KeV}, 10^{9} \mathrm{ph} / \mathrm{s} \\
\text { @ } 10 \mathrm{KeV}, 400 \mathrm{~nm} \text { focused, } 2 \\
\text { mm unfocused. }\end{array}$ & $\begin{array}{l}\text { Jorg Maser (maser@aps.anl.gov) } \\
\text { 630-252-1091 }\end{array}$ \\
\hline 2-BM-B (XOR) & Tomography, XRD & Bend, 3-33 KeV, 100x2mm & $\begin{array}{l}\text { Francesco de Carlo } \\
\text { (decarlo@ aps.anl.gov) } \\
630-252-0148\end{array}$ \\
\hline $\begin{array}{l}\text { 5-BM-D } \\
\text { (DND) }\end{array}$ & XAFS & Bend, 4.5-25 KeV, 30x5 mm & $\begin{array}{l}\text { Jean Francois Gaillard } \\
\text { (Jf-gaillard@ @orthwestern.edu) } \\
\text { 847-467-1376 }\end{array}$ \\
\hline $\begin{array}{l}\text { 5-ID-B } \\
\text { (DND) }\end{array}$ & XRF imaging & $\begin{array}{l}\text { Undulator, } 4.5-25 \mathrm{KeV}, 5 \mu \mathrm{m} \\
\text { spot }\end{array}$ & $\begin{array}{l}\text { John Quintana (jpq@nwu.edu) } \\
\text { 630-252-0221 }\end{array}$ \\
\hline 10-ID-B (MR) & XAFS, $\mu$ XAFS & $\begin{array}{l}\text { Undulator, } 4.8-32 \mathrm{KeV}, 5 \mu \mathrm{m} \\
\text { spot }\end{array}$ & $\begin{array}{l}\text { Ken Kemner (kemner@ anl.gov) } \\
630-252-1163\end{array}$ \\
\hline $\begin{array}{c}\text { 11-ID-C } \\
\text { (BESSRC) }\end{array}$ & $\begin{array}{l}\text { High energy } \\
\text { scattering }\end{array}$ & Elliptical Wiggler, $40-200 \mathrm{KeV}$ & $\begin{array}{l}\text { Mark Beno (beno@anl.gov) } \\
\text { 630-252-3507 }\end{array}$ \\
\hline $\begin{array}{l}\text { 11-ID-D } \\
\text { (BESSRC) }\end{array}$ & XAFS, XRD & Elliptical Wiggler, 4-50 KeV & $\begin{array}{l}\text { Mark Beno (beno@ anl.gov) } \\
630-252-3507\end{array}$ \\
\hline $\begin{array}{l}\text { 12-BM-B } \\
\text { (BESSRC) }\end{array}$ & XAFS, XRD & Bend, 2.4-100 KeV & $\begin{array}{l}\text { Paul Fenter (fenter@ anl.gov) } \\
630-2552-7053\end{array}$ \\
\hline $\begin{array}{l}\text { 12-ID-D } \\
\text { (BESSRC) }\end{array}$ & $\begin{array}{l}\text { Scattering, XPS, } \\
\text { standing waves, XRD }\end{array}$ & Undulator, 3-27 KeV & $\begin{array}{l}\text { Paul Fenter (fenter@ anl.gov) } \\
630-2552-7053\end{array}$ \\
\hline $\begin{array}{c}\text { 13-ID-C } \\
\text { (GSECARS) }\end{array}$ & $\begin{array}{l}\mu \mathrm{XRF}, \mu \mathrm{XAFS}, \\
\text { scattering, XRD, } \\
\text { fluorescence } \mu- \\
\text { tomography, } \\
\text { GIXAFS }\end{array}$ & $\begin{array}{l}\text { Undulator, } 4-50 \mathrm{KeV}, 10^{12}-10^{13} \\
\mathrm{ph} / \mathrm{s} @ 10 \mathrm{KeV}, 3 \mu \mathrm{m} \text { spot } \\
\text { microfocused, } 30 \mu \mathrm{m} \text { spot } \\
\text { beamline mirror focused. }\end{array}$ & $\begin{array}{l}\begin{array}{l}\text { Steve Sutton } \\
\text { (sutton@ cars.uchicago.edu) }\end{array} \\
630-252-0426\end{array}$ \\
\hline $\begin{array}{l}\text { 13-BM-D } \\
\text { (GSECARS) }\end{array}$ & $\begin{array}{l}\text { Tomography, XAFS, } \\
\text { XRD }\end{array}$ & $\begin{array}{l}\text { Bend, 5-70 KeV, } 10^{11} \mathrm{ph} / \mathrm{s} @ 10 \\
\mathrm{KeV}, 30 \times 1 \mathrm{~mm}\end{array}$ & $\begin{array}{l}\text { Mark Rivers } \\
\text { (rivers@cars.uchicago.edu) } \\
630-252-0422\end{array}$ \\
\hline $\begin{array}{l}\text { 18-ID } \\
\text { (BIO) }\end{array}$ & XAFS & $\begin{array}{l}\text { Undulator, } 3.5-35 \mathrm{KeV}, 5 \times 2 \mathrm{~mm} \\
\text { unfocused, } 200 \times 20 \mu \mathrm{m} \text { focused }\end{array}$ & $\begin{array}{l}\text { Raul Barrea } \\
\text { (barrea@ bio.aps.anl.gov) } \\
630-252-0541\end{array}$ \\
\hline $\begin{array}{l}20-\mathrm{ID} \\
\text { (PNC) }\end{array}$ & $\begin{array}{l}\mu \mathrm{XRF}, \mu \mathrm{XAFS} \\
\mu \mathrm{XRD}\end{array}$ & $\begin{array}{l}\text { Undulator, 3-50 KeV, } 10^{12}-10^{13} \\
\text { ph/s @ } 10 \mathrm{KeV}, 5 \mu \mathrm{m} \text { spot }\end{array}$ & $\begin{array}{l}\text { Steve Heald (heald@aps.anl.gov) } \\
630-252-9795\end{array}$ \\
\hline $\begin{array}{l}20-\mathrm{BM} \\
\text { (PNC) }\end{array}$ & Tomography, XRD & $\begin{array}{l}\text { Bend, 3.5-27 KeV, } 10^{11} \mathrm{ph} / \mathrm{s} @ \\
10 \mathrm{KeV}, 30 \times 1 \mathrm{~mm} \text { unfocused, } \\
50 \times 100 \mu \mathrm{m} \text { focused }\end{array}$ & $\begin{array}{l}\text { Steve Heald (heald@aps.anl.gov) } \\
\text { 630-252-9795 }\end{array}$ \\
\hline
\end{tabular}

GIXAFS $=$ Grazing Incidence XAFS

$\mathrm{XAFS}=\quad \mathrm{X}$-ray Absorption Fine Structure Spectroscopy

$\mathrm{XANES}=\mathrm{X}$-ray Absorption Near-Edge Structure Spectroscopy

$\mathrm{XPS}=\quad \mathrm{X}$-ray Photoelectron Spectroscopy

$\mathrm{XRD}=\quad \mathrm{X}$-ray Diffraction

$\mathrm{XRF}=\mathrm{X}$-ray Fluorescence 
Center for Advanced Microstructures and Devices

Louisiana State University

6980 Jefferson Hwy

Baton Rouge, LA 70806

Home Page: http://www.camd.lsu.edu/

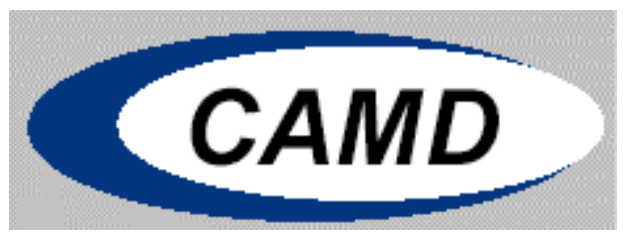

Environmental Science Liaison: Amitava Roy (225) 578-6706, reroy@1se.edu

User Administration: Lee Ann Broussard (225) 578-4606, leeann@1su.edu

\begin{tabular}{|l|l|l|l|}
\hline Beamline & Techniques & Beam Characteristics & $\begin{array}{l}\text { Special } \\
\text { Capabilities }\end{array}$ \\
\hline 5B & XAFS, XRF & $1.2-12 \mathrm{keV}$ & $\begin{array}{l}\text { DCM, InSb and YB } 66 \\
\text { crystals, windowless }\end{array}$ \\
\hline $5 \mathrm{~A}$ & X-ray Microprobe & $1.2-12 \mathrm{keV}, 15 \times 15 \mu \mathrm{m}^{2}$ & $\begin{array}{l}\text { DCM, KB mirrors, Ge } \\
\text { array detector }\end{array}$ \\
\hline & $\begin{array}{l}\text { Small angle scattering } \\
\text { /GIXAFS }\end{array}$ & $2.5-13 \mathrm{keV}$ & Pink (filtered) radiation \\
\hline 7A & Microtomography/XRF & (under construction) & $\begin{array}{l}\text { Microscope and FTIR } \\
\text { spectrometer }\end{array}$ \\
\hline & $\begin{array}{l}\text { Infrared spectroscopy } \\
\text { Element-specific } \\
\text { Microtomography/XAFS }\end{array}$ & Wiggler (under construction) & $\begin{array}{l}\text { DCM and multilayer } \\
\text { monochromator }\end{array}$ \\
\hline
\end{tabular}

$\mathrm{XAFS}=\quad \mathrm{X}$-ray Absorption Spectroscopy

GIXAFS $=\quad$ Grazing Incidence X-ray Absorption Fine Structure

$\mathrm{XRF}=\quad \mathrm{X}$-ray Fluorescence 


\section{Cornell High Energy Synchrotron Source}

200L Wilson Lab

Rt. 366 \& Pine Tree Road

Ithaca, NY 14853

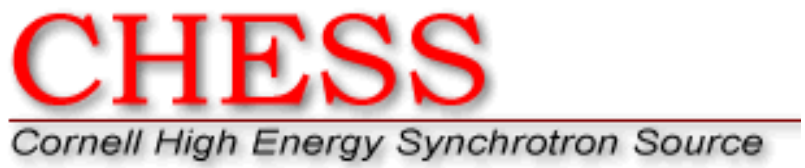

Home Page: http://www.chess.cornell.edu/

Technical Issues: Ernest Fontes (607) 255-2959, ef11 @ cornell.edu

User Administration: Lana Walsh (607) 255-0920, 1lw3@ cornell.edu

\begin{tabular}{|c|c|c|c|}
\hline Beamline & Techniques & Beam Characteristics & Special Capabilities \\
\hline A2 & $\begin{array}{l}\text { High-res diffraction } \\
\text { Radiography }\end{array}$ & Wiggler, 6-50 keV, double focus & 6-circle diffractometer \\
\hline B2 & XAFS & Bend & $\begin{array}{l}\text { Image plates, solid-state } \\
\text { detectors }\end{array}$ \\
\hline $\mathrm{C} 1$ & $\begin{array}{l}\text { High-res diffraction, } \\
\text { Inelastic scattering }\end{array}$ & $\begin{array}{l}\text { Bend, } 6-25 \mathrm{keV} \text {, straight and side bounce } \\
\text { focusing }\end{array}$ & $\begin{array}{l}\text { 6-circle diffractometer, } \\
\text { CCD }\end{array}$ \\
\hline D1 & SAXS, Radiography & $\begin{array}{l}\text { Bend, 6-20 keV, wide-bandpass } \\
\text { multilayer }\end{array}$ & $\mathrm{CCD}$, vacuum flight tubes \\
\hline F3 & $\begin{array}{l}\text { Powder diffraction, } \\
\text { general diffraction }\end{array}$ & Bend, 6-25 keV, wide-bandpass capable & $\begin{array}{l}\text { Kappa geometry } \\
\text { oscillation camera }\end{array}$ \\
\hline G1 & SAXS, GISAXS & $\begin{array}{l}\text { Wiggler, } 8-16 \mathrm{keV} \text {, double-focus capable, } \\
\text { wide-bandpass optics }\end{array}$ & $\mathrm{CCD}$ \\
\hline G2 & High-res diffraction & Wiggler, side-bounce transmission crystal & $\begin{array}{l}\text { Horizontal and vertical } \\
\text { diffractometers }\end{array}$ \\
\hline G3 & High-res diffraction & $\begin{array}{l}\text { Wiggler, double-focus capable, wide- } \\
\text { bandpass optics }\end{array}$ & $\begin{array}{l}\text { UHV growth chamber } \\
\text { and fluorine laser }\end{array}$ \\
\hline
\end{tabular}

$\mathrm{XAFS}=\quad \mathrm{X}$-ray Absorption Spectroscopy

SAXS $=\quad$ Small Angle X-ray Scattering

GISAXS $=\quad$ Grazing Incidence Small Angle Scattering 
National Synchrotron Light Source

Brookhaven National Laboratory, Upton, NY 11973

Home Page: http://nslsweb.nsls.bnl.gov

Beamline Specifications Page:

http://nslsweb.nsls.bnl.gov/nsls/beamlines/beaminfo.htm

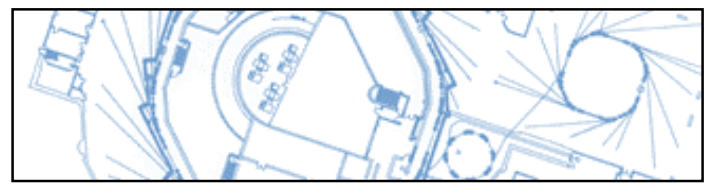

\begin{tabular}{|c|c|c|c|}
\hline Beamline & Techniques & Beam Characteristics & Contact \\
\hline U2B & $\begin{array}{l}\text { IR spectroscopy, } \\
\text { microspectroscopy }\end{array}$ & Bend, $50-4000 \mathrm{~cm}^{-1}, 3-10 \mu \mathrm{m}$ & $\begin{array}{l}\text { Lisa Miller } \\
\text { lmiller@bnl.gov } \\
631-344-2091 \\
\end{array}$ \\
\hline U7A & XAFS, XPS & Bend, $180-1200 \mathrm{eV}$ & $\begin{array}{l}\begin{array}{l}\text { Daniel Fischer } \\
\text { dfischer@bnl.gov }\end{array} \\
631-344-5177 \\
\end{array}$ \\
\hline U10B & IR microspectroscopy & Bend, $50-4000 \mathrm{~cm}^{-1}, 3-10 \mu \mathrm{m}$ & $\begin{array}{l}\text { Lisa Miller } \\
\text { lmiller@bnl.gov } \\
631-344-2091\end{array}$ \\
\hline $\mathrm{X} 1 \mathrm{~A} 1$ & $\begin{array}{l}\text { Soft X-ray imaging and } \\
\text { XANES }\end{array}$ & $\begin{array}{l}\text { Undulator, } 250-400 \mathrm{eV}, 30-50 \\
\mathrm{~nm} \text { spot }\end{array}$ & $\begin{array}{l}\text { Chris Jacobsen } \\
\text { Chris.Jacobsen@ stonybrook.edu } \\
631-344-7570\end{array}$ \\
\hline $\mathrm{X} 1 \mathrm{~A} 2$ & $\begin{array}{l}\text { Soft X-ray imaging and } \\
\text { XANES }\end{array}$ & $\begin{array}{l}\text { Undulator, } 350-900 \mathrm{eV}, 30-50 \\
\text { nm spot }\end{array}$ & $\begin{array}{l}\text { Chris Jacobsen } \\
\text { Chris.Jacobsen@ stonybrook.edu } \\
631-344-7570\end{array}$ \\
\hline X3B1 & $\begin{array}{l}\text { Powder diffraction, } \\
\text { XAFS }\end{array}$ & Bend, 6-30 KeV, mm spot & $\begin{array}{l}\text { Peter Stephens } \\
\text { pstephens@ sunysb.edu } \\
631-632-8156\end{array}$ \\
\hline $\mathrm{X} 7 \mathrm{~A}$ & Powder diffraction & Bend, 4-45 KeV, mm spot & $\begin{array}{l}\text { Thomas Vogt } \\
\text { tvogt@bnl.gov } \\
631-344-3731\end{array}$ \\
\hline $\mathrm{X} 11 \mathrm{~A}$ & XAFS & Bend, $4.5-35 \mathrm{KeV}$, mm spot & $\begin{array}{l}\text { Lisa Tranquada } \\
\text { ltran@bnl.gov } \\
631-344-7731\end{array}$ \\
\hline $\mathrm{X} 19 \mathrm{~A}$ & XAFS & Bend, 2-8 KeV, mm spot & $\begin{array}{l}\text { Wolfgang Caliebe } \\
\text { caliebe@bnl.gov } \\
631-344-4744\end{array}$ \\
\hline $\mathrm{X} 23 \mathrm{~A} 2$ & XAFS, DAFS, XRD & Bend, $4.7-30 \mathrm{KeV}$, mm spot & $\begin{array}{l}\text { Joseph Woicik } \\
\text { woicik@ bnl.gov } \\
631-344-5236\end{array}$ \\
\hline $\mathrm{X} 26 \mathrm{~A}$ & $\mu \mathrm{XRF}, \mu \mathrm{XAFS}, \mu \mathrm{XRD}$ & Bend, 3-30 KeV, 7-10 $\mu \mathrm{m}$ spot & $\begin{array}{l}\text { Tony Lanzirotti } \\
\text { lanzirotti@bnl.gov } \\
\text { 631-344-5626 }\end{array}$ \\
\hline $\mathrm{X} 18 \mathrm{~B}$ & XAFS & Bend, 5.7-40 KeV, mm spot & $\begin{array}{l}\text { Syed Khalid } \\
\text { khalid@bnl.gov } \\
\text { 631-344-7496 }\end{array}$ \\
\hline $\mathrm{X} 23 \mathrm{~B}$ & XAFS, XRD & Bend, 3-10.5 KeV, mm spot & $\begin{array}{l}\text { Lisa Tranquada } \\
\text { ltran@bnl.gov } \\
631-344-7731\end{array}$ \\
\hline $\mathrm{X} 27 \mathrm{~A}$ & Tomography & Bend, $8-40 \mathrm{KeV}, 3 \mu \mathrm{m}$ spot & $\begin{array}{l}\text { Keith Jones } \\
\text { kwj@bnl.gov } \\
631-344-4588\end{array}$ \\
\hline
\end{tabular}

DAFS $=\quad$ Diffraction Anomalous Fine Structure Spectroscopy

XAFS $=\quad$ X-ray Absorption Fine Structure Spectroscopy

$\mathrm{XANES}=\mathrm{X}$-ray Absorption Near-Edge Structure Spectroscopy

$\mathrm{XPS}=\quad \mathrm{X}$-ray Photoelectron Spectroscopy

$\mathrm{XRD}=\quad \mathrm{X}$-ray Diffraction

$\mathrm{XRF}=\mathrm{X}$-ray Fluorescence 


\section{Stanford Synchrotron Radiation Laboratory}

Stanford Linear Accelerator Center

2575 Sand Hill Road

Menlo Park, California, 94025

Home Page: http://www-ssrl.slac.stanford.edu

Beamline Specifications Page: http://www-ssrl.slac.stanford.edu/beamlines/

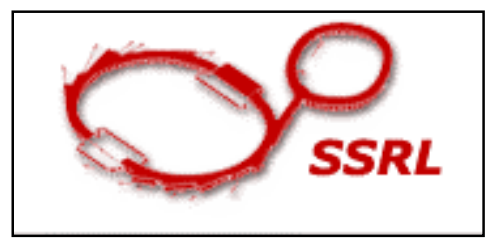

Contacts:

Beam Lines and Technical Issues: John Bargar (650-926-4949) bargar@ssrl.slac.stanford.edu

User Administration: Cathy Knotts (650-926-3191) knotts@ ssrl.slac.stanford.edu

\begin{tabular}{|c|c|c|c|}
\hline Beamline & Techniques & Beam Characteristics & Special Capabilities \\
\hline $1-4$ & SAXS & Bend, $6700-10800 \mathrm{eV}, 0.25 \times 1 \mathrm{~mm}$ spot & SAXS Camera, focused \\
\hline $2-1$ & Powder diffraction & Bend, $2400-10000 \mathrm{eV}, 1 \times 2 \mathrm{~mm}$ spot & Focused \\
\hline $2-3$ & XAFS & Bend, $2400-30000 \mathrm{eV}, 2 \times 20 \mathrm{~mm}$ & \\
\hline $3-3$ & NEXAFS, XSW & Bend, $800-3500 \mathrm{eV}, 1.5 \times 2.5 \mathrm{~mm}$ spot & YB66 monochromator \\
\hline $4-1$ & XAFS & Wiggler, $2400-35000 \mathrm{eV}, 2 \times 20 \mathrm{~mm}$ spot & \\
\hline $4-2$ & $\begin{array}{l}\text { XAFS, GIXAFS, } \\
\text { SAXS }\end{array}$ & Wiggler, $2400-45000 \mathrm{eV}, 0.5 \times 4 \mathrm{~mm}$ spot & SAXS Camera, focused \\
\hline $4-3$ & XAFS & Wiggler, $2400-35000 \mathrm{eV}, 2 \times 20 \mathrm{~mm}$ spot & \\
\hline $6-2$ & $\begin{array}{l}\text { XAFS, GIXAFS, } \\
\text { XSW }\end{array}$ & Wiggler, $2050-20000 \mathrm{eV}, 0.5 \times 4 \mathrm{~mm}$ spot & Focused \\
\hline $7-2$ & $\begin{array}{l}\text { WAXS, surface X- } \\
\text { ray scattering }\end{array}$ & Wiggler, $2400-35000 \mathrm{eV}, 2 \times 20 \mathrm{~mm}$ spot & \\
\hline $7-3$ & XAFS & Wiggler, $2400-35000 \mathrm{eV}, 2 \times 20 \mathrm{~mm}$ spot & \\
\hline $8-1$ & PES & Bend, $10-200 \mathrm{eV},>0.1 \mathrm{~mm}^{2}$ & \\
\hline $8-2$ & NEXAFS, PES & Bend, $80-1200 \mathrm{eV},>0.1 \mathrm{~mm}^{2}$ & Circular polarization \\
\hline $9-3$ & XAFS, GIXAFS & Wiggler, $4600-40000 \mathrm{eV}, 0.5 \times 4 \mathrm{~mm}$ spot & Biological XAFS, focused \\
\hline $10-1$ & NEXAFS, PES & Wiggler, $250-1200 \mathrm{eV},>0.1 \mathrm{~mm}^{2}$ & \\
\hline $10-2$ & XAFS, GIXAFS & Wiggler, $2400-40000 \mathrm{eV}, 0.5 \times 4 \mathrm{~mm}$ spot & \\
\hline $11-2$ & $\begin{array}{l}\text { XAFS, GIXAFS, } \\
\text { XSW }\end{array}$ & Wiggler, $4500-37000 \mathrm{eV}, 0.5 \times 4 \mathrm{~mm}$ spot & $\begin{array}{l}\text { MES beamline, actinide } \\
\text { facility, focused }\end{array}$ \\
\hline
\end{tabular}

GIXAFS = Grazing Incidence X-ray Absorption Spectroscopy

NEXAFS $=$ Near-Edge X-ray Absorption Fine Structure Spectroscopy

PES $=\quad$ Photoemission Spectroscopy

SAXS $=\quad$ Small Angle X-ray Scattering

WAXS $=$ Wide Angle X-ray Scattering

$\mathrm{XAFS}=\quad \mathrm{X}$-ray Absorption Fine Structure Spectroscopy

$\mathrm{XRD}=\quad \mathrm{X}$-ray Diffraction

$\mathrm{XSW}=\mathrm{X}$-ray Standing Wave 


\section{Synchrotron Radiation Center}

3731 Schneider Dr.

Stoughton, WI 535-3097

Home Page: http://www.src.wisc.edu/

Beamline Specifications Page: http://www.src.wisc.edu/facilities/beamlines/list/

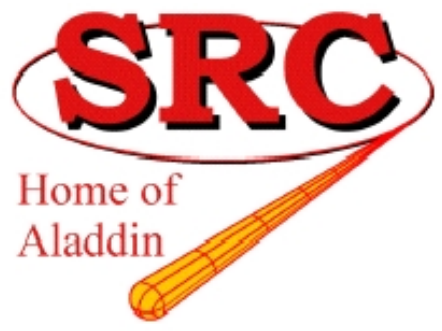

Contacts:

Beam Lines and Technical Issues: Mark Bissen (608-877-2146) mbissen@src.wisc.edu

User Administration:

Ralf Wehlitz (608-877-2164)

knotts@ssrl.slac.stanford.edu

\begin{tabular}{|l|l|l|}
\hline Instruments & \multicolumn{1}{|c|}{ Beam Characteristics } & \multicolumn{1}{c|}{ Special Features } \\
\hline HERMON & $62-1400 \mathrm{eV}$ & Circularly polarized light \\
\hline 10 meter TGM & $210-800 \mathrm{eV}$ & Circularly polarized light \\
\hline DCM & $1500-4000 \mathrm{eV}$ & InSb(111) and Quartz(1010) crystals \\
\hline $\begin{array}{l}\text { Grasshoppers (MK V, MK } \\
\text { II) }\end{array}$ & $32-900 \mathrm{eV}$ & Microscope with scanning stage \\
\hline FT Infrared & $200-8000 \mathrm{~cm}^{-1}$ & Operational 2004 \\
\hline VLS PGM & $50-1800 \mathrm{eV}$ (undulator) & \\
\hline
\end{tabular}

TCM = Toroidal Grating Monochromator

HERMON = High Energy and High Resolution Monochromator

$\mathrm{DCM}=\quad$ Double Crystal Monochromator

VLS $=\quad$ Varied Line Spacing

PGM = Plane Grating Monochromator

$\mathrm{FT}=\quad$ Fourier Transform 


\section{Appendix B. EnviroSync - A National Organization Representing MES Synchrotron Radiation Users}

An organization known as EnviroSync was established in early 1998 to represent the growing multidisciplinary community of SR users who focus on molecular environmental science problems. EnviroSync is patterned after BioSync, an organization of bioscience users of U.S. SR facilities formed in 1989, and GeoSync, a similar organization representing geoscience users of these facilities that was formed in 1988. EnviroSync meetings have been held annually since 1998 at one of the two American Chemical Society National Meetings each year. A Steering Committee, appointed at the first of these meetings, served from 1999 to 2001. A new Steering Committee Chair and Secretary were elected at the 2002 American Chemical Society Meeting in Orlando, FL, and several new Steering Committee members were appointed. The current EnviroSync steering committee (and their affiliations) is listed below. This community now numbers between 300 and 400 active individuals (including graduate students and post-docs) in the U.S.. The main purposes of EnviroSync are to (1) serve as an advocate for the MES-SR community, (2) assess the state of existing SR facilities for MES research on a continuing basis, (3) assess the SR needs of the MES community on a continuing basis, and (4) serve as an advisory group to federal agencies concerning the need for new SR facilities in the MES area.

In late 1997, Dr. Robert Marianelli, then Director of the Chemical Sciences Division, Office of Basic Energy Research, Department of Energy, requested that EnviroSync be formed in order to help prioritize the growing number of requests to federal agencies for funding to build new SR facilities for MES research at the four DOE-sponsored synchrotron light sources. EnviroSync was also expected to help assess the needs of the MES community for increasingly sophisticated SR facilities and staff scientists to help train MES users at these facilities. These needs were initially highlighted in two DOE-sponsored workshops, one held at Airlie Center, VA on July 58,1995 , which was attended by about 60 scientists from a variety of disciplines as well as representatives from the DOE and NSF. The second workshop was held at the Stanford Synchrotron Radiation Laboratory on January 17-18, 1997, and was attended by about 25 scientists, including representatives from each of the four DOE-supported synchrotron light sources. The Airlie Workshop resulted in a 125-page report issued in December 1995 [7], which discusses a wide variety of molecular-scale environmental science problems requiring the use of SR methods, as well as new opportunities for MES research at SR facilities. It also presents an assessment of the needs of the MES community for existing SR beam line (BL) stations and new beam lines optimized for X-ray spectroscopic and X-ray fluorescence studies of very dilute, heterogeneous samples, including $\mu$ XANES and $\mu$ XRF studies at spatial resolution of 1-5 $\mu \mathrm{m}$. At the time of the Airlie Workshop Report (late 1995), there were the equivalent of about 3.5 full-time BL end or side stations optimized for MES research at the ALS, APS, NSLS, SSRL, and CHESS, providing collectively about 700 days of beam time to the MES community. These facilities were completely saturated by MES and other users in 1995. The beam time needs of this community were anticipated to grow to about 1450 beam station days by 1998 , based on a written survey of about 200 MES users in 1995. In addition, the total number of full-time equivalent BL end or side stations available for MES research was expected to grow from about 3.5 in 1995 to about 6.5 by 1998 . One of the main outcomes of the Airlie Workshop was verification that several new MES BL end or side stations were needed immediately to help satisfy the growing demand for SR beam time by the MES community. Funding was requested 
by SSRL for one new MES beam line (BL 11-2), and it was provided by the Chemical Sciences Division of OBES-DOE. Commissioning of this beam line end station was completed in 2001, and it is now in operation and is oversubscribed by a factor of at least two.

The second MES workshop held in January 1997 focused on the soft X-ray/VUV/IR (50 - 1500 $\mathrm{eV}$ ) needs of the MES community and inventoried the existing SR facilities in this energy range. A 59-page workshop report [8] describing these findings was released on July 30, 1997. At that time, there were no soft X-ray/VUV/IR SR facilities dedicated to or optimized for MES research in spite of the growing number of MES users who required such facilities. An inventory of existing soft X-ray/VUV/IR BL end stations available for X-ray spectroscopy, X-ray microscopy, and photoemission spectroscopy (PES) studies indicated that all such BL stations at the ALS, NSLS, and SSRL (about 9 in 1997) were oversubscribed and that none was optimized for MES samples, which often require photon in-photon out capabilities and "wet" sample environments. The major outcome of this workshop was the recommendation that a new MES soft X-ray/VUV undulator BL be built at the ALS and optimized for PES, NEXAFS, X-ray emission spectroscopy (XES), and scanning transmission X-ray microscopy (STXM) studies of "wet" environmental samples to take advantage of the very high brightness of the ALS in the 50$1500 \mathrm{eV}$ energy range. A proposal was prepared by a subgroup of EnviroSync and submitted to OBES-DOE. The proposal was funded for construction of phase 1 of the project (BL 11.0.2 with STXM and PES end stations), which is currently operational with some commissioning still being performed. Also presented in the second MES report was an update of the current state of X-ray facilities available for MES users and the needs for such facilities based on developments since the 1995 Airlie House MES Workshop Report.

At the fourth annual meeting of EnviroSync, which was held at the Orlando, Florida ACS meeting in March 2002 and was attended by about 50 members, EnviroSync Co-Chair Gordon Brown presented a preliminary version of this report, which was discussed by the membership present. Stephen Sutton (GSECARS, University of Chicago) was elected Chair of EnviroSync for the period 2002-2004, Chris Jacobsen (SUNY Stony Brook) was appointed secretary of EnviroSync, and John Bargar (SSRL) and Rich Reeder (SUNY Stony Brook) were added to the EnviroSync Steering Committee. In addition, several members of the EnviroSync Steering Committee (Bargar, Bertsch, Brown, Jacobsen, Reeder, Shuh, Sutton, Traina) met with Dr. Roland Hirsch, Program Manager in the Office of Biological and Environmental Research at DOE, to discuss a preliminary version of this report and the best means of disseminating the final report to federal agencies. 


\section{EnviroSync Steering Committee (2002-2004)}

Patrick G. Allen

John R. Bargar

Paul M. Bertsch

Gordon E. Brown, Jr.

Russell R. Chianelli

David L. Clark

Steven Colson

Chris Jacobsen

Roger C. Prince

Richard J. Reeder

Dale E. Sayers

David K. Shuh

Lynda Soderholm

Steve R. Sutton (Chair)

Samuel J. Traina
Lawrence Livermore National Laboratory (allen42@1lnl.gov)

Stanford Synchrotron Radiation Laboratory, Stanford University (bargar@SLAC.Stanford.EDU)

Savanah River Ecology Laboratory, University of Georgia (bertsch@srel.edu)

Stanford University and SSRL (gordon@pangea.stanford.edu)

University of Texas, El Paso (chianell@utep.edu)

Los Alamos National Laboratory (dlclark@lanl.gov)

Pacific Northwest National Laboratory (steven.colson@pnl.gov)

State University of New York, Stony Brook (Chris.Jacobsen@stonybrook.edu)

Exxon Mobil R \& D Laboratory (roger.c.prince@exxonmobil.com)

State University of New York, Stony Brook (rjreeder@notes.cc.sunysb.edu)

North Carolina State University (dale_sayers@ncsu.edu)

Lawrence Berkeley National Laboratory (dkshuh@lbl.gov)

Argonne National Laboratory (soderholm@anlchm.chm.anl.gov)

GeoSoilEnviroCARS, University of Chicago (Sutton@cars.uchicago.edu)

University of California, Merced (sam.traina@ucop.edu) 


\section{Appendix C: Abbreviations Used}

\begin{tabular}{|c|c|}
\hline AFM & Atomic Force Microscope \\
\hline ALS & Advanced Light Source, Lawrence Berkeley National Laboratory \\
\hline APS & Advanced Photon Source, Argonne National Laboratory \\
\hline BioSync & A national organization of synchrotron users in the biosciences \\
\hline $\mathrm{BM}$ & Bending magnet (also called dipole magnet) \\
\hline CAMD & Center for Advanced Microstructures and Devices, Louisiana St. Univ. \\
\hline CAT & Collaborative Access Team \\
\hline CCD & Charge-coupled Device \\
\hline CHESS & Cornell High Energy Synchrotron Source, Cornell University \\
\hline CMT & Computed MicroTomography \\
\hline CTR & Crystal Truncation Rod diffraction \\
\hline DAFS & Diffraction Anomalous Fine Structure Spectroscopy \\
\hline DOE & Department of Energy \\
\hline EnviroSync & A national organization of synchrotron users in environmental science \\
\hline EPA & Environmental Protection Agency \\
\hline ESCA & Electron Spectroscopy for Chemical Analysis \\
\hline EXAFS & Extended X-ray Absorption Fine Structure \\
\hline FCMT & Fluorescence Computed Microtomography \\
\hline FTIR & Fourier Transform Infrared Spectroscopy \\
\hline GeoSync & A national organization of synchrotron users in the earth sciences \\
\hline GIXAFS & Grazing incidence X-ray absorption spectroscopy \\
\hline GR & Green Rust \\
\hline ID & Insertion device, a wiggler or undulator \\
\hline IR & Infrared \\
\hline $\mathrm{KB}$ & Kirkpatrick-Baez, an optical focusing configuration \\
\hline LBNL & Lawrence Berkeley National Laboratory \\
\hline MES & Molecular Environmental Science \\
\hline NEXAFS & Near Edge X-ray Absorption Fine Structure \\
\hline NOM & Natural Organic Matter \\
\hline NSF & National Science Foundation \\
\hline NSLS & National Synchrotron Light Source, Brookhaven National Laboratory \\
\hline PES & Photoemission Spectroscopy \\
\hline PEEM & Photoemission Electron Microscopy \\
\hline PRB & Permeable Reactive Barrier \\
\hline RFETS & Rocky Flats Environmental Technology Site, Colorado \\
\hline SAXS & Small Angle X-ray Scattering \\
\hline SEM & Scanning Electron Microscopy \\
\hline SLAC & Stanford Linear Accelerator Center, Stanford University \\
\hline SPEM & Scanning Photoemission Microscope \\
\hline SR & Synchrotron Radiation \\
\hline SRC & Synchrotron Radiation Center, University of Wisconsin-Madison \\
\hline SSRL & Stanford Synchrotron Radiation Laboratory, Stanford University \\
\hline STXM & Scanning Transmission X-ray Microscope \\
\hline UHV & Ultra-High Vacuum \\
\hline VUV & Vacuum Ultraviolet \\
\hline WAXS & Wide Angle X-ray Scattering \\
\hline XANES & X-ray Absorption Near Edge Structure \\
\hline XAFS & X-ray Absorption Fine Structure \\
\hline XES & X-ray Emission Spectrscopy \\
\hline XPS & X-ray Photoelectron Spectroscopy \\
\hline XRD & X-ray Diffraction \\
\hline XRF & X-ray Fluorescence \\
\hline XSW & X-ray Standing Wave \\
\hline
\end{tabular}

